\title{
WestVirginiaUniversity
}

THE RESEARCH REPOSITORY @ WVU

Graduate Theses, Dissertations, and Problem Reports

2006

\section{Effects of duty cycles on diesel engine component life estimation}

Dave Jayasinghe

West Virginia University

Follow this and additional works at: https://researchrepository.wvu.edu/etd

\section{Recommended Citation}

Jayasinghe, Dave, "Effects of duty cycles on diesel engine component life estimation" (2006). Graduate Theses, Dissertations, and Problem Reports. 1733.

https://researchrepository.wvu.edu/etd/1733

This Thesis is protected by copyright and/or related rights. It has been brought to you by the The Research Repository @ WVU with permission from the rights-holder(s). You are free to use this Thesis in any way that is permitted by the copyright and related rights legislation that applies to your use. For other uses you must obtain permission from the rights-holder(s) directly, unless additional rights are indicated by a Creative Commons license in the record and/ or on the work itself. This Thesis has been accepted for inclusion in WVU Graduate Theses, Dissertations, and Problem Reports collection by an authorized administrator of The Research Repository @ WVU. For more information, please contact researchrepository@mail.wvu.edu. 


\title{
EFFECTS OF DUTY CYCLES ON DIESEL ENGINE COMPONENT LIFE ESTIMATION
}

\author{
Dave S. Jayasinghe \\ Thesis submitted to the \\ College of Engineering and Mineral Resources \\ At West Virginia University \\ In partial fulfillment of the requirements \\ For the degree of \\ Master of Science \\ In \\ Mechanical Engineering
}

Mridul Gautam, Ph.D., Chairman

Natalia Schmid, Ph.D.

W. Scott Wayne, Ph.D.

Department of Mechanical and Aerospace Engineering

Morgantown, West Virginia

2006

Keywords: Duty Cycle, Diesel, Cylinder Pressure, Life Model

Copyright 2006 Dave S. Jayasinghe 


\title{
Effects of Duty Cycles on Diesel Engine Component Life Prediction
}

\author{
Dave S. Jayasinghe
}

\begin{abstract}
Engine manufactures have relied on over designed of engines and performance testing to ensure product reliability. The efforts to maximize efficiency and to predict performance characteristics have evoked an interest to study the in-cylinder pressure throughout the respective duty cycle. The duty cycle of an engine is defined as the history of speed and load conditions over which the engine operates in a specific application. Understanding the transient on-road diesel engine duty cycles has been one of major goals for the engine developers. To date there have not been any research performed to identify a wide variety of on-road diesel engine duty cycles. One of the world largest diesel engine manufactures, Cummins Inc., had interest in developing and understanding how the effective life of a diesel engine component is related to its duty cycle. West Virginia University Engine and Emissions Research Laboratory (EERL) was commissioned to conduct this study.

The objective of this study is to create a mathematical model that predicts the effective life of diesel engine components with respect to its operational duty cycle. In particular, power cylinder components were considered along with the variations of incylinder pressure. Four different duty cycles were evaluated in this study: a concrete mixer, heavy hauler, dump truck, and a transit bus. In-cylinder pressure data for all four duty cycles were statistically analyzed using the tools from non-parametric function and regression analysis. A mathematical model that predicts the power cylinder component lives was created. Mimicking the infield operation, heavy hauler displays the minimum power cylinder component life, while concrete mixer has the maximum life. Ultimately, this mathematical model will enable the engine manufactures to produce more cost effective components for different duty cycle applications, while fulfilling the customer requirements.
\end{abstract}




\section{ACKNOWLEDGEMENTS}

As I write the final chapters at my beloved WVU, I'm compelled to thank a lot people that made this journey possible. Not for these generous souls I would have not been the person that I'm today. First and foremost I have to express my deepest gratitude to Dr. Mridul Gautam. You have been an advisor, a teacher, a friend and a brother to me. Thank you so much for your guidance, support, believing in me and always been there for me. Also, my sincere appreciation goes to Dan Carder, who was my direct supervisor and a great friend. Thanks for your advice, humor and support in and out of the college. Without Dan, I wouldn't have ever learned the simplest way of loading a boat on to a trailer. Thanks for those great memories. The same goes to Tom Spencer and Richard Atkinson, for all your help and making my life at EERL more pleasurable.

Next, I need to offer my genuine gratitude for the extraordinary support of Dr. Natalia Schmid. Thanks for all you time and effort towards the fulfillment of my masters project. Also, I would like to thank the faculty members Dr. Scott Wayne, Dr. Nigel Clark, Dr. Larry Banta, Dr. Jacky Prucz, Dr. Giampiero Campa and Dr. Greg Thompson for supporting me in various ways towards the completion of my academics. I would also like to take this opportunity to thank Mr. Ric Kline and other engineers from Cummins Inc., in believing me and funding the project and helping us though out all the obstacles.

Also, a group that I can never forget, the staff of our great department, Wes Riddle, Ryan Barnett, Jean Kopasko, Marilyn Host, Fern Wood, Debbie Willis, Ron Jarrett, Byron Rapp, Chuck Coleman, Jason England and Ted Christian. You guys made my life gratifying every second I worked with you all and I'm greatly appreciative of that. 
Raffaello Ardanese, Sam George and Xiaohan Chen, I'm deeply appreciative of all the time and effort you guys spent making this project a success. I would never forget all the good times we had working together on this project. Thanks to my contemporaries - Aaron, Michelangelo, Josh, Chamila, Aseem, Karthik, Ben, Bobby, Mohan, Shashi, Glenn, Nate, Ram, Guru, Ravi, Hemanth, Mahesh, Viney, Sier, Nick and John. You guys are awesome and thanks for all the great memories in Morgantown.

Finally, I must reserve my deepest thanks to my family. The support and love that I received from my parents who are also my role models is the foundation for any success that I have achieved. From the day I was born, Thaththi and Ammi, you showed me the light, gave me the courage and hope, taught me patience and provided me with spirituality, stood next to me like a pillar, sheltered me from sun and rain and gave me the ultimate, the best parents any son could ever wish for. Also, my loving sister you are so awesome, and can't dream of having anyone better than you. Shilpani, my lovely fiancée, thank you so much for been there encouraging and supporting me every step of the way. Can't say enough of all four of you and I'm greatly appreciative of the gift of you that god have given to me. Also, I want to thank all four of my grand parents, aunt Ruth, little brothers Prabash and Teddy and my extended family for been who you are.

"Let us rise up and be thankful, for if we didn't learn a lot today, at least we learned a little, and if we didn't learn a little, at least we didn't get sick, and if we got sick, at least we didn't die; so, let us all be thankful."

Venerable Load Buddha 


\section{TABLE OF CONTENTS}

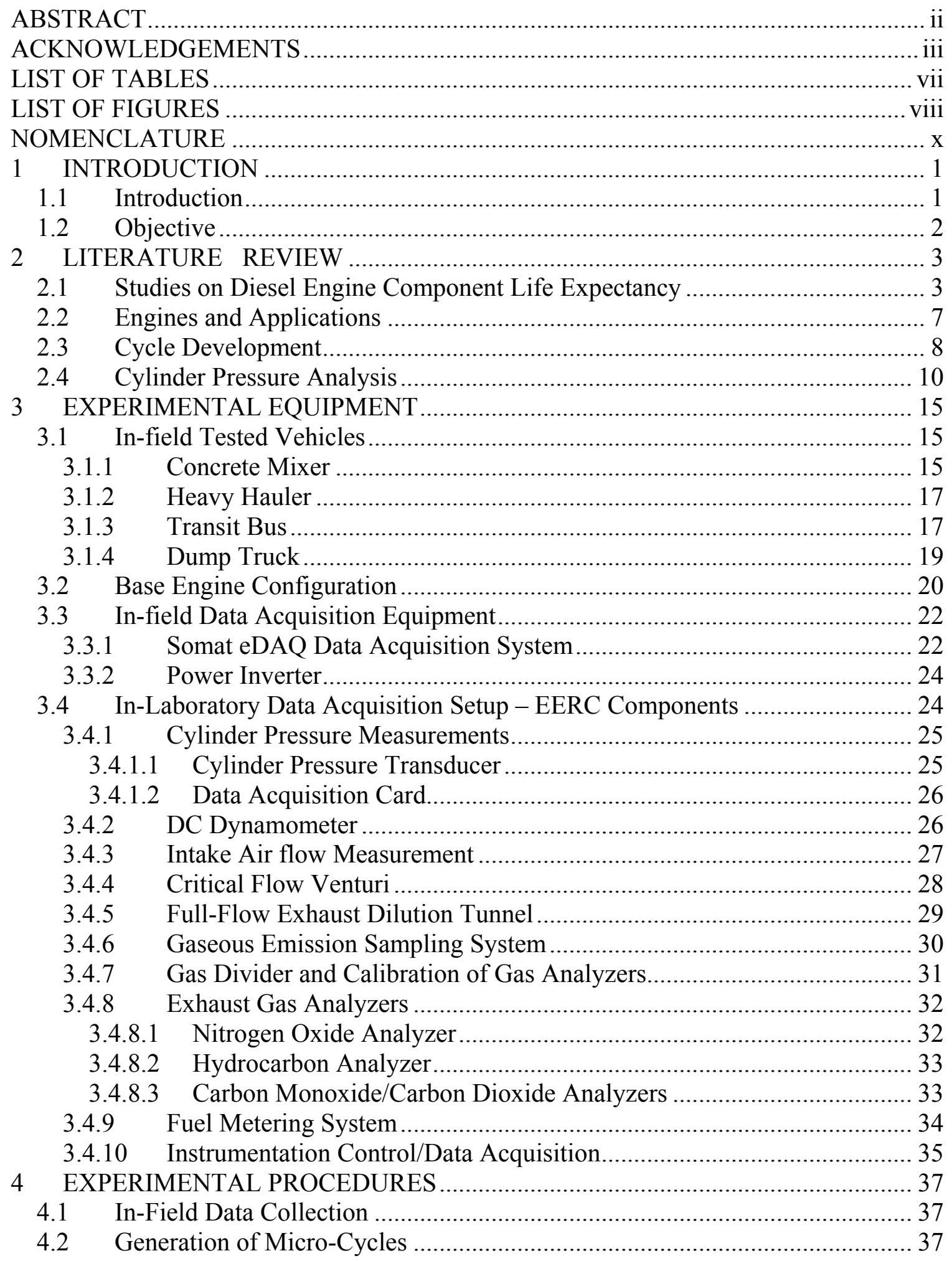


4.2.1 Things Considered During Transient Cycle Generation............................. 38

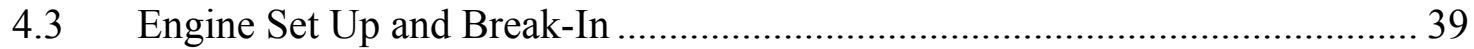

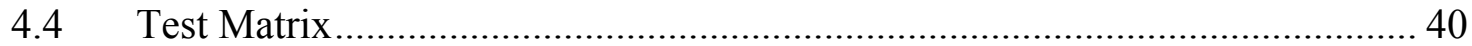

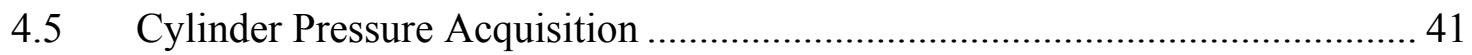

4.5.1 Aspects Considered during Cylinder Pressure Evaluation ........................ 43

4.5.2 Derivation the Volume of Slider-Crank Model ........................................ 45

4.5.3 Work Done by a Piston Cylinder ............................................................. 47

4.5.4 Indicated Mean Effective Pressure ………............................................ 49

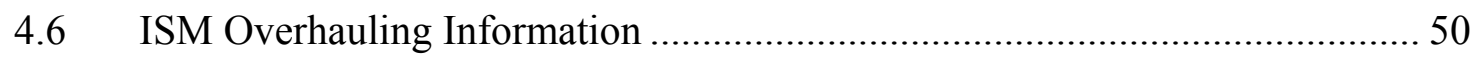

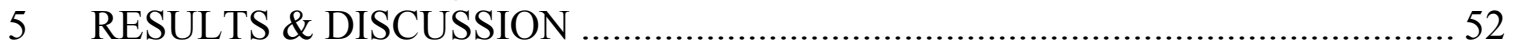

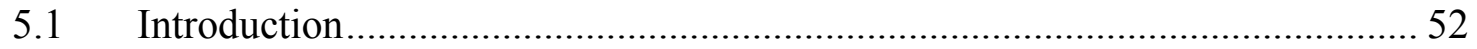

5.2 Power Cylinder Piston Life Model ............................................................... 52

5.2.1 Cylinder Pressure Evaluation................................................................ 53

5.2.2 Evaluating the Life Estimation Problem.................................................. 57

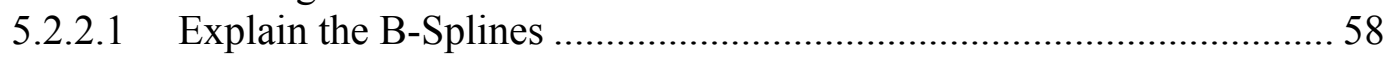

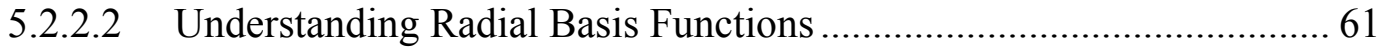

5.2.2.3 Implementation of Radial Basis Function.............................................. 63

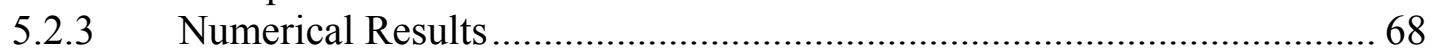

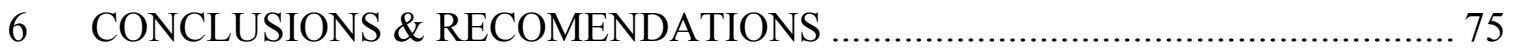

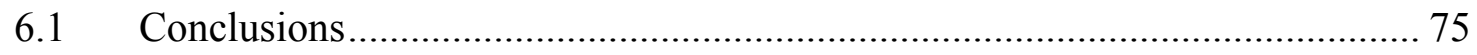

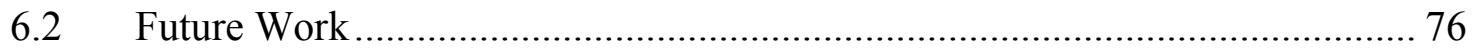

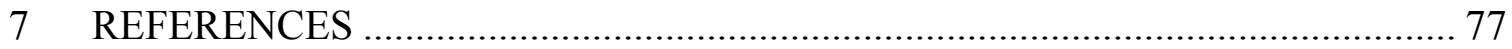

APPENDIX A - Codes Used for Test cell Data Acquisitions and Calculations............. 81 


\section{LIST OF TABLES}

Table 1: Comparison of various engine ratings with respect to the application -------------- 8

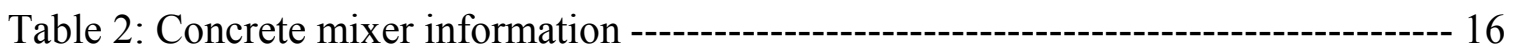

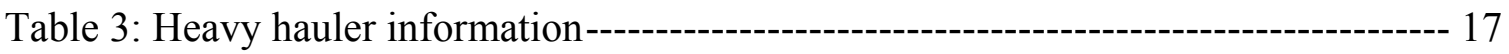

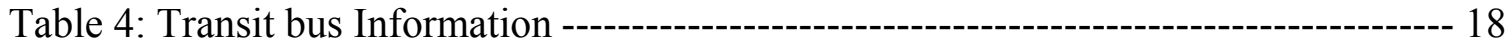

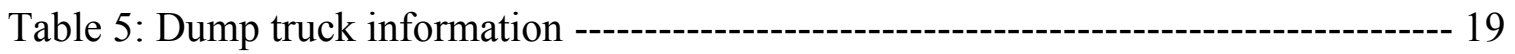

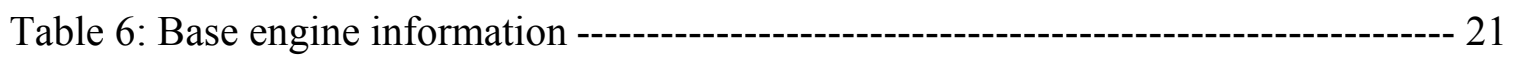

Table 7: Test Matrix for Test Cell Testing ------------------------------------------------------ 41

Table 8: Calculations of pressure pulse measurements ------------------------------------------ 42

Table 9: The life data and the B-spline Coefficients for the modeled cycles -------------- 69

Table 10: The possibilities for C1 and C2------------------------------------------------------ 71

Table 11: B-spline coefficients of the pressure distributions for the duty cycles (Testing data) ------------------------------------------------------------------------------------------- 73

Table 12: Final Life Estimations for the Individual Duty Cycles --------------------------- 74 


\section{LIST OF FIGURES}

Figure 1: Central Supply Concrete Mixer used for Testing Purposes ............................ 16

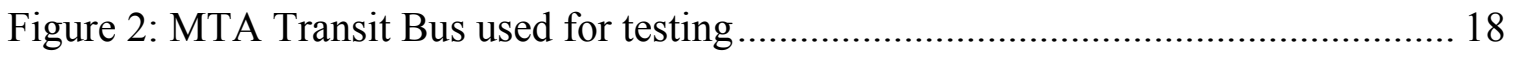

Figure 3: Kentuckiana Dump Truck used for testing.................................................. 20

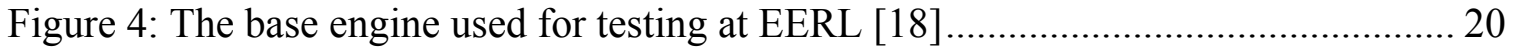

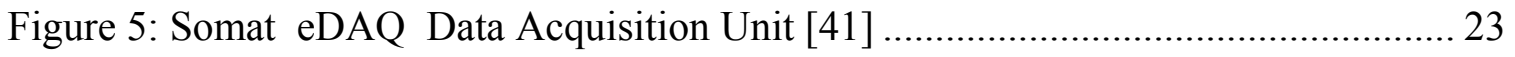

Figure 6 Tripplite Inc. Model PV1200 Power Inverter............................................... 24

Figure 7: Water-Cooled Cylinder Pressure Transducer [27] ......................................... 25

Figure 8: The EERL's Gaseous Emissions Analyzer Bench [14] ................................. 31

Figure 9: Schematic of West Virginia University's Engine and Emissions Research

Laboratory Emissions Measurement System [14] ............................................. 36

Figure 10: Example of Pressure Traces during a Portion of a Micro Cycle .................... 42

Figure 11: A Small Portion of Pressure Traces Acquired with Respect to the Engine

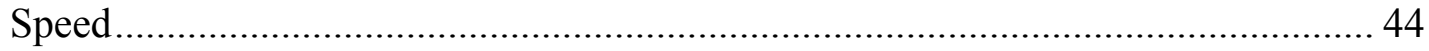

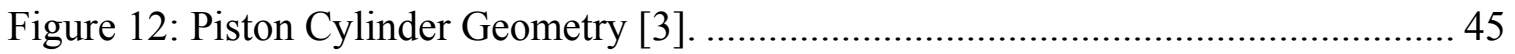

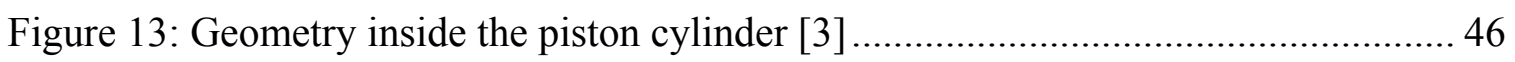

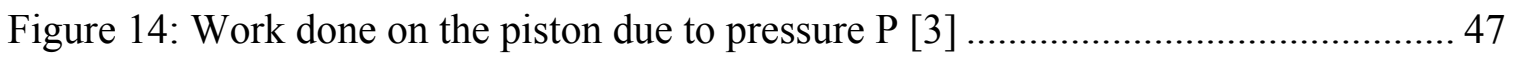

Figure 15: Pressure Distribution Binned for All Four Duty Cycles ............................... 55

Figure 16: Normalized Accumulative Summation for Each Binned Pressure Distribution

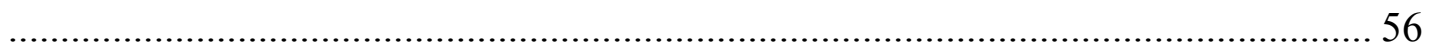

Figure 17 Illustration of the function to be determined .............................................. 58

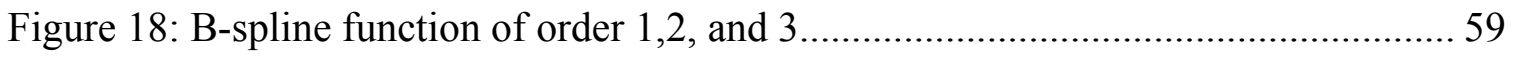

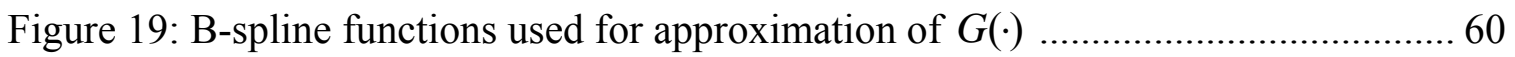

Figure 20: $r$ values were selected in relation to the coefficients of B-splines ................. 64

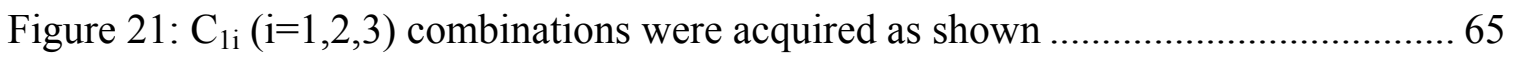

Figure 22: Shown are Cumulative Distribution Functions for Each Binned Pressure

Distribution (Assumed Cycles) Graphed jointly with the Corresponding B-spline

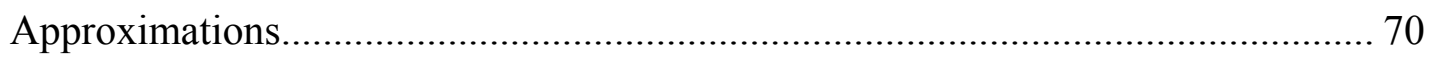


Figure 23: Shown are Cumulative Distribution Functions for Each Binned Pressure Distribution (Acquired Duty Cycles) Graphed jointly with the Corresponding Bspline Approximations... 


\section{NOMENCLATURE}

\begin{tabular}{|c|c|}
\hline $\mathrm{AC}$ & Alternating Current \\
\hline BMEP & Break Mean Effective Pressure \\
\hline C-EGR & Cooled Exhaust Gas Recirculation \\
\hline CAN & Controller Area Network \\
\hline CFR & Codes of Federal Regulation \\
\hline CFV & Critical Flow Venturi \\
\hline CVS & Constant Flow Sampler \\
\hline DC & Direct Current \\
\hline DFMEA & Design Failure Modes and Effects Analysis \\
\hline D.I. & Direct Injection \\
\hline ECM & Engine Control Module \\
\hline EERL & Engine and Emission Research Laboratory \\
\hline EPA & Environmental Protection Agency \\
\hline FMEP & Frictional Mean Effective Pressure \\
\hline FTP & Federal Transient Procedure \\
\hline GCS & Governor Central Speed \\
\hline GVWR & Gross Vehicle Weight Rating \\
\hline HFID & Heated Flame Ionization Detector \\
\hline $\mathrm{HP}$ & Horse Power \\
\hline IMEP & Indicated Mean Effective Pressure \\
\hline LEF & Laminar Flow Element \\
\hline MEMS & Mobile Emissions Monitoring Systems \\
\hline
\end{tabular}




$\begin{array}{ll}\text { NDIR } & \text { Non-Dispersive Infrared } \\ \text { NIST } & \text { National Institute of Standards and Technology } \\ \text { NTE } & \text { Not-To-Exceed } \\ \text { PCMCIA } & \text { Personal Computer Memory Card International Association } \\ \text { PFMEA } & \text { Performance Failure Modes and Effects Analysis } \\ \text { PMEP } & \text { Pumping Mean Effective Pressure } \\ \text { RBF } & \text { Radial Basis Function } \\ \text { RPS } & \text { Revolutions Per Second } \\ \text { RTD } & \text { Resistive Temperature Device } \\ \text { SAE } & \text { Society of Automotive Engineers } \\ \text { SCFM } & \text { Standard Cubic Feet per Minute } \\ \text { SOI } & \text { Start of Injection } \\ \text { T.D.C. } & \text { Top Dead Center } \\ \text { UZAM } & \text { Ultra Zero Air Monitoring } \\ \text { VGT } & \text { Variable Geometry Turbocharger } \\ \text { WVU } & \text { West Virginia University }\end{array}$




\section{INTRODUCTION}

\subsection{Introduction}

Engine manufactures have relied on over-designed engines and performance testing to ensure product reliability. The effort to maximize efficiency and to predict performance characteristics have evoked an interest to study the in-cylinder pressure throughout the respective duty cycles. The duty cycle of an engine is defined as the history of speed and load conditions over which the engine operates in a specific application. The different speed and load combinations, the amount of time the engine spends at those speed and load combinations, and how the engine transitions from one speed and load combination to another are all key elements of the duty cycle.

Understanding the transient on-road diesel engine duty cycles was a major goal for the engine developers. One of the world's largest diesel engine manufacturers, Cummins Inc., had interest in developing and understanding how the effective life of a diesel engine component would vary according to its duty cycle. West Virginia University Engine and Emissions Research Laboratory (EERL) was commissioned to conduct a study in order to identify these component life predictions.

For this study, a Cummins ISM post-2002 on-road engine was selected. The selection of the ISM was based upon its versatility and use in on-road applications. This 10.9 liter diesel engine with ratings varying from $280-450 \mathrm{hp}$, is used in a wide variety of applications such as line haul trucks, dump trucks, transit buses, concrete mixers, delivery trucks, recreational vehicles and emergency vehicles. 
This study comprised of three distinct phases. Phase I involved acquisition of ECM - broadcast torque, speed and other engine parameters from infield vehicles over their regular duty cycles. Phase II entailed collection of data on in-cylinder pressure and other various engine design parameters in an engine dynamometer test cell. During Phase II the in-laboratory testing was conducted on a Cummins ISM 2004 current product engine equipped with Cooled Exhaust Gas Recirculation (C-EGR) and the latest ECM (CM 875). All the engine dynamometer test cell work was conducted at WVU EERL. Phase III entailed analysis, documentation, and interpretation of data, which was collected in Phase II.

How the engine duty cycle impacts the life of various diesel engine components is not well understood or quantified. As the first step in understanding component life, diesel engine in-cylinder pressure related components were selected. Then, failure and warranty data were gathered from the component manufacturers. Using manufacturer data as a model, calculations were performed to evaluate effective life for gathered duty cycle data.

\subsection{Objective}

Engine design parameters for multiple duty cycles are essential for ensuring longevity of engine components. The objective of the study was to predict the life of incylinder pressure related components of a heavy-duty diesel engine using in-cylinder pressure data. The range over which the in-cylinder pressure operates as a function of duty-cycle was evaluated to aid component design. This understanding will significantly minimize the production costs of next generation engines by discounting the engineering practice of overrating an engine for a certain application. 


\section{LITERATURE REVIEW}

This chapter contains a review of published literature on procedures and methodologies, which have been used in diesel engine duty cycle studies. A more indepth review will be done on diesel engine component life expectancy, cylinder pressure analysis and test cycle generation. A portion of this review discusses previous studies performed at WVU and information from various engine manufacturers regarding engine ratings and configurations.

\subsection{Studies on Diesel Engine Component Life Expectancy}

This section discusses published material on component life expectancy related to diesel engines. A fewer studies have been performed with regard to other aspects of diesel engines. Most of the studies involve a mathematical model or a probabilistic approach based upon field tests.

A method of estimating product durability requirements was reported by Aldridge (2004). According to this method an understanding of the vehicle usage is a key element in the general process of defining the product durability requirements.

This method was directed towards virtual testing, in order to analytically determine product failure distributions, and also create product life distributions. Ability to predict product life distributions would enhance the life estimations of a certain product.

Prior to testing, the author conducted a review of Design Failure Modes and Effects Analysis (DFMEA) and Process Failure Modes and Effect Analysis (PFMEA) to recognize the highest risk durability parameters. The review was followed up by an 
exercise to understand and identify parameters, which influence the engine duty cycles, and those parameters which combined with environmental and customer inputs drive product operation and damage criterion.

The research done by Shareef and Karmali (2003), focused on failure of diesel engines due to collapse of fuel injector cam shafts under high friction and load. Some of the main reasons for the failure of diesel engine fuel injector cams are surface distresses involving scuffing, frosting, pitting and high friction. Even though it is hard to quantify the relationship between relative features of failure, the authors reported that some of those features are "plastic straining, cyclic softening/hardening, crack initiation/propagation, impact, skidding, and third body formation". The objectives of their study (Shareef and Karmali, 2003) were to examine the untimely failure of fuel injector cams and verify the pitting life of a cam in terms of injection cycles. This study also attempted to identify how engine load, speed, number of loading cycles, lubrication condition, and surface roughness affected the life of the injection cam.

Weibull analysis (Wiebull.com, 2005), also known as life data model is a method to predict the life of all products in a population by fitting a statistical distribution to life data from a representative sample of units. This parameterized distribution approximates important life parameters such as probability of failure at a certain time or a failure rate.

Understanding this method requires collecting life data, selecting a model that will fit the data and be able to model the useful life, approximating the parameters that will fit the distribution to the given data, and generating results that will guesstimate the useful life. Life data means measuring the useful life of a product, which could be expressed and this could be in miles, hours, cycles or any other relevant parameter. 
A probability density function is a mathematical model that describes the distribution of a given amount of data. Weibull probability density has the following form:

$$
f(t)=\frac{\beta}{\eta}\left(\frac{t-\gamma}{\eta}\right)^{\beta-1} e^{-\left(\frac{t-\gamma}{\eta}\right)^{\beta}}, \text { where }
$$

$\eta$-describes the bulk of the distribution,

$\beta$-describes the shape of the distribution, and

$\gamma-$ describes the location of the distribution in time.

These parameters control the scale, shape and the location of the Weibull distribution. This distribution could be utilized in a variety of forms using 1, 2 or 3 parameters. Depending on the life distribution, an analyst could choose the parameters that will make the function fit closely to the data.

Another method was developed by Aldridge (2003) to predict system reliability and durability using customer usage data, component malfunction distributions, system failure criteria, manufacturing dissimilarities, and variations in customer severity. Weibull and Monte Carlo analysis were used in developing this method. Monte Carlo analysis resolves a problem by generating a suitable amount of random numbers and observing the fraction of the numbers obeying some property or properties (Mathworld, 2005). The technique is valuable for obtaining numerical solutions to problems which are too complicated to resolve analytically. The authors cited the following benefits of utilizing Weibull and Monte Carlo analysis:

- It could provide the ability to create virtual life distribution models based upon customer usage and production variation data and able to measure and analytically assess the models. 
- It could drastically cut down the product delivery time and create a greater understanding of key failure mechanisms. It could also predict failure time and failure distribution for a given assembly.

Even though the number of cycles (initial bound was 100 million cycles for an accelerated test (Aldridge, 2003)) at peak pressure is the main criteria, other parameters such as engine loading, speed and system operating pressures were considered. Understanding all the parameters involved in the failure is best described using a matrix, and building up relationships for individual parameters such as number of cylinder events at various speed ranges. This is followed up by identifying the cycling requirements for an accelerated test. As mentioned above, the cycling requirement has been found to be in the vicinity of 100 million cycles.

After performing the analysis it was concluded that damage from the accelerated bench test was inadequate in terms of field testing expectations. The virtual testing demonstrated only less than half of the damage expected in a real life situation. This outcome demands for an increase in the number of cycles at a higher pressure level.

It was reported that another benefit of this methodology is the ability to define better and broader accelerated tests for the future, and develop a comprehensive method to predict reliability for individual components.

Aldridge (2005) developed another method to predict component life in conjunction with estimations of failure distributions from available warranty data, customer usage data, and application specific data. This study tests out reasonable suspension strategy and time based analysis to predict failure distribution. Since neither one of those methods yields satisfactory results, a distance based suspension strategy was 
proposed. By means of Monte-Carlo suspension strategy and mixed Wiebull model they were able to predict failure rates and yield satisfactory results.

Another study conducted by Aldridge (2005) focused on applying and verifying probabilistic life prediction, while also designing and verifying components for advanced diesel engines. Probabilistic life prediction of engine components was done using two parameter Weibull distributions along with maximum likelihood estimation. A dynamic fatigue test (500-hour rig test) was performed in order to gather sample data for the life prediction.

\subsection{Engines and Applications}

This study was conducted on a Cummins ISM 10.9 Liter diesel engine, which was equipped with a Cooled Exhaust Gas Recirculation (CEGR) unit. Considering the onroad market, this engine has been the most versatile of all the Cummins engine families (Cummins.com, 2005). The Cummins ISM engine is utilized in all of the main on-road heavy-duty truck sectors in the US. The main sectors are on-highway, vocational, fire/emergency and transit bus. Each of these main categories could be classified into sub sectors. For an example, concrete mixers and dump trucks are considered to be in the vocational category. Table 1 illustrates the ratings of similar engine families from a few diesel engine manufactures. Comparisons were made with Cummins ISM, Caterpillar C11 (Cat.com, 2005), Volvo VE D-12 (Volvo.com, 2005), and Detroit Diesel Series 60 (Detroitdiesel.com, 2005). Even though some manufacturers do not manufacture engines for some of the classifications, they use different engine families to compensate for these categories. For example, Caterpillar does not have a C-11 engine for the transit bus sector, but the company manufactures a C-9 engine that is utilized in this category. The 
table below draws comparisons in rated power (hp) for similar engine families of various engine manufacturers.

Table 1: Comparison of various engine ratings with respect to the application

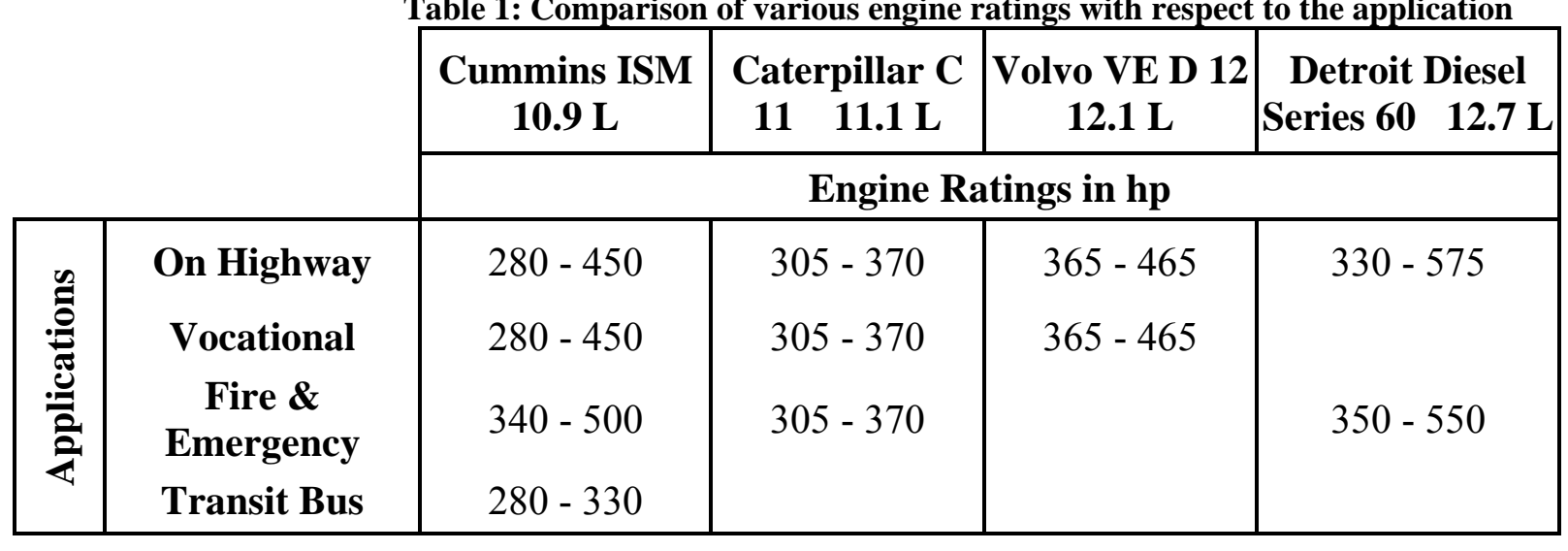

\subsection{Cycle Development}

This section discusses the development of duty cycles for the laboratory testing purposes. The rarity of published data regarding duty cycle generation for on-road vehicles leads to exploring the sector of off-road vehicles. Nevertheless, the considerations and methods were discussed below with respect to duty cycle generation for test cell purposes.

With the initiation of EPA regulatory program (Phase I - Control of exhaust emissions of non-road diesel engines over $37 \mathrm{~kW}$ ) actual test cycles were developed for off-road applications by Ullman et al., (1999). These cycles were developed using actual in-use speed and load data acquired from an agricultural tractor, a backhoe loader, and a crawler tractor. After the data acquisition, using an iterative process, chi-square statistical data were compared to identify representative micro-trips of the in-use operation. For a specific application the micro-trips were combined to form a test cycle. This test cycle 
was statistically analyzed relative to the in-use cycle of the same application for the validation purposes. After the validation process the test cycle was transformed into speed and torque points of one second interval. With the help of a reference speed, also known as the Governor Central Speed (GCS), the speed points were normalized. Equivalently, the Transient Federal Test Procedure (FTP) was used to normalize the torque points. Following these procedures Ullman et al., (1999) were able to create a test cycle that was used for in-laboratory assessments.

Gautam and Krishnamurthy (2005) developed a method to produce an engine test cycle that would represent real-world heavy-duty truck applications. Development and use of an on-road cycle in a test cell environment helped better understand in-use emissions during Not-to-Exceed (NTE) zone operation, engine development and ECM calibrations. This cycle has developed strictly adhering to the current emissions standards while collecting and analyzing various engine activity and statistical data within real life operation of a heavy duty-truck.

Prior to the development of the test cycle, the Mobile Emissions Monitoring System (MEMS) unit was used to gathering engine operating conditions and in-use-break specific emissions. After testing a vehicle on a mix of driving routes that included inner city and highway driving, a database was developed using the representative engine cycles. Then considering all the driving conditions and routes, a test cycle was developed that was representative of NTE zone operation.

With a sequence of vibration durability tests, Aldridge (1987) compressed thousands of hours of customer usage data into realistic length laboratory tests. According to the author, typical U.S. drivers operate engines from 3,000 to 5,000 hours 
for each 100,000 mile segment. These operational hours are much higher than the typical dynamometer tests of 100 to 1,000 hours. This makes it critical to determine the time basis, which is the time that the engine will spend in each speed range during in-house testing. Hence, slow RPM sweeps during the field testing were ignored since they are statistically insignificant and engine wear is minimal during these periods.

\subsection{Cylinder Pressure Analysis}

Understanding cylinder pressure in regards with different duty-cycles played a critical role during this study. Hence, the following review was done to understand cylinder pressure measurement techniques, as well as calculations and analysis involving cylinder pressure.

The research done by Brunt and Platts (1999) focused on errors in gross heat release calculations performed during in-cylinder pressure data analysis. Heat release analysis and burn rate analysis using in-cylinder pressure data are critically important in order to better understand diesel engines.

Heat release in diesel engines is of huge importance, since it has significant influence on combustion noise, pressure rise rate and NOx emissions. Nevertheless, misleading results could produce by both erroneous experimental measurements and heat release models. The traditional single zone first law heat release model could produce such errors and the author illustrated these errors when using this model to simulate direct injection diesel engine pressure diagrams. It was shown that the highest uncertainty errors could be attributed to the assumption of a wrong rate of heat transfer between power cylinder charge and combustion chamber walls. To avoid this scenario, an alternative heat release model was proposed, and it resulted in a large improvement in results over a 
wide range of operating conditions. The alternative heat release model utilized a variable polytropic index to account for heat transfer, where it was specifically suited for diesel engines.

Another study conducted by Assanis et al., (2000) is based upon understanding transient heat release analysis of diesel engines, created a systematic mythology for performing these transient heat release analysis. The researchers developed a novel method to infer the mass of air trapped in the cylinder and the mass of fuel injected on a cycle-by-cycle basis. The cyclic mass of air trapped in the cylinder was found by accounting for pressure gradients, piston motion \& short-circuiting during the valve overlap period. The cyclic mass of fuel injected was computed from the measured injector needle pressure history during the injection period. These parameters were then used in conjunction with cycle-resolved pressure data to accurately define the instantaneously thermodynamic state of the mixture and to calculate transient heat release profiles.

It was understood, unlike in the steady-state operation, where standard flow meters can be used to measure both fuel $\&$ air flow rates, during the transient engine operation, cycle fuel rates need to be resolved at much faster rates, which could be of the order of fractions of a second. Hence, a method was developed to deduce critical parameters for transient analysis from available, measured signals. The method involves determination of the following.

Start of Fuel Injection - Dynamics of Start of Injection (SOI) is inferred from measuring the fuel injection pressure profile, and processing of the rocker arm strain gage signals. 
Cyclic Fuel Mass \& Rate of Injection - In this instance, the fuel injection pressure profile and in-cylinder pressure profile can be understood by processing the rocker arm strain gain signal which will ultimately help understanding the rate of injection. Assuming one-dimensional, quasi-steady, incompressible fuel flow through the nozzle, the instantaneous mass flow rate was deduced with the same pressure profiles.

Trapped Air Mass - Trapped air mass was calculated assuming that the temperature at the inlet valve closing is equal to that of the air is in the intake manifold. The determination of trapped air mass experimentally involves 2 stages: (i) when the exhaust valve(s) are closed \& (ii) when the intake \& exhaust valves are both open \& overlapping.

Finally, it was concluded that the above mentioned transient effects could be captured only with the above developed method to analyze a long sequence of cycles under the transient operation conditions.

Williams and Witter (2001) developed a method to identify misfiring cylinders with the help of crankshaft angular velocity measurements. To identify the misfiring cylinders, cylinder pressure and cylinder torque were reconstructed using crank shaft angular velocity. Calculating IMEP for each cylinder with the help of in-cylinder pressure data enabled creating a linear parameterization between IMEP and cylinder excitation torque. Once the IMEP was calculated, indicated torque was determined for each cylinder using swept volume of the cylinder. Then, the indicated torque was used to identify the presence of misfire, the misfiring cylinders, the degree of misfire, and most importantly, the faulty cylinders before excessive damage was done.

Rocco (1993) has performed analysis on how the T.D.C. setting error could affect the direct injection diesel engine in-cylinder pressure data. Since in-cylinder pressure data 
are critical in calculating IMEP, and rate of heat release as a method to understand combustion process, it is imperative that T.D.C. setting error be accounted for. The authors reported that:

- For a D.I. diesel engine, even a small T.D.C. setting error could produce a wide uncertainty near the Top Dead Center (T.D.C.) where the highest incylinder pressures rise could be seen.

- With a small error at T.D.C., net heat release rate curves can have substantial differences in shape and value. Also, it is noticed that an error of $1 \%$ at T.D.C. could yield up to $10 \%$ variation in the calculation of net heat release.

- Considering the conversion from net heat release analysis to mechanical work performed, significant error could be seen in the calculation of mechanical work. Hence, this could hinder the performance evaluation of an engine.

A study conducted at Detroit Diesel Corporation by Brown and Neill (1992) explains a non-contact method of determining in-cylinder pressure for a reciprocating engine. This method was based on a pattern recognition technique, and compared the crankshaft speed fluctuations to known reference patterns.

It was shown that the non-intrusive method of measurement of in-cylinder pressure with flywheel angular velocity fluctuations can produce an error less than $6 \%$ of the rms value. Alternatively, when the in-cylinder pressure was less than $10 \%$ of the operating condition, this method had only $1 \%$ chance of predicting that a faulty cylinder was healthy. 
Further, an under fueling cylinder could reduce the peak cylinder pressure on the healthy cylinders up to $25 \%$. So, indication of a low cylinder pressure doesn't necessarily imply that a certain cylinder is faulty.

The research done by Payri et al., (2005) introduced a novel method to analyze incylinder pressure in a direct injection diesel engine. The reasoning behind this was to decompose the cylinder pressure signal into three regions during the regular engine operation, which would provide more complete basis for analysis. These regions are pseudo-motored, combustion and resonance excitation. Since the combustion process of a DI diesel engine is a significant source of noise, a combustion noise analysis was performed to validate this method.

The authors showed that, the amount of energy in the resonance signal, compared to the amount of energy in the pseudo-motored signal tends to be a more relevant indicator of the in-cylinder pressure relative to the combustion noise. Also, according to this approach speed and load dissimilarities have been analyzed and proven that the combustion signal is mostly controlled by the speed, whereas the resonance signal mostly depends on the engine load. The resonance signal depends on the load mainly due to its dependence on temperature.

This study was a powerful example of how the combustion process could be analyzed with alternative methods, such as combustion noise relative to in-cylinder pressure. 


\section{EXPERIMENTAL EQUIPMENT}

This section includes the outline of the experimental apparatus and equipment used during in-field data logging and test cell data logging.

\subsection{In-field Tested Vehicles}

In this section all the vehicles used for in-use testing will be discussed. These vehicles were comprised of a concrete mixer, heavy hauler, dump truck, and a transit bus.

\subsubsection{Concrete Mixer}

A concrete mixer equipped with a 2004 Cummins ISM was located in Clarksburg, WV. The truck was manufactured by International Trucking Company with a front engine configuration, which utilized an Eaton-Fuller ${ }^{\circledR}$ fully automatic transmission. Data was collected on the mixer while it performed regular duties of loading concrete from the plant, traveling, idling at both plant and the job site with accessory loading and unloading concrete at the work site. Even though the mixer was performing the same job, it was utilized in different work sites, hence data was captured for different cycles. The Somat ${ }^{\circledR}$ data acquisition software was able to record 5 different cycles the concrete mixer performed during the test period. 
Table 2: Concrete mixer information

\begin{tabular}{|c|c|}
\hline Vehicle Application & Concrete mixer \\
Owner & Central Supply Co. \\
& Central Supply Co. \\
Location & Post Office Box 968 \\
Clarksburg, WV 26301 & International \\
Vehicle Manufacturer & $5500 i$ \\
Model & 2004 \\
Model Year & Cummins ISM 370 \\
Engine & 2004 \\
Engine Model Year & $370 \mathrm{hp}$ \\
Rated Power & Yes \\
C-EGR Equipped & \\
\hline
\end{tabular}

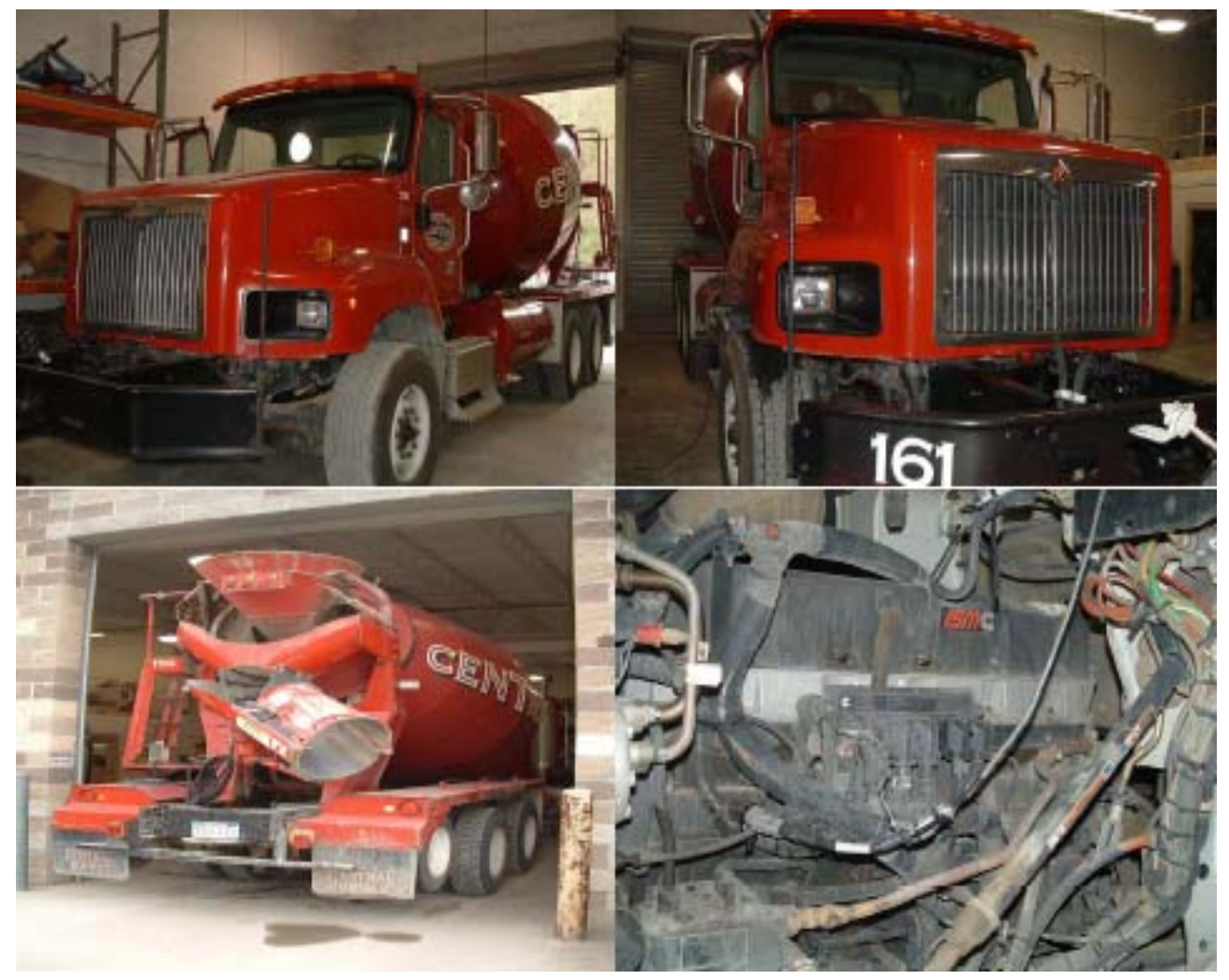

Figure 1: Central Supply Concrete Mixer used for Testing Purposes 


\subsubsection{Heavy Hauler}

Table 3: Heavy hauler information

\begin{tabular}{|c|c|}
\hline Vehicle Application & Heavy Hauler \\
Owner & Douglas Herzog \\
Location & \\
& 1223, Mercedes Bend \\
Toms River, NJ 08753 \\
Vehicle Manufacturer & International \\
Model & 8600 \\
Model Year & 2004 \\
Engine & Cummins ISM 370 \\
Engine Model Year & 2004 \\
Rated Power & $370 \mathrm{hp}$ \\
C-EGR Equipped & Yes \\
\hline
\end{tabular}

The truck was tested with in Morgantown and Pittsburgh areas. The heavy hauler was a day cab with a 10 speed manual Eaton transmission. After the tractor trailer was hooked up GVWR scaled 80,000 lbs for this application. Testing was performed at EPA approved city and highway routes comprises from Morgantown to Washington, PA and back.

\subsubsection{Transit Bus}

Testing for the transit bus was conducted in Baltimore, MD metropolitan area. The bus had a rear engine configuration with a Eaton-Fuller ${ }^{\circledR}$ fully automatic transmission. This New Flyer 40 footer has recently been added to the Baltimore transit fleet. The testing route consisted of city driving as well as highway driving, while performing daily rituals such as loading and unloading passengers, idling at the bus stops and driving in the daily rush hour. Somat ${ }^{\circledR}$ DAQ was able to capture 6 hours of data. 
Table 4: Transit bus Information

\begin{tabular}{|c|c|}
\hline Vehicle Application & Transit Bus \\
Owner & Maryland Transit Administration \\
Location & Maryland Transit Administration \\
& 6 St. Paul St, Baltimore \\
MD 21202-1614 \\
Vehicle Manufacturer & New Flyer \\
Model & D40LF \\
Model Year & 2005 \\
Engine & Cummins ISM 370 \\
Engine Model Year & 2005 \\
Rated Power & $370 \mathrm{Hp}$ \\
C-EGR Equipped & Yes \\
\hline
\end{tabular}

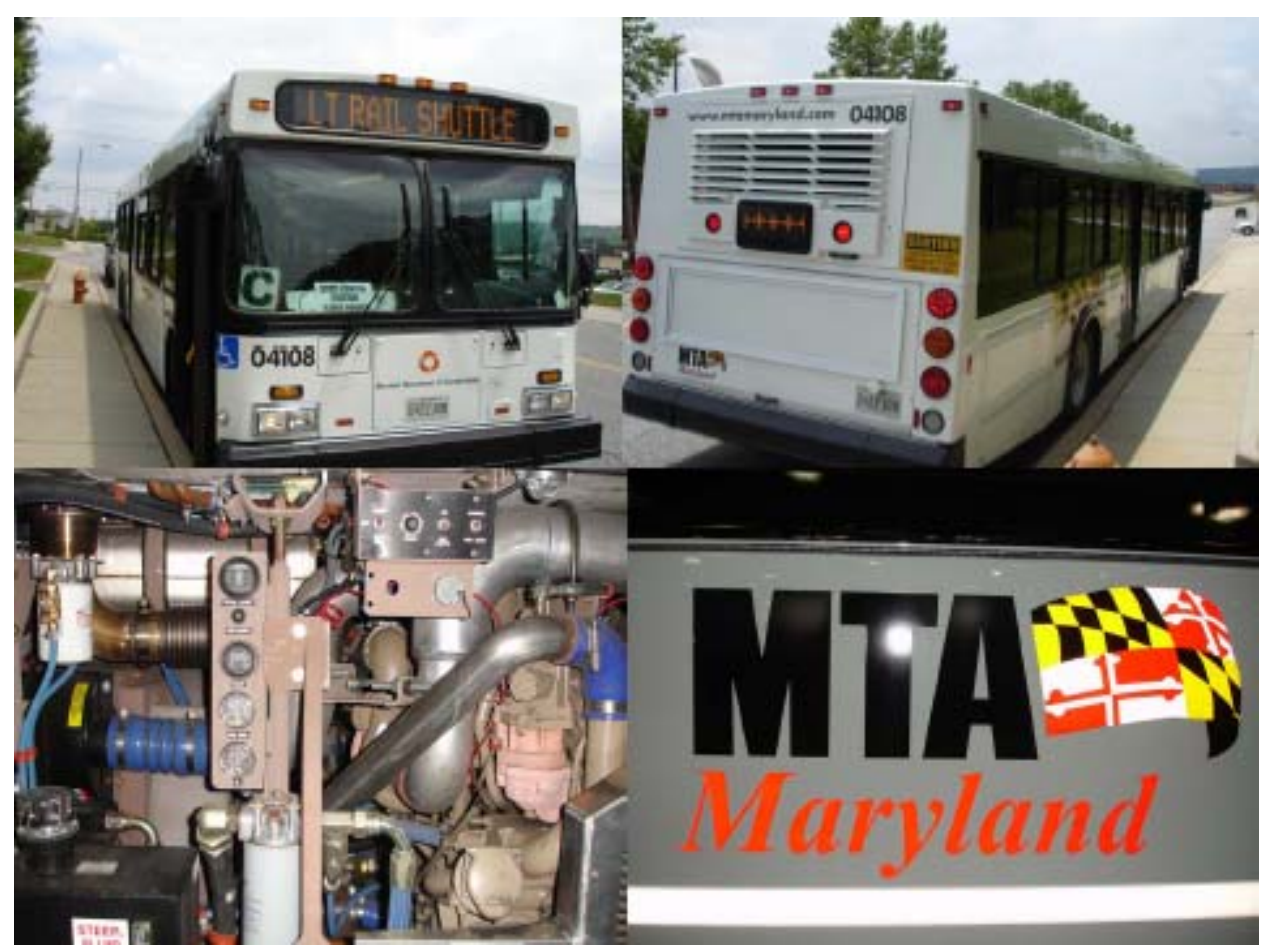

Figure 2: MTA Transit Bus used for testing 


\subsubsection{Dump Truck}

The dump truck tested in this study, was located in Clarksville, IN. The vehicle was used to move earth fill from an excavating site to a near-by dump site. Even though this wasn't a lengthy route, the duty cycle comprised of constant loading and unloading for the entire 10-hour nonstop work shift. The average duty cycle involved loading at the excavating site, traveling to the dump site, unloading at the dump site, traveling back empty to the excavating site. The engine was idling while the truck was getting loaded. The significant difference in this duty cycle was having low engine speeds and high engine loads for greater amount of time within the operation. The dump truck was manufactured by International Truck Company and uses a Eaton-Fuller ${ }^{\circledR}$ fully automatic transmission.

Table 5: Dump truck information

\begin{tabular}{|c|c|}
\hline Owner & Dump Truck \\
Location & Kentuckiyana Trucking Inc. \\
& Kentuckiyana Trucking Inc. \\
& Emery Ln, Clarksville, IN 47129 \\
Vehicle Manufacturer & International \\
Model & $5600 i$ \\
Model Year & 2004 \\
Engine & Cummins ISM 370 \\
Engine Model Year & 2004 \\
Rated Power & $370 \mathrm{Hp}$ \\
C-EGR Equipped & Yes \\
\hline
\end{tabular}




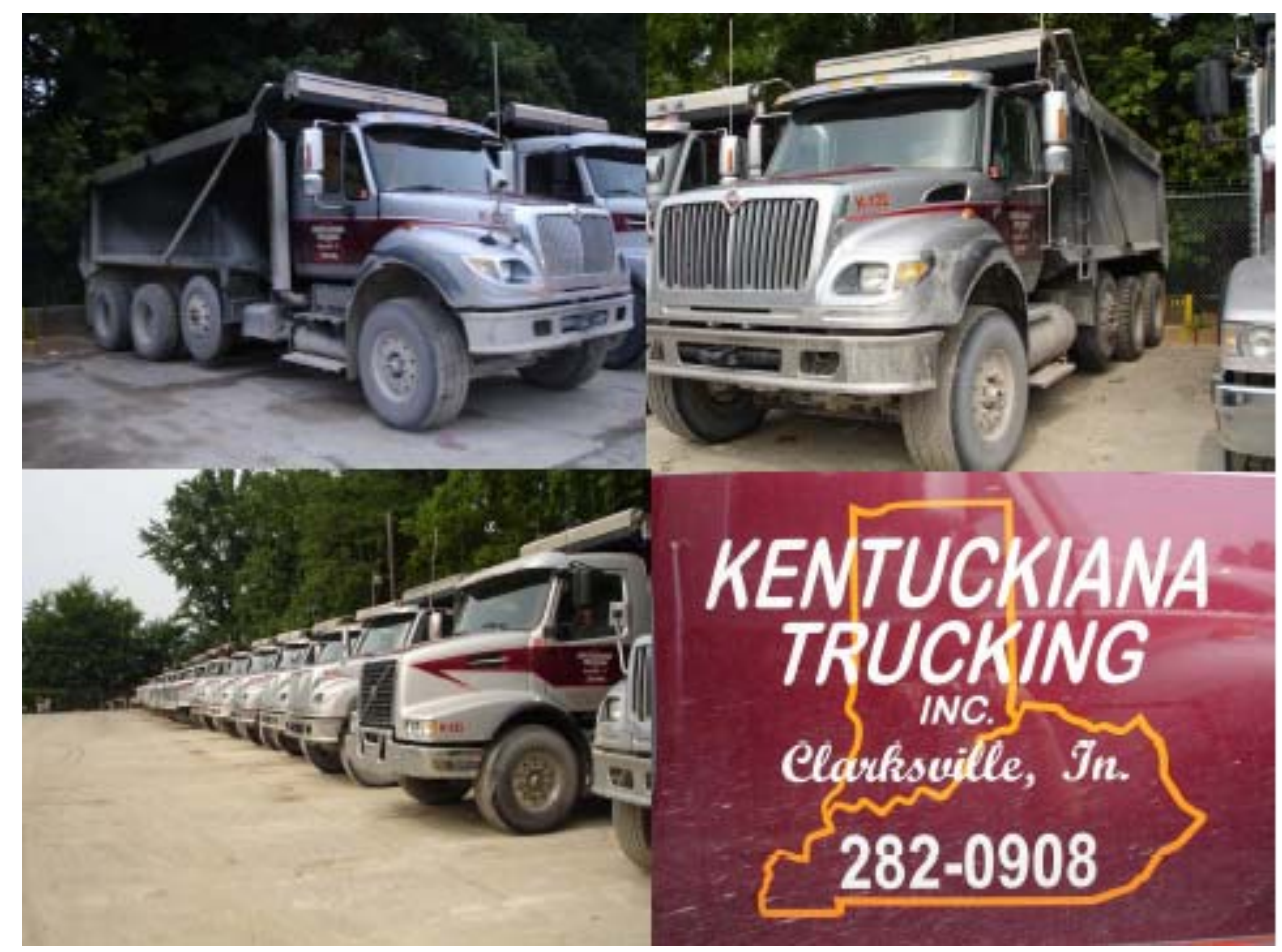

Figure 3: Kentuckiana Dump Truck used for testing

\subsection{Base Engine Configuration}

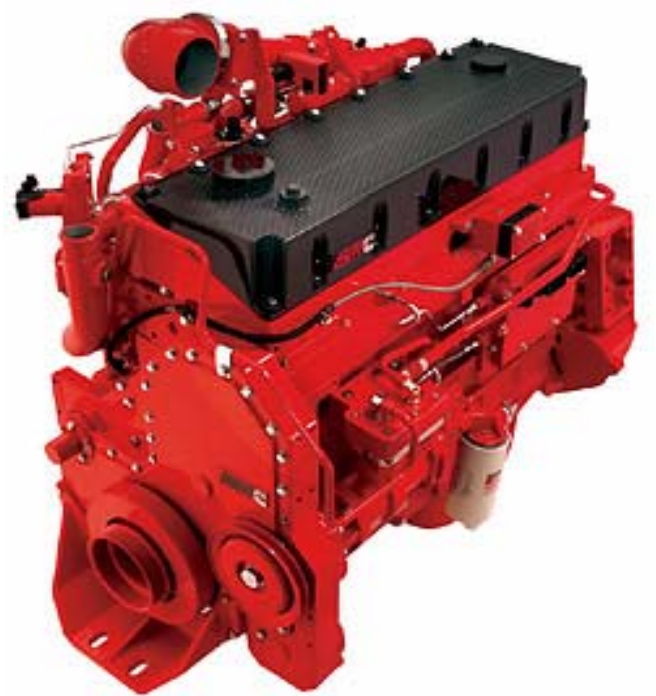

Figure 4: The base engine used for testing at EERL [18] 
Table 6: Base engine information

\begin{tabular}{|c|c|}
\hline Engine Manufacturer & Cummins Inc. \\
Engine Model & ISM 370 \\
Model Year & 2004 \\
ESN & 35108713 \\
Displacement & $10.8 \mathrm{~L}$ \\
ECU & CM 875 \\
Rated Power & $370 \mathrm{Hp} @ 2100 \mathrm{rpm}$ \\
Peak Torque & $1450 \mathrm{ft}-1 \mathrm{bs} @ 1200 \mathrm{rpm}$ \\
High Idle & $2330 \mathrm{rpm}$ \\
Configuration & Inline 6 \\
Bore (m) x Stroke (m) & $0.127 \mathrm{~m}$ x 0.145 m \\
Induction & Turbo Charged \\
Fuel Type & Diesel \\
Injection & Electronically Controlled \\
Valves per Cylinder & Four \\
Engine Strokes per Cycle & Four \\
\hline
\end{tabular}

The Cummins ISM 370 diesel engine meets the 2004 EPA emissions regulations using Cooled Exhaust Gas Recirculation (C-EGR) associated with advance timing in combustion and fuel injection (Cummins.com, 2005). The Cummins ISM engine uses advance technology such as Holset ${ }^{\circledR}$ Variable Geometry Turbocharger (VGT), Cummins C Break ${ }^{\mathrm{TM}}$ by Jacobs ${ }^{\circledR}$ and Fleetguard ${ }^{\circledR}$ Fuel system. The advantages of using a variable geometry turbocharger are good transient response, better fuel economy, increased useful engine operating speed range, advanced engine break capabilities, reduced engine volume for a given rating, and ability to utilize high pressure ratio compressors (holset.co.uk, 2005). By utilizing an advanced fuel system, The Cummins ISM 370 could improve efficiency and extend the engine life, reduce restriction to fuel flow, supports extended service intervals and maintain fuel/water separation efficiency over time (fleetguard.com, 2005). 


\subsection{In-field Data Acquisition Equipment}

To recreate specific duty cycles on the laboratory dynamometer, engine parameters such as speed and load were gathered using in-field data acquisition. Main components of the in-field data acquisition system are the Somat ${ }^{\circledR}$ data acquisition module, laptop, power inverter, and the connecting cables.

\subsubsection{Somat eDAQ Data Acquisition System}

Somat ${ }^{\circledR}$ eDAQ was a rugged modular data acquisition system, which had the capability of collecting analog data from sensors as well as digital data from vehicle network interfaces (Somat.com, 2005). This unit had a built-in PCMCIA slot to accommodate Type II or Type III cards of various storage capacities that could be read with a PC or a laptop afterwards.

The eDAQ utilized a user friendly vehicle bus interface that suppored a wide range of vehicle network interfaces, including: CAN, J1850 PWM, J1850 VPW and SAE 1939. With the compact design of this unit, it could travel unobtrusively in vehicles, hidden under a seat, under a dashboard, or in the trunk. It had a small footprint of only $11 "$ x 9" (28cm x $23 \mathrm{~cm})$, and could withstand shocks up to $20 \mathrm{~g}$, was sealed to dust, and could operate successfully in extreme testing environments. 


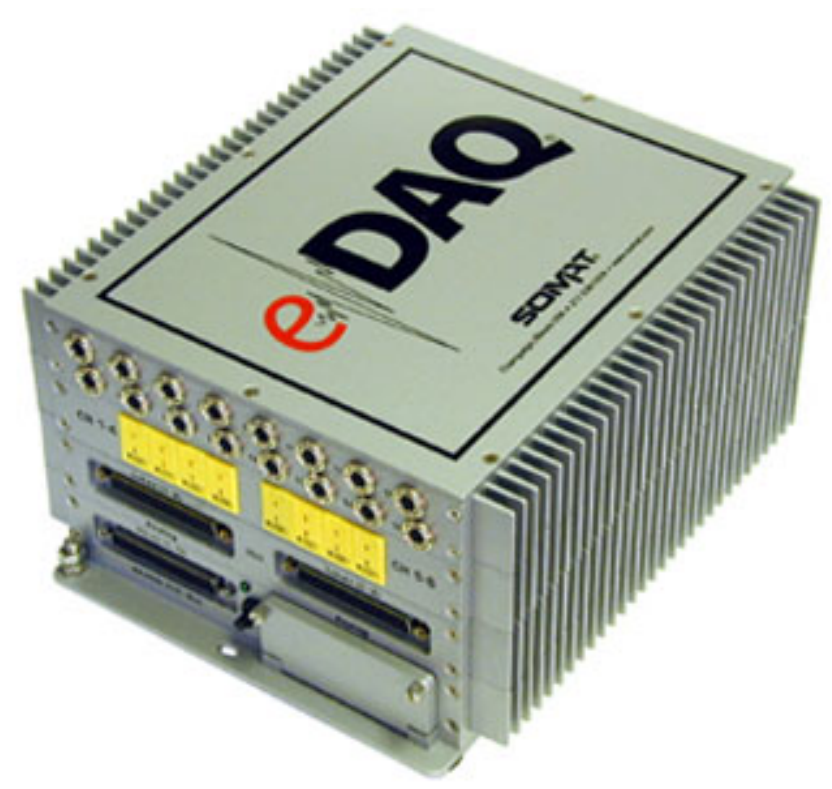

Figure 5: Somat eDAQ Data Acquisition Unit [41]

The eDAQ system was powered by a 12 volt power supply, which was connected to either the cigarette lighter or directly to the vehicle power grid. Somat ${ }^{\circledR}$ was connected to the vehicle interface with either a 9-pin Duetsch or a 3-pin Duetsch connector.

The engine speed was measured by Somat ${ }^{\circledR}$ eDAQ directly from the engine control unit. Other events such as parasitic engine losses such as water and hydraulic pump drag, alternator drag, air compressor drag, and fan windage losses were not accounted for during these measurements by Somat ${ }^{\circledR}$ system. These parasitic loadings could be significantly different from those encountered during engine tests that are performed on an engine dynamometer, which would inevitably affect even brake-specific emissions results. Nevertheless, actual torque wasn't recorded by the DAQ system, but the load was recorded as a percentage of the maximum load. This percentage value could be translated into actual load by referencing the engine map. 


\subsubsection{Power Inverter}

In order to supply power to the laptop, a DC to AC power inverter was used. Tripplite Inc., manufactured the inverter, a model PV1200, used for the in-field testing. The inverter converted the $12 \mathrm{~V}$ DC power supplied by the vehicle's alternator into $110 \mathrm{~V}$ AC power that could be utilized for data acquisition. The power inverter is shown below in Figure 6.

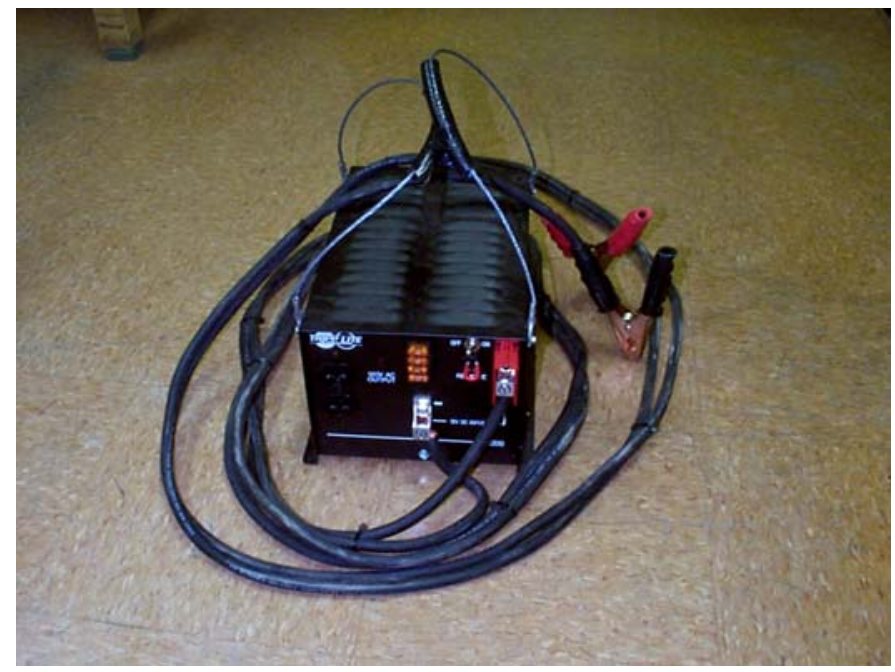

Figure 6 Tripplite Inc. Model PV1200 Power Inverter

\subsection{In-Laboratory Data Acquisition Setup - EERC Components}

All the in-laboratory testing was performed at the West Virginia University Engine and Emissions Research Laboratory (EERL) located on the WVU Evansdale campus in Morgantown, WV. EERL employs a full-scale CFV-CVS (critical flow venturi-constant volume sampler) system with all laboratory apparatus and equipment constructed according to the specifications delineated in the CFR 40, Part 86, Subpart N. These 
components will be briefly discussed in this section. Also a schematic of the laboratory testing setup will be shown in Figure 9.

\subsubsection{Cylinder Pressure Measurements}

For cylinder pressure acquisition a KISTLER ${ }^{\circledR}$ pressure transducer was used and for data acquisition a $\mathrm{NI}^{\circledR}$ hi-speed daq card was used. A Labview code was written to facilitate data acquisition and analysis of in-cylinder pressure data (Ardanese, 2005).

\subsubsection{Cylinder Pressure Transducer}

To evaluate the cylinder pressure traces, a KISTLER ${ }^{\circledR}$ water-cooled ThermoCOMP pressure transducer (Type: 6061B) was utilized (Kistler.com, 2006). This transducer could measure pressures up to 250 bar (3626 PSI). The sensor was comprised of a double walled diaphragm, which minimized the thermal shock. In addition, the sensor was water cooled to reduce the load cycle drift also known as the zero offset of the pressure signal.

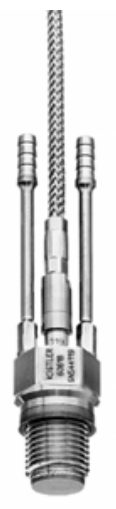

Figure 7: Water-Cooled Cylinder Pressure Transducer [27]

The piezoelectric functionality of this sensor could be summarized as, when a measurable pressure acts upon the diaphragm, it converts the pressure in to a proportional 
force. Then, a quartz packet converts this load into an electrostatic charge, where an electrode feeds this negative charge into a charge amplifier. Finally the charge amplifier converts the signal in to a readable positive voltage.

\subsubsection{Data Acquisition Card}

When acquiring cylinder pressure traces roughly around $40 \mathrm{kHz}$, it was necessary to utilize a high speed data acquisition card such as a S-Series Multifunction DAQ (250 kS/s, 16-Bit) made by National Instruments (NI.com, 2005). This NI ${ }^{\circledR}$ PCI-6143 daq card had 8 differential 16-bit analog inputs as well as 8 digital I/O lines and was capable of simultaneous sampling and high throughput. The $\mathrm{NI}^{\circledR}$ PCI-6143 provided a very low cost per channel while maintaining high dynamic accuracy and simultaneity. During testing, two digital channels were used for encoder pulses while an analog channel was used for the pressure transducer signal. A code written in LabVIEW was used since it supported the platform for NI ${ }^{\circledR}$ PCI-6143 daq card.

\subsubsection{Dynamometer [Vinay Nagendran, 2003]}

EERL employed a GE Model DYC-243 fan cooled, direct current (DC) dynamometer (power rating of $200 \mathrm{Hp}$; current rating of $300 \mathrm{amps}$ at $3000 \mathrm{rpm}$ ). This specific dynamometer was capable of absorbing $550 \mathrm{hp}$ and providing up to $500 \mathrm{hp}$ during motoring of the engine. An electric dynamometer closely resembles the electric motors in operation. The DC dynamometer consisted of an armature and stator assembly, which generates the torque. The engine output was measured by a load-cell mounted on the dynamometer frame and altering the load on the dynamometer also varies the load applied. The load cell was calibrated by suspending known weights from an arm of known length, mounted opposite to the load cell. This technique provided tension equal 
to the maximum value of force reachable by the dynamometer at any given time. Engine speed was recorded with a digital speed encoder within the dynamometer.

\subsubsection{Intake Air flow Measurement}

A Meriam Instruments Laminar Flow Element (LFE) was used to quantify the intake airflow rates. The LFE was made up of a series of small capillary tubes oriented parallel to the direction of the airflow. The capillary matrix produced a laminar flow of air from the turbulent flow entering it. A pressure drop was created in the LFE from the friction of the air passing through the tiny capillaries. A calibration equation was supplied by Meriam Instruments that helped calibrate the LFE. The absolute temperature and pressure upstream of the capillary matrix and the pressure downstream of the matrix were the solitary parameters required for intake volume flow determination and the equation is shown below (CFR, 2000).

$$
\dot{V}_{\text {Actual }}=\left(B \times(\Delta P)+C \times(\Delta P)^{2}\right) \times\left(\frac{\mu_{\text {std }}}{\mu_{\text {flow }}}\right)
$$

Where,

$\dot{V}_{\text {Actual }}=\quad$ volume flow rate of air through LFE

$\mathrm{B}=$ coefficient supplied by Meriam Instruments

$\mathrm{C}=$ coefficient supplied by Meriam Instruments

$\mu_{\text {std }}=$ standard kinematic viscosity

$\mu_{\text {flow }}=$ actual flow kinematic viscosity

$\Delta P=$ differential pressure across LFE

A correction factor was used to account for viscosity variations and is as follows: 


$$
\begin{gathered}
\text { Correction Factor }=\left(\frac{529.67}{459.67+T\left({ }^{\circ} \mathrm{F}\right)}\right) \times\left(\frac{181.87}{\mu g}\right) \\
\mu g=\frac{14.58+\left(\frac{459.67+T\left({ }^{\circ} \mathrm{F}\right)}{1.8}\right)}{110.4+\left(\frac{459.67+T\left({ }^{\circ} \mathrm{F}\right)}{1.8}\right)}
\end{gathered}
$$

The LFE used for all in-laboratory testing at EERL was a Meriam Model 50MC24 LFE with inside diameter $10.2 \mathrm{~cm} \mathrm{(4} \mathrm{in.)} \mathrm{and} \mathrm{maximum} \mathrm{flow} \mathrm{rate} \mathrm{of} 11.32 \mathrm{~m}^{3} / \mathrm{min}(400$ cfm) [Carder, 1999]. A MKS 223 B differential pressure transducer was used to measure the differential pressure across the laminar flow element, while absolute upstream pressure was determined with a Setra Model C280E pressure transducer. The temperature of the inlet air upstream of the LFE was recorded with a Resistive Temperature Device (RTD).

\subsubsection{Critical Flow Venturi}

A CVS system was used to regulate the flow of diluted exhaust gases passing through the dilution tunnel according to the specifications mentioned in CFR 40. When the critical flow venturi reached sonic conditions (choked flow); a constant mass flow rate was maintained in the dilution tunnel. During the sonic operation, flow through the venturi was a function of the diameter of the throat and the pressure and temperature of the gas upstream. Pressure data was collected with a Viatran model 1042 AC3AAA20

pressure transducer as the temperature was documented with a resistive temperature device (RTD). Knowing the absolute temperature and absolute pressure, mass flow rate was calculated as follows: 


$$
Q=\frac{K_{V} P}{\sqrt{T}}
$$

Where,

$\mathrm{Q}=\quad$ the flow rate in $\mathrm{scfm}$ at standard conditions $\left(20^{\circ} \mathrm{C}\right.$ and $\left.101.3 \mathrm{Kpa}\right)$

$\mathrm{K}_{v}=$ the calibration coefficient of the venturi

$\mathrm{P}=$ the absolute pressure at the inlet of the venturi in Kpa

$\mathrm{T}=$ the absolute temperature at the inlet of the venturi in ${ }^{\circ} \mathrm{K}$

\subsubsection{Full-Flow Exhaust Dilution Tunnel}

Since exhaust emissions testing primarily depends on understanding the effects of emissions after mixing with the ambient air, it is necessary to simulate "real world" conditions while acquiring data. Not only does the CVS simulate "real world" conditions by interacting with dilution air, it also quenches post-cylinder combustion reactions and decreases the exhaust gas dew point to hamper condensation. Exhaust line quenching is necessary to prevent measurement inconsistencies of emission. Additionally, by eliminating water in the sampling stream, it reduces the risk of certain gaseous components are being soluble such as nitrogen dioxide $\left(\mathrm{NO}_{2}\right)$, which could unfavorably influence measurement accuracy.

The EERL utilized a full-flow dilution tunnel for conducting emissions research. A full-flow dilution tunnel collects the entire exhaust stream from the engine and mixes with the clean ambient air. The full-flow system housed at EERL was designed and operated in-accordance with specifications outlined in CFR 40, Part 86, Subpart N. This system is based upon the CFV-CVS principle. This method embarks a large centrifugal blower that draws the diluted exhaust gas mixture from the tunnel through critical flow 
venturi. The primary dilution tunnel was constructed with stainless steel to prevent oxidation contamination and degradation from occurring. The Primary tunnel was approximately $0.45 \mathrm{~m}$ (18 in.) in diameter and $12.2 \mathrm{~m}$ (40 ft.) in length. The blower was driven by a $56.2 \mathrm{~kW}\left(75 \mathrm{Hp}\right.$ ) GE electric motor. Four venturis (three $28.32 \mathrm{~m}^{3} / \mathrm{min}(1000$ $\mathrm{scfm})$ and one $\left.11.32 \mathrm{~m}^{3} / \mathrm{min}(400 \mathrm{scfm})\right)$ were available to provide total flow rates ranging from 400-3400 scfm. Exhaust gases from the test engine enters the tunnel at its centerline and pass through a mixing orifice plate located three feet downstream from the beginning of the mixing region. Dilute gaseous samples were acquired at a distance of $4.6 \mathrm{~m}$ (15 ft.) downstream of the plate with heated sampling probes, where the samples were transferred to the analyzers via electrically heated Teflon lines. The particulate matter (PM) sampling system utilized a $0.10 \mathrm{~m}$ (4 in.) stainless steel secondary dilution tunnel located at the end of the sampling region to provide additional dilution air to ensure a soot collection filter face temperatures of less than $51.7^{\circ} \mathrm{C}\left(125^{\circ} \mathrm{F}\right)$.

\subsubsection{Gaseous Emission Sampling System}

As shown in the Figure 8 below, at EERL gaseous sampling system consisted of heated probes situated in the dilution tunnel and heated sampling lines linking the probes with the gas analyzers. Three heated sampling probes were located ten tunnel diameters (approximately $4.57 \mathrm{~m}$, or $180 \mathrm{in}$.) downstream of the mixing zone to make sure total turbulent mixing of the exhaust gases with the background air occured. The sampling probes and the analyzer bench were connected with electrically heated sampling lines. The hydrocarbon sampling line was held at a temperature of $190.5^{\circ} \mathrm{C} \pm 5^{\circ} \mathrm{C}\left(375^{\circ} \mathrm{F} \pm\right.$ $10^{\circ} \mathrm{F}$ ) using Fuji model No. 223-1806 temperature controller. This sampling line was held at a high temp to prevent high molecular weight hydrocarbons from condensing in 
the process. The other sample lines for the $\mathrm{NO}_{\mathrm{x}}$ and $\mathrm{CO} / \mathrm{CO}_{2}$ were maintained at $112.8^{\circ} \mathrm{C}$ $\pm 5^{\circ} \mathrm{C}\left(235^{\circ} \mathrm{F} \pm 10^{\circ} \mathrm{F}\right)$ to prevent water condensation in the line.

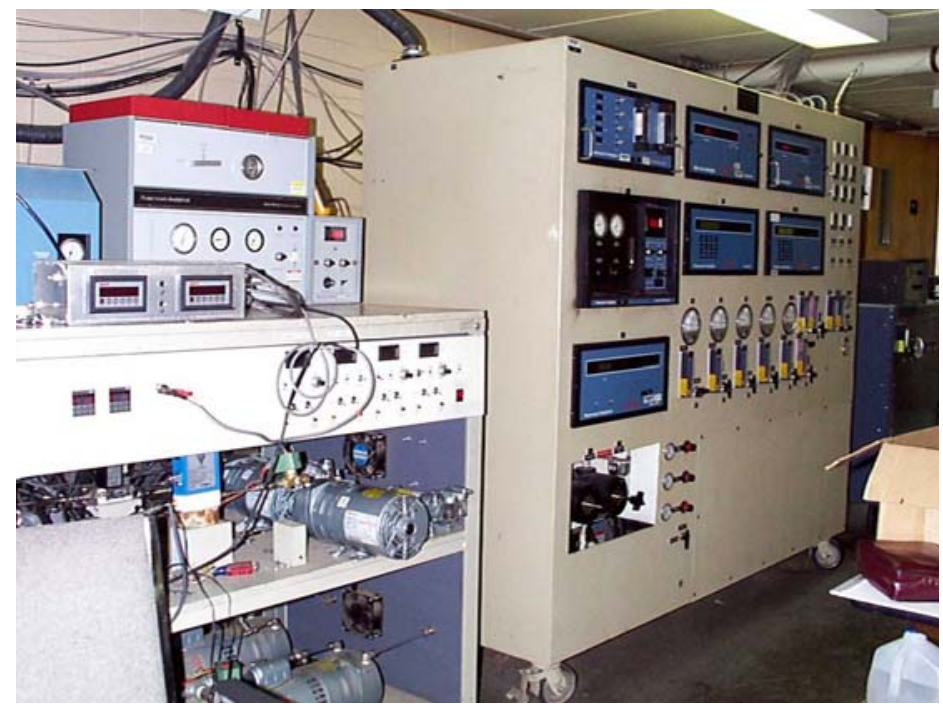

Figure 8: The EERL's Gaseous Emissions Analyzer Bench [14].

\subsubsection{Gas Divider and Calibration of Gas Analyzers}

For each exhaust gas analyzer, the zero and span gas values were checked prior to each test run using respective calibration gases with $1 \%$ accuracy traceable to NIST standards and a ten point calibration curve was produced. Calibration gases included the "top bottle" (span gas), and zero gas (zero air and ultra zero air monitoring, (UZAM) gas). The temperature was controlled using Fuji Model 223-1806 temperature controllers located on the emissions bench. A STEC Inc. SGD-710C gas divider was employed to provide stepped input to the analyzers during the calibration process. The gas divider was comprised of two inlet ports, one for the span gas, and the other for balance air or zero gases, and one output port that delivered the blended gas to the respective analyzer. The gas can be supplied at increments of $10 \%$ of span concentration. The core of the gas 
divider consists of a set of ten capillaries, and the mass flow rate through each capillary was proportional to the pressure drop across the capillaries.

\subsubsection{Exhaust Gas Analyzers}

The exhaust gas analysis bench consisted of laboratory grade (certification quality) analyzers for measurement of $\mathrm{CO}_{2}, \mathrm{CO}, \mathrm{NO}_{x}$, and $\mathrm{THC}$. Given below is a description of each gas analyzer, which is used in the EERL gaseous emissions analyzer bench.

\subsubsection{Nitrogen Oxide Analyzer [Rosemount, 1992]}

The $\mathrm{NO} / \mathrm{NO}_{\mathrm{x}}$ analyzer used was a Rosemount Model 955 Chemiluminescent analyzer. This analyzer was capable of detecting concentrations of $\mathrm{NO}$ or $\mathrm{NO}$ and $\mathrm{NO}_{2}$ together, which also known as $\mathrm{NO}_{\mathrm{x}}$. In the $\mathrm{NO}$ mode, the analyzer quantitatively converts $\mathrm{NO}$ in the sample into $\mathrm{NO}_{2}$ by gas-phase oxidation with molecular ozone $\left(\mathrm{O}_{3}\right)$. Ozone for this reaction is produced by passing air or oxygen over an ultra violet source. During the oxidation process, approximately $10 \%$ of the $\mathrm{NO}_{2}$ molecules are electrically excited, followed by an immediate return to the non-excited state. This conversion process generates a photon emission. Then a photomultiplier tube was used to identify the photon emission quantity, which is proportional to the NO amount present in the sample. The internal NOx converter was maintained between $660^{\circ} \mathrm{F}\left(350^{\circ} \mathrm{C}\right)$ and $750{ }^{\circ} \mathrm{F}(399$ ${ }^{\circ} \mathrm{C}$ ) en route for maximum $\mathrm{NO}_{2}$ conversion efficiency. If the determination of $\mathrm{NO}$ concentration only is desired, the sample could bypass the converter and be measured directly by selecting the $\mathrm{NO}$ mode of the analyzer. In the case of $\mathrm{NO}_{\mathrm{x}}$ detection, the total analyzer response would determine the amount of NO present in the original sample, as well as the $\mathrm{NO}$ created through the dissociation of $\mathrm{NO}_{2}$ in the converter. 


\subsubsection{Hydrocarbon Analyzer [Rosemount, 1992]}

A Rosemount Model 402 Heated Flame Ionization Detector (HFID) analyzer was utilized to measure the Total Hydrocarbon Content (THC) in the diesel exhaust . By counting the elemental carbon atoms in the exhaust sample the analyzer determined the amount of hydrocarbon in the exhaust stream. The sample gas flow was synchronized and flowed through a hydrogen/helium-fueled flame that caused the production of ions. Ions are produced when a regulated flow of sample gas flows through the flame and are collected on the polarized electrodes causing current to flow through the associated electronic measuring circuitry. This assimilation of ions by the electrodes produces a small current flow, which is then quantified and related to the number of carbon atoms contained in the exhaust sample. Hydrocarbons are measured wet, which means, water vapor is not evaporated out from the sample going into the $\mathrm{HC}$ analyzer. The multiplier switch, which is located on the front of the Model 402, allows selection of measurement ranges which best suits the resolution for the particular gas concentration being sampled. On the largest scale of the measurement range of the $\mathrm{HC}$ analyzer goes up to 250,000 ppm.

\subsubsection{Carbon Monoxide/Carbon Dioxide Analyzers [Horiba, 2001]}

The gaseous constituents of $\mathrm{CO}$ and $\mathrm{CO}_{2}$ were determined with Horiba Model AIA-210LE and Horiba Model AIA-210 Non-Dispersive Infrared (NDIR) analyzers. An NDIR analyzer operates utilizing the principle of infrared light absorption. NDIR analyzers use the exhaust gas species being measured to detect itself by the principle of selective absorption, in which the infrared energy of a particular wavelength, specific to a certain gas, will be absorbed by that gas. Infrared energy of other wavelengths will be 
transmitted by that gas, just as the absorbed wavelength will be transmitted by other gases. This sort of NDIR analyzer does not create a linear output, so calibration curves were generated for the analyzers before each testing session began.

\subsubsection{Fuel Metering System}

The fuel metering system was critical, in order to create accurate exhaust dilution ratios. The total tunnel flow rates were determined with the CFV-CVS system, but the predicament lies in the understanding of raw exhaust mass flow rates. A few factors restrain measuring the exhaust flow rate directly, such as engine backpressure limits, elevated temperatures, and high particulate matter concentrations. So, a different approach was used to estimate exhaust mass flow rate by understanding intake airflow rate along with engine fuel consumption rate.

The fuel flow rate was measured with a Max Flow Media 710 Series Fuel Measurement System [Carder, 1999]. The fuel was drawn from the storage tank exterior to the lab through a filter and into a vapor removal device, so it could be maintained at constant pressure of $206.8 \mathrm{kPa}$ ( $30 \mathrm{psi}$ ). Then fuel went through a bypass system where surplus fuel was routed through a pressure regulator to a heat exchanger and back to the storage tank. In this process, the heat exchanger used the bypass supply fuel to cool the engine return fuel. The amount of fuel that was not returned to the tank entered a Model 214 piston-displacement flowmeter and to a level-controlled tank. Within this tank the metered fuel mixed with the unused engine return fuel which was already cooled by the internal heat exchanger. The tank maintains its volume constant to measure the fuel used by the engine. A secondary fuel pump boosted the fuel pressure to the level needed by high-pressure diesel injection systems such as the common rail system. A bubble 
detector purged any vapors in the system by controlling a solenoid valve that connected to-engine and from-engine fuel lines. After departing the solenoid valve, the fuel entered an external heat exchanger that maintained a constant fuel temperature.

\subsubsection{Instrumentation Control/Data Acquisition}

Most of the in-laboratory data obtained during the testing undertaken in this study was collected with software and hardware previously developed and installed at EERL, other than the software and hardware purchased from National Instruments for cylinder pressure data acquisition. The in-house data acquisition system used an RTI-815F data acquisition board for data collection as well as rack-mounted signal conditioning units (Analog Devices Model 3B). The software and hardware purchased from National Instruments was discussed above in this chapter. All the laboratory data was recorded in ADC codes and later converted to the proper engineering units with a Visual Basic based reduction program developed in-house at WVU EERL. 


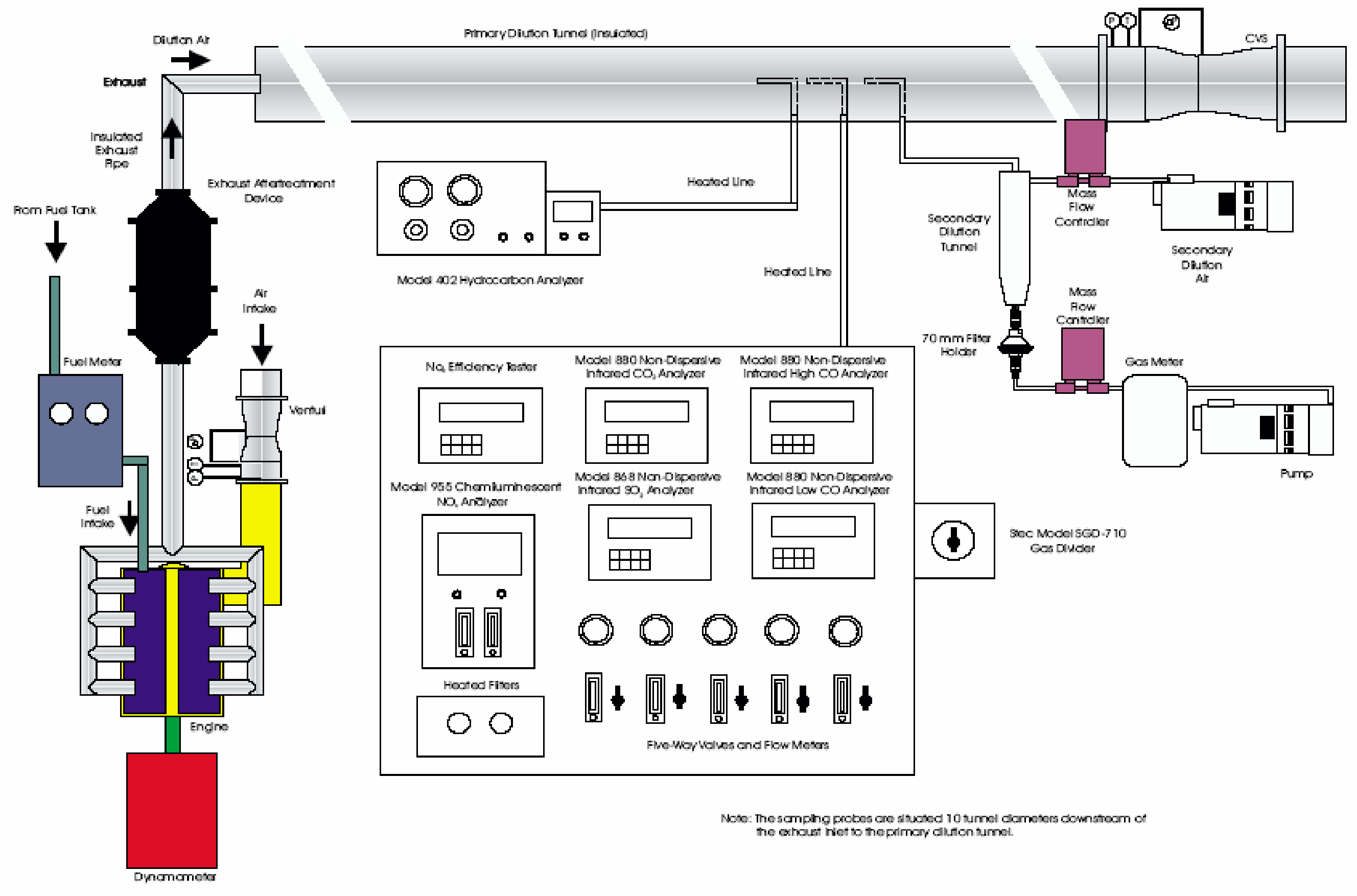

Figure 9: Schematic of West Virginia University's Engine and Emissions Research Laboratory Emissions Measurement System [14]. 


\section{EXPERIMENTAL PROCEDURES}

Described below are the procedures and calculations used with in both in-use and test cell testing phases. These procedures were followed to maintain the accuracy and distinctiveness of these experiments. Information gathered from Cummins certified technicians was also mentioned in an attempt to provide some insight on useful life of a Cummins ISM engines.

\subsection{In-Field Data Collection}

Since this project was concentrated on Cummins ISM post 2002 engines, recruitment of on-road vehicles for logging duty cycle data was a challenge. The test vehicles procured for this project were typically used for mass transportation, commercial transportation and vocational activities; hence employed on, virtually, a daily basis. Measures had to be taken to limit downtime and minimize the impact on daily routines.

For instance, the Somat ${ }^{\circledR}$ data logger was installed in all the test vehicles an hour before the specific vehicle begins its daily schedule. This facilitated the infield data logging with no additional downtime for the vehicle, thereby limiting the compensation to the owner that would have been required to pay for the additional time.

\subsection{Generation of Micro-Cycles}

A diversified collection of data was gathered from four vehicles (heavy hauler, concrete mixer, transit bus, and dump truck), while they followed operational cycles that were typical of those encountered in a regular day's operation. The collection of data was primarily focused on engine speed and load. After analyzing the whole duty cycle, 
proportional mini duty cycles were created to capture similar speeds and loads on the engine. Mini cycles had a duration anywhere from 20 minutes to 45 minutes. The representative cycles had to be limited to 45 minutes since the limitation of the test cell data acquisition system. The representative cycles developed from in-field testing were later recreated in the laboratory using a ISM engine instrumented with a cylinder pressure transducer, laboratory-grade analyzers and a dynamometer test bed. Before the begin of test cell testing, speed and load settings applied to the dynamometer were adjusted until the in-laboratory load and speed data closely correlated with load and speed data taken in field.

\subsubsection{Things Considered During Transient Cycle Generation}

The objective of producing a representative transient duty cycle was to include all the typical, repeatable activities undergone by a vehicle and to record their corresponding speed-load data in real-time operation. Under transient operation, it is complicated to optimize the engine parameters. Particulates may be formed due to excess fuel injected into the cylinder during speed and load changes and a whole host of engine parameters ranging from turbocharger, in-cylinder temperatures, injection timing, cooled EGR parameters to exhaust system dynamics and after-treatment systems. Consequently when developing cycles, the following criteria was observed.

1. The cycle should be representative of similar applications.

2. The developed cycle must involve all in-field operations of the vehicle.

3. The test cycle should go through the maximum range of speed and torque points in relation to in-field activity.

4. Lengthy idling times should be discarded. 
5. The cycle should be able to account for the entire accessory load on the original vehicle.

6. Data should be collected with the same operator during all the in-field trips for a certain duty cycle.

\subsection{Engine Set Up and Break-In}

Once the engine arrived in the laboratory, it was set up on a test bed, using engine mounts as supports. Afterwards, to ensure oil requirements do not affect the emission measurements, an 80-hour break-in was performed. Any unknown prior damage to the engine was fixed during the break-in period and so as not to hinder testing afterwards. An $\mathrm{AC}$ dynamometer was used for the break in process and operated the engine at 50\%-75\% of the rated load conditions.

For the laboratory testing, a $\mathrm{GE}^{\circledR}$ Dynamometer was attached to the engine flywheel using a driveshaft, an adapter plate, and a bonded-rubber coupling damper made by Walken ${ }^{\circledR}$. A new adapter plate was machined to accommodate the fly-wheel bolt pattern that was unique for this engine. The damper dissipates harmonic vibrations as well as provides for the absorption of any shock loads that may be encountered during testing. This drive system has substantial rotational inertia and turns with the same angular velocity as the engine.

During the testing, charge air cooling was done with water-to-air cooling relative to air-to-air cooling done in the on-road application. Similarly, engine coolant was cooled with a water-to-water cross flow heat exchanger relative to the air-to-water radiator in the field application. Other necessary instrumentations were instrumented to 
acquire necessary parameters such as EGR inlet/outlet coolant temperature and exhaust delta pressure.

Additionally, care was taken to keep the retrofit exhaust temperatures and back pressure values within the CFR specifications for test cell testing. During the testing backpressure was maintained at 40 (in. of $\mathrm{H}_{2} \mathrm{O}$ ) and the intake restriction was maintained at 15 (in. of $\mathrm{H}_{2} \mathrm{O}$ ). The exhaust was routed to the primary dilution tunnel by means of exhaust piping. Joints in the exhaust transfer tube were sealed with aluminum wrap capable of withstanding the high temperatures. More than $12 \mathrm{ft} .(6.1 \mathrm{~m})$ of accessible transfer tube was insulated with exhaust insulation, which was made of fiber-glass wool and wire mesh. The piping length was insulated in accordance with the requirements of CFR 40, Part 86. The exhaust transfer tube was insulated to minimize thermophoretic losses of PM, and to avoid temperatures from falling below $375^{\circ} \mathrm{C}$, which is essential to avoid condensation of higher molecular weight hydrocarbons. Temperatures were recorded using J-type thermocouples.

Prior to beginning performance and emissions testing of the engine for its various duty cycles, the engine was mapped several times to assure the rated conditions and repeatability. An engine map is a full-load curve for the entire speed domain ranging from low-idle (700 RPM) through rated speed (2100 RPM) to high idle (2300 RPM).

\subsection{Test Matrix}

Shown below in Table 7 is the test matrix utilized during the testing. Each duty cycle was comprised of four micro cycles that was 30-40 minutes in length. Each and every micro cycle was tested three times to assure repeatability. For the entire testing intake air was conditioned at $70 \mathrm{C}$ and $50 \%$ humidity according to $\mathrm{CFR}$ regulations. 
Table 7: Test Matrix for Test Cell Testing

\begin{tabular}{|c|c|c|}
\hline Duty Cycle & Cycle No: & $\begin{array}{c}\text { Number of } \\
\text { Repeats }\end{array}$ \\
\hline \multirow{4}{*}{ 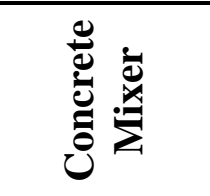 } & Cycle 1 & 3 \\
\hline & Cycle 2 & 3 \\
\hline & Cycle 3 & 3 \\
\hline & Cycle 4 & 3 \\
\hline \multirow{4}{*}{ 总 } & Cycle 1 & 3 \\
\hline & Cycle 2 & 3 \\
\hline & Cycle 3 & 3 \\
\hline & Cycle 4 & 3 \\
\hline \multirow{4}{*}{ 承 } & Cycle 1 & 3 \\
\hline & Cycle 2 & 3 \\
\hline & Cycle 3 & 3 \\
\hline & Cycle 4 & 3 \\
\hline \multirow{4}{*}{ 吾 } & Cycle 1 & 3 \\
\hline & Cycle 2 & 3 \\
\hline & Cycle 3 & 3 \\
\hline & Cycle 4 & 3 \\
\hline
\end{tabular}

\subsection{Cylinder Pressure Acquisition}

In-cylinder pressure is a critical component that would affect the life of components such as piston cylinders, piston liners and cylinder heads. In-cylinder pressure acquisition was done by using a Kistler ${ }^{\circledR}$ pressure transducer mounted on the side of the sixth cylinder cavity, NATIONAL INSTRUMENTS ${ }^{\mathrm{TM}}$ S series multifunction DAQ and other laboratory equipment which was documented in the previous chapter.

The four duty cycles, concrete mixer, dump truck, heavy hauler and transit bus were cut down into micro cycles of 4 sections each for the convenience of data acquisition and laboratory limitations. The laboratory limit for a single cycle is 53 minutes due to data acquisition limitations, which led to having micro trips of 30-45 minutes in length. The limitations mainly based on the capabilities of the lab hardware including the emissions sampling system. An example of recorded cylinder pressure and 
engine speed is presented in the Figure 10. The cylinder pressure was recorded relative to the crank angle while the engine speed was recorded at the same instance to establish a relationship between other laboratory measured components.

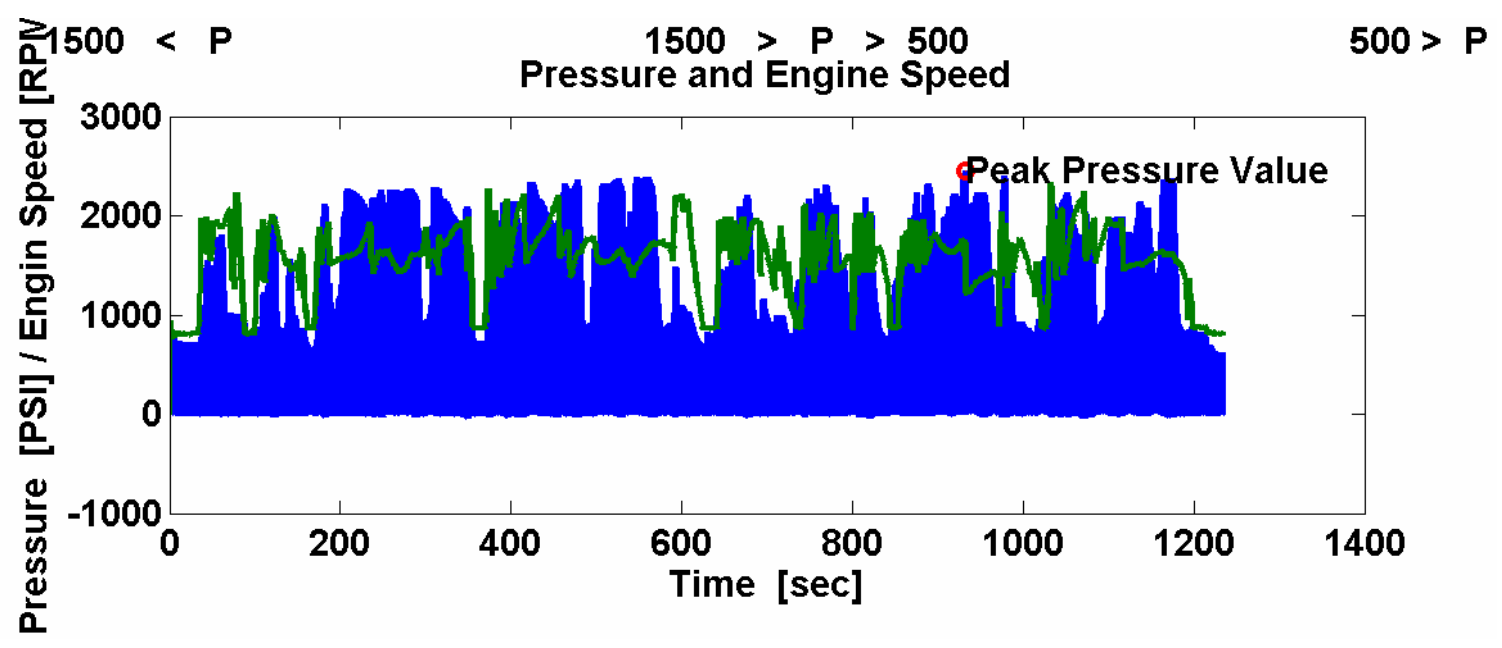

Figure 10: Example of Pressure Traces during a Portion of a Micro Cycle

The acquisition of in-cylinder pressure was performed at a sampling frequency of about $20-40 \mathrm{kHz}$ depending on the engine speed, which acquired a data point at every .35 degrees of the crank angle. Since the engine speed could not be stabilized, a pulse per crankshaft turn signal generated by an optical encoder (1024 pulses/rev) was used to distinguish the engine cycles.

Table 8: Calculations of pressure pulse measurements

\begin{tabular}{|l|cc|}
\hline & Idle & High Idle \\
\hline Encoder Resolution (pulses/rev) & 1024 & 1024 \\
Engine Speed (RPM) & 700 & 2300 \\
Encoder Pulses per Min (pulses/min) & 716800 & 2355200 \\
Encoder Pulses per Sec (pulses/sec) & 11946.67 & 39253.33 \\
& & \\
Engine Revs per Sec (RPS) & 11.67 & 38.33 \\
Engine Revs in Degrees per Sec (degree/sec) & 4200 & 13800 \\
Engine Degrees per Pulse (deg/pulse) & 0.352 & 0.352 \\
\hline
\end{tabular}


Table 8 shows the calculation of the pressure pulse measurement frequency. As indicated in Table 8 for every 0.352 degrees of the crank angle a pressure pulse and a speed point was recorded.

\subsubsection{Aspects Considered during Cylinder Pressure Evaluation}

In our experiments, a piezoelectric pressure transducer was used to measure the in-cylinder pressure. The inherent nature of the transducer causes a drift in the pressure trace. This drift was assumed to be constant during one engine cycle, and increased with continued testing. The drifting of the pressure trace was corrected using the initial cylinder pressure as the simulated cylinder pressure throughout the testing process.

Intake manifold pressure was considered as the initial pressure for the compression stroke. However pressure drops over valves and tuning effects in the intake passage can influence a pressure gradient between the intake manifold and the piston cylinder. Wave effects due to valve openings and piston motion are two other factors that can influence pressure readings. Another possibility is to use the air mass flow and volumetric efficiency to support the estimate given by the intake manifold. Nevertheless, intake manifold pressure was added throughout the in-cylinder pressure trace to obtain a more realistic value. Figure 11 displays a smaller section of the acquired cylinder pressure data. These data are corrected for the drift but are not correlated with the intake manifold pressure, hence indicates start of compression pressure as 0 PSI. 


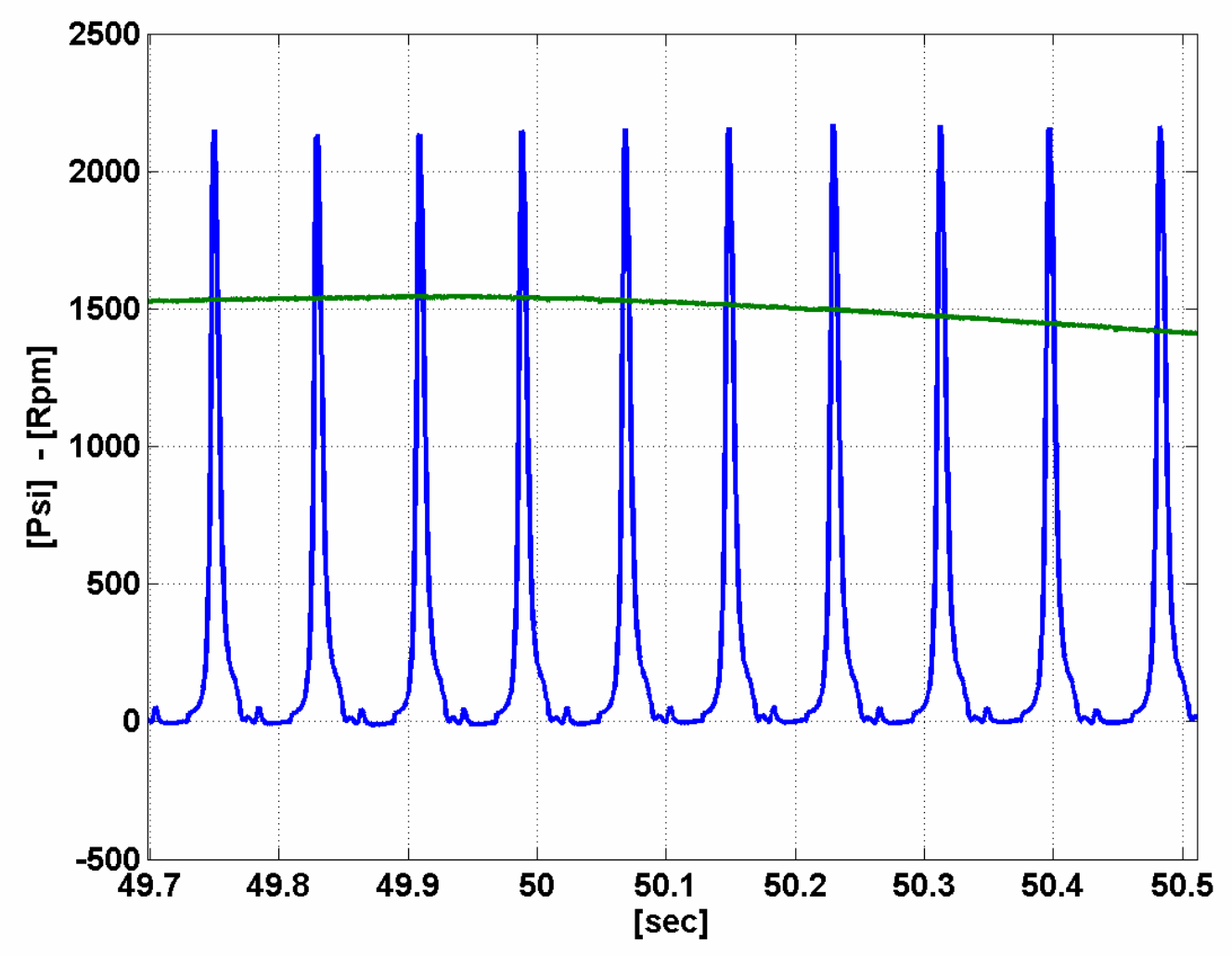

Figure 11: A Small Portion of Pressure Traces Acquired with Respect to the Engine Speed

The main problem with pressure sensor was not capturing the high frequency pressure pulsations originating from the opening and closing of exhaust and inlet valves. The main reason for not capturing pressure pulsations was the location of the pressure sensor after the poppet valve. Having the pressure sensor after the poppet valve is likely to give less than optimal results in pressure readings due to turbulence after the valve. The following is a reasonable example of this scenario. The pressure measured from the sensor was lower than the pressure in the intake manifold in few operating conditions, thus indicating a pressure increase over the EGR coolers, which is physically impossible. This discrepancy with pressure measurements leads to the belief that there is another explanation other than measurement problems of in-cylinder pressure. The formerly 
discussed pressure pulsations could be one such clarification, where it will drive a flow through the EGR-system even if the static pressures indicate a flow in the opposite direction.

\subsubsection{Derivation the Volume of Slider-Crank Model}

Understanding piston cylinder volume was critical for the calculations of cylinder pressure. To derive the volume off of a piston cylinder, crank angle is used as a function of compression ratio, the stroke, bore and connecting rod length (CSU, 2005). These geometric parameters are identified in the Figure 12.

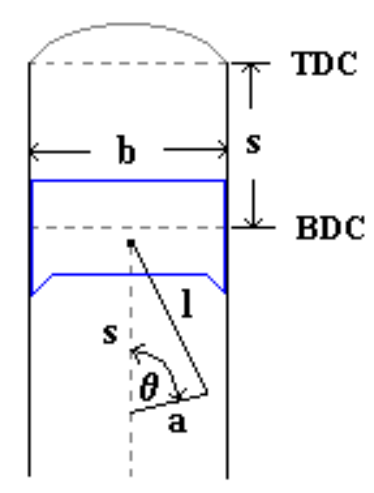

Figure 12: Piston Cylinder Geometry [3].

$\mathrm{b}=$ bore

$\mathrm{s}=$ stroke

$1=$ connecting rod length

$\mathrm{a}=$ crank radius $(=1 / 2 \mathrm{~s})$

$\theta=$ crank angle

$\mathrm{TDC}=$ top dead center

$\mathrm{BDC}=$ bottom dead center 
When the crank angle is at $0^{\circ}$, the piston cylinder head is at the TDC. The volume corresponding to this position is known as clearance volume, $\left(\mathrm{V}_{\mathrm{c}}\right)$. Vise versa when the crank angle is at $180^{\circ}$, and the position cylinder reaches its maximum volume $\left(\mathrm{V}_{1}\right)$ it is called the BDC or Bottom Dead Center. The difference between these maximum and minimum volume, $\left(\mathrm{V}_{1}-\mathrm{V}_{\mathrm{o}}\right)$, is known as the displacement volume, $\left(\mathrm{V}_{\mathrm{d}}\right)$. This displacement volume could be written as a function of bore and stroke:

$$
V_{d}=\frac{\pi}{4} b^{2} s
$$

Also, it is known that at any given crank angle the volume is given by

$$
V=V_{C}+\frac{\pi}{4} b^{2} s
$$

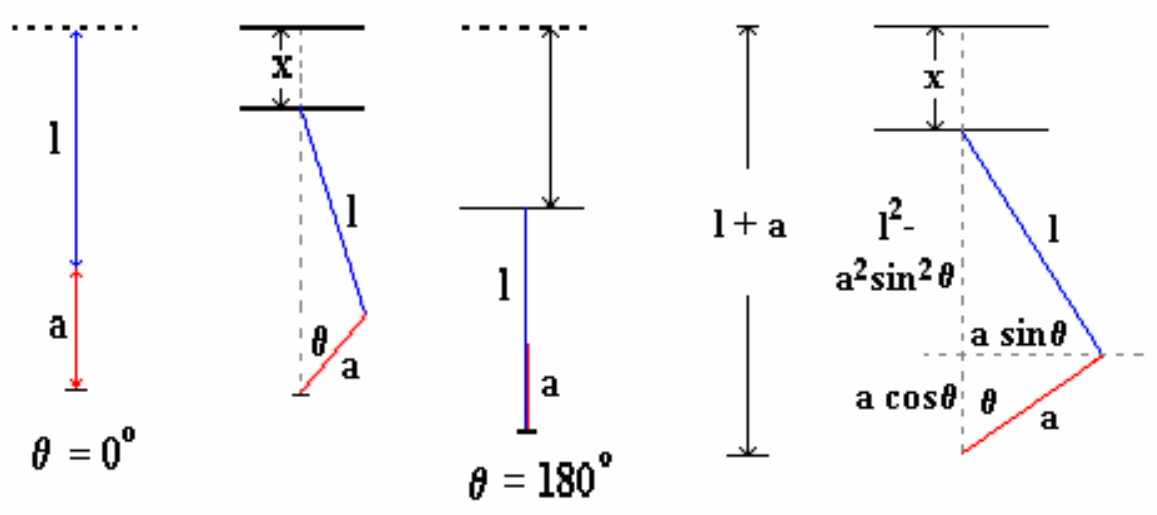

Figure 13: Geometry inside the piston cylinder [3]

$$
x=a+l-\left[\left(l^{2}-a^{2} \sin ^{2} \theta\right)^{1 / 2}+a \cos \theta\right]
$$

From the above diagrams, we could derive a relationship for the distance from the TDC as mentioned above. Where, $r=V_{1} / V_{o}$ is the compression ratio. Substituting 
known volumes obtained, a final formula was derived for the volume with respect to the crank angle.

$$
\begin{aligned}
& \mathrm{V}_{\mathrm{C}}=\mathrm{V}_{0}=\text { Minimum Volume } \\
& \mathrm{V}_{1}=\text { Maximum Volume } \\
& \mathrm{V}_{\mathrm{d}}=\text { Displacement Volume }
\end{aligned}
$$

$$
\begin{gathered}
V_{d}=V_{1}-V_{c} \quad V_{1}=V_{d}+V_{c} \\
r=\frac{V_{1}}{V_{c}}=\frac{V_{d}+V_{c}}{V_{c}}=1+\frac{V_{d}}{V_{c}} \\
V_{c}=\frac{V_{d}}{(r-1)} \\
V=\frac{V_{d}}{(r-1)}+\left[1+\frac{1}{a}-\cos \theta-\left(\left(\frac{1}{a}\right)^{2}-\sin ^{2} \theta\right)^{1 / 2}\right]
\end{gathered}
$$

\subsubsection{Work Done by a Piston Cylinder}

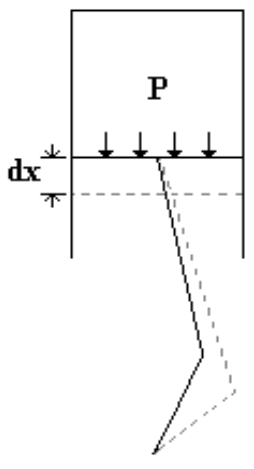

Figure 14: Work done on the piston due to pressure $P$ [3] 
The work done by the gas pressure on the piston cylinder is shown in Figure 14. Considering the crank case pressure is atmospheric, the gas pressure will be considered relative to the crank case pressure.

$$
P=P_{\text {gas }}=P_{\text {crank case }}
$$

Considering a small displacement of $d x$, the work could be assumed as $d W$. With this in mind, the following relationship for $d W$ was developed:

$$
d W=F d x=P A d x=P d v
$$

For a fixed volume change in the piston cylinder, work is given by:

$$
W=\int P d v
$$

The work per unit mass of fuel and air also known as specific work.

$$
w=\frac{W}{w}
$$

Similarly specific volume could be shown as:

$$
v=\frac{V}{m}
$$

This work mentioned above is known as indicated work and will be represented as $\left(W_{i}\right)$. The amounts of friction involved in the rings, liners and bearings are included with a friction work term, which is known as $\left(W_{f}\right)$. The useful work the crank shaft sees is the brake work, which is known as $\left(W_{b}\right)$. Now break work could be identified relative to indicated work and friction work.

$$
W_{b}=W_{i}-W_{f}
$$

After dividing the above equation from indicated work, mechanical efficiency, $\eta_{m}$, could be defined as: 


$$
\eta_{m}=\frac{W_{b}}{W_{i}}=1-\frac{W_{f}}{W_{i}}
$$

\subsubsection{Indicated Mean Effective Pressure}

The pressure within a piston cylinder changes regularly with during the expansion or the power stroke. The pressure increases due to the heat addition, and then decreases due to the increase in cylinder volume. So, IMEP is used to describe the ideal average pressure which the engine can output. During the calculation of IMEP, friction of bearings losses are considered, but the pumping losses of the crankcase are not taken into account. Now BMEP or brake mean effective pressure can be calculated from the externally measured torque and, BMEP could be shown in relationship with IMEP as

$$
B M E P=I M E P-F M E P-P M E P
$$

Here FMEP is the friction mean effective pressure (pressure times swept volume which gives the required work per cycle used for friction) and PMEP is the pumping mean effective pressure (pressure times swept volume which gives the required work per cycle used for pumping). BMEP is useful in understanding the engine performance and state of tune, although, engine rpm should be considered at which the engine is operating to determine the power potential. Different engines can be compared directly as swept volume has been removed from the power or torque figures to calculate $B M E P$, which is a useful tool in engine performance studies.

Shown below are a few ways of calculating BMEP: 


$$
\begin{gathered}
B M E P=\frac{\text { Power }}{\text { Swept Volume } \times \text { RPS }} \\
B M E P=\frac{2 \times \pi \times \text { Torque }}{\text { Swept Volume }}
\end{gathered}
$$

\subsection{ISM Overhauling Information}

The overhauling information was obtained from Cummins authorized service centers, and based upon a majority of their customer's failure and warranty information. The overhauling of a diesel engine mainly depends on the mileage it has accumulated. For a Cummins ISM engine depending on the application, the overhauling intervals are as follows;

- Short-haul applications - after 500,000 to 600,000 miles.

- Long-haul applications - after 700,000 to 800,000 miles.

Overhauling presents mainly two options, in-frame overhauling and exchanging the engine for a rebuilt unit. If the option were to have an in-frame overhauling, the following components will be replaced.

1. Cylinder liners

2. Power cylinder pistons and connecting rods

3. Piston rings

4. Rod bearings

5. Main bearings

6. Cylinder head

7. Optional replacements - Fuel injectors

- Turbo Charger

- Vibrational damper 
- Lube oil pump

- Water pump

The option of replacing the turbo charger, vibrational damper, fuel injectors, water pump and the lube oil pump are given to the customer. If the failure occurred in either the cam-shaft or the crank-shaft or if there's any visible failure or fatigue signs in these components, exchanging the engine for a rebuilt unit is recommended.

Considering the external components of the Cummins ISM engine, EGR valve and the differential pressure tubes have seen the most failure rates. EGR valve failure occurs due to the sticking of the poppet valve at a certain position inside the EGR valve. The differential pressure tubes fail due to constant accumulation of particulate matter in the internal walls. 


\section{RESULTS \& DISCUSSION}

\subsection{Introduction}

The objective of this study was to predict the useful life of critical components for the Cummins ISM diesel engine. Four vehicles (heavy hauler, concrete mixer, transit bus, and dump truck) were tested on different routes as mentioned earlier in Chapter 3. Operational cycles were observed in regular days' operation. The collection of data was primarily focused on engine speed and load. After analyzing the whole duty cycle, proportional mini duty cycles were created to capture similar speeds and loads on the engine. The representative cycles developed from in-field testing were later recreated in the laboratory environment using an ISM engine.

During the instrumentation process a pressure transducer was installed in the intake cavity of the sixth cylinder. After the instrumentation, the cylinder pressure transducer was calibrated to be in-sync with the crank angle.

\subsection{Power Cylinder Piston Life Model}

The main purpose of this study was to predict the life span of diesel engine components according to their operating conditions and the duty cycle. If the diesel engine is considered as a system composed of multiple components for example, $\mathrm{n}$ components, then the system reliability is a product of the individual reliabilities.

$$
R_{\text {System }}=\left(R_{1}\right) \times\left(R_{2}\right) \times \ldots \ldots \ldots . .\left(R_{n}\right) .
$$

En-route to understanding reliability and the life expectations of a diesel engine, it was important to understand the life of each critical component. This study was 
performed to evaluate and predict the life cycle of cylinder pressure related to components such as power piston cylinders, piston liners and cylinder heads. For this, life and pressure data of the component were gathered from the manufacturers of the components for the bench tests that have performed. The data was used to create the model for analyzing and predicting the life of these components. The methodology for predicting the life of a component proposed in this chapter could be used to evaluate the life of other critical components and, finally of the diesel engine as a whole system.

\subsubsection{Cylinder Pressure Evaluation}

The acquired pressure data were stored in binary format due to the demanding nature and storage capabilities. The methods of data storage are described below.

STEP 1 - A MatLab code was developed to translate these binary data into a text file with three columns for time, pressure and engine speed. These were the only parameters acquired during the high speed data acquisition phase. While converting binary data, the program sums up the pressure data with the gathered intake manifold pressures. Intake manifold pressure data were acquired from the EERL lab setup.

STEP 2 - Another MatLab code was used to create a histogram of the above mentioned test file with pressure data into a series of bins ranging from 500psi to 2400psi. The MatLab codes for processing required data can be found in the appendix. After binning was completed for the pressure data, all four micro cycles in one duty cycle were combined to form a single cycle. Combining all four cycles had the advantage of analyzing a single duty cycle as a whole.

Figure 15 illustrates the combined histograms for cylinder pressures in all four duty cycles. Even though the distributions look somewhat similar, heavy hauler and the 
dump truck have higher pressure ranges than the concrete mixer and transit bus. Higher speed and load conditions present during the heavy hauler and the dump truck operations have resulted in these higher pressure bins. Considering daily routines of these cycles, it is obvious that the heavy hauler and the dump truck have the most intense cycles relative to the concrete mixer and the transit bus.

Cumulative distribution functions obtained from the histograms in Figure 15 are shown in Figure 16. We found that the distribution functions would be easier to compare if they were normalized. The distribution functions look somewhat similar and almost all the graphs instigate around $90 \%$ of the total sum. This means that the $90 \%$ of the pressure in these duty cycles fall below 500 psi. This result is accurate since for every four stroke cycle the pressures at intake stroke, exhaust stroke and small amount of compression and power strokes lies below 500 psi. 

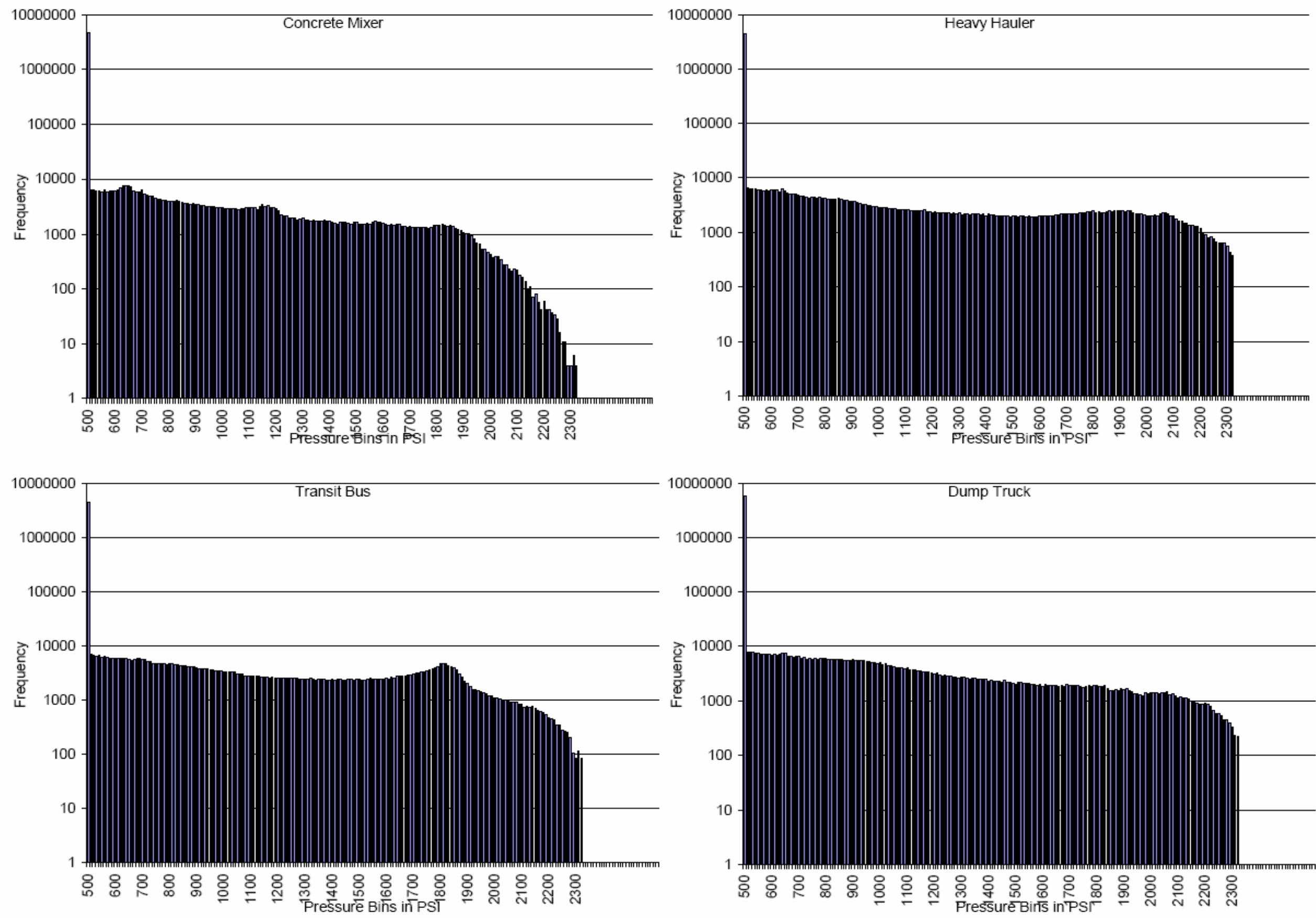

Figure 15: Pressure Distribution Binned for All Four Duty Cycles 

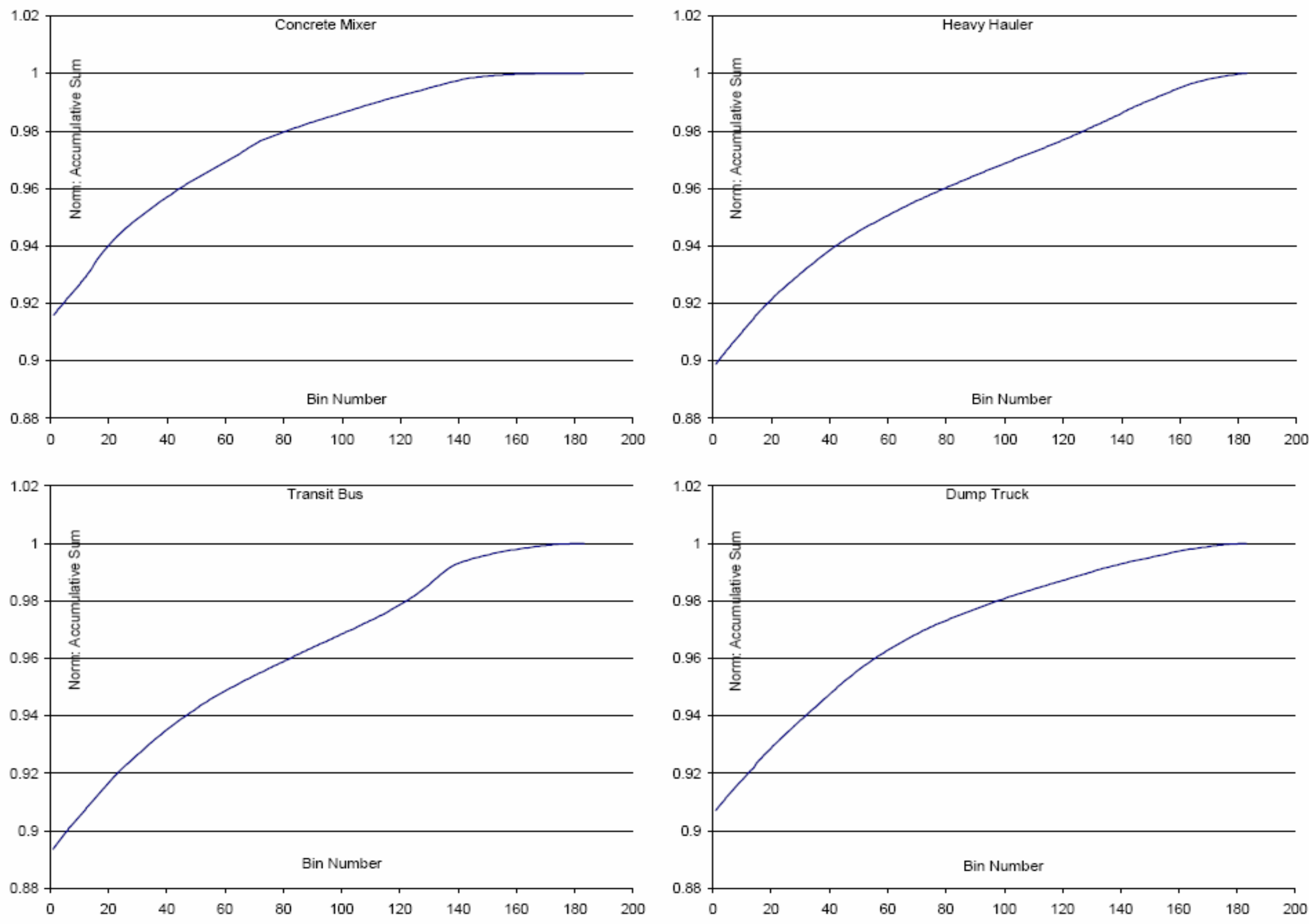

Figure 16: Normalized Accumulative Summation for Each Binned Pressure Distribution 


\subsubsection{Evaluating the Life Estimation Problem}

Consider two sets of data. The first set includes pressure data for 4 duty cycles. The other set is composed of four points each representing the average life of power cylinder pistons for one of the engine duty cycles. The major objective of this section is to estimate a continuous function that related the pressure data and the "life" points. This is a non-linear regression problem.

To be more specific, given four sets of data $\left(G^{(1)}(\bullet), y^{(1)}\right),\left(G^{(2)}(\bullet), y^{(2)}\right),\left(G^{(3)}(\bullet), y^{(3)}\right),\left(G^{(4)}(\bullet), y^{(4)}\right)$, where $G^{(i)}(\bullet), i=1, \ldots \ldots, 4$ is the distribution function of the cycle pressure data for the $\mathrm{i}^{\text {th }}$ application and $y^{(i)}, i=1, \ldots, 4$ is the average life point characterizing the $\mathrm{i}^{\text {th }}$ application. The life points $y^{(1)}, \ldots, y^{(4)}$ are pre-determined. Ideally, these life data should be obtained from the bench tests that the component manufactures have performed.

Figure 17 illustrates the forward model: the mapping of input data into the output data using an unknown function $f(\bullet)$. The problem of continuous function estimation from a finite amount of data (only 4 pairs of input-output data are available) is an illposed problem. In order to regularize the problem, that is, to make it well-posed the following approach was proposed.

1. We first reduced the dimension of the input data. The entire distribution function of the pressure data is approximated using a B-spline based approximation with 3 simple B-spline functions. Thus the distribution function, a continuous function, was now represented by 3 coefficients in the B-spline based approximation.

2. We approximated the mapping function, $f(\bullet)$, using linear combination of 2 multidimensional Radial Basis Functions (RBF), that is, 


$$
f(\mathbf{x})=w_{0}+\sum_{m=1}^{2} w_{m} \phi\left(\left\|\mathbf{x}-c_{m}\right\|\right),
$$

where $\{\phi(\bullet)\}$ is a set of known basis functions (RBFs in our case) positioned at the location parameter $C_{m}, w_{0}, \ldots \ldots, w_{2}$ are the coefficients of the representation, and $\mathbf{x}$ is a point in the space of the B-spline coefficients (input space).

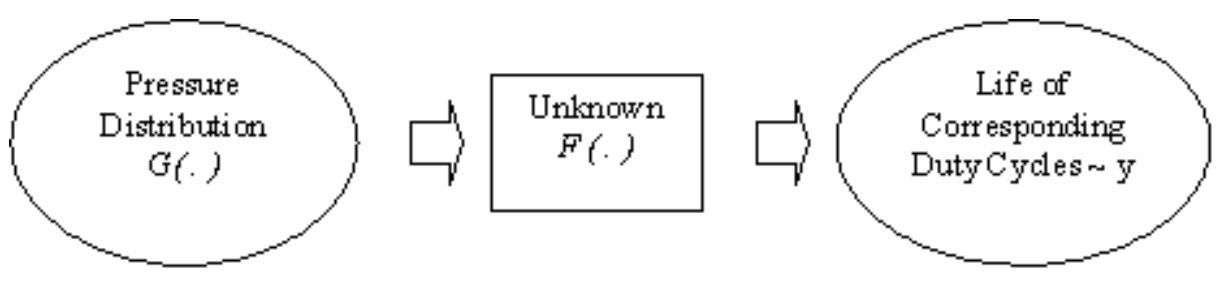

Figure 17 Illustration of the function to be determined

\subsubsection{Explain the B-Splines}

After graphing the cumulative distribution function, a necessity arises for reducing the number of dimensions in data representations. The best suited method is to find a low-order approximation to individual curves. We considered a number of methods and selected a simple B-spline based approximation. B-spline functions have a number of useful properties for approximating non-negative valued continous functions.

Consider a partition of the interval $[0,1]$ into $\mathrm{L}$ equal in length subintervals. A basic $\mathrm{B}$-spline of order $\mathrm{k}<\mathrm{L}$ is a function that posesses the following properties:

1. It has the local support consisting of first $\mathrm{k}$ subintervals on the partition of the interval $[0,1]$.

2. It has an axis of symmtry and takes value 1 at the point of symmetry. 
3. It is (k-1) times continously differentiable at any point within the region of its support.

4. The B-spline of order $\mathrm{k}$, denote $\mathrm{B}^{(\mathrm{k})}(\mathrm{t})$, can be obtained by convolving $\mathrm{k}$ $\mathrm{B}$-splines of order $1, \mathrm{~B}^{(1)}(\mathrm{t})$, that is,

$$
\begin{aligned}
B^{(k)}(t)= & B^{(1)}(t) * \ldots * B^{(1)}(t) \\
& \stackrel{k \text {-fold convolution }}{\longleftrightarrow} .
\end{aligned}
$$

The example of simple B-spline function of order 1,2, and 3 are shown in

Figure 18.
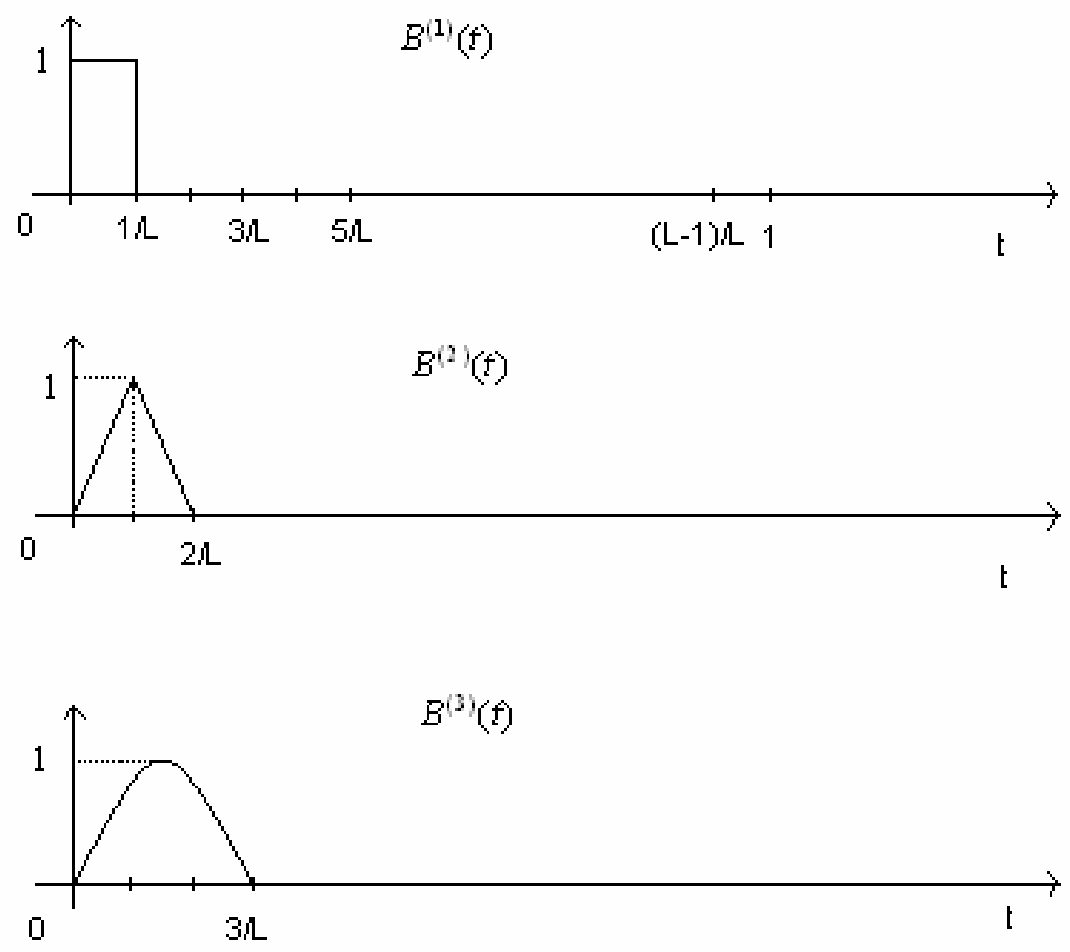

Figure 18: B-spline function of order 1,2, and 3 
A detailed introduction to B-splines and their prroperties can be found in (Schumaker,1981). B-splines form a basis for approximation of arbitrary non-negative valued functions. Given a continous distribution function $G(\cdot)$ defined on the interval $[0,180]$, our task was to find a good approximation to the function $G(\cdot)$ using four basic B-spline functions, that is,

$$
\tilde{G}(x)=\sum_{i=1}^{4} v_{i} \cdot B_{i}^{(3)}(x)
$$

where $B_{i}^{(3)}(x)$ is the $\mathrm{i}$-th $\mathrm{B}$-spline function and $\mathrm{v}_{\mathrm{i}}$ is the coefficient indicating how much $B_{i}^{(3)}(x)$ contributes to $\tilde{G}(x)$.

The representation in (a) assumes that the interval $[0,180]$ is divided into two equal in length subintervals. The division of the interval $[0,180]$ and B-spline functions used for approximation of $G(\cdot)$ are shown in Figure 19.

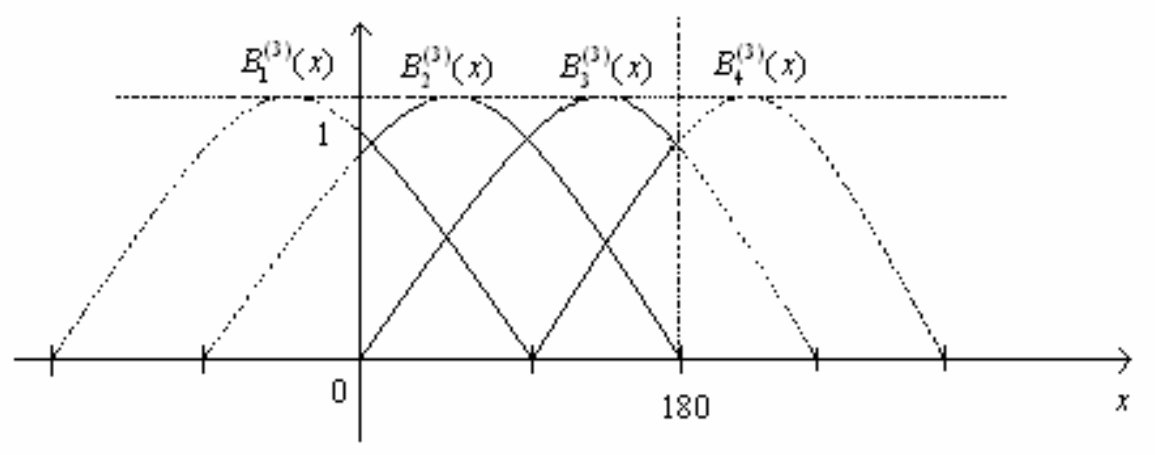

Figure 19: B-spline functions used for approximation of $G(\cdot)$

Note that $B_{i}^{(3)}(x), i=2,3,4$ is a shifted version of $B_{1}^{(3)}(x)$.

To find a "good" approximation to $G(\cdot)$, we have to specify an optimization criterion providing the "sense" in which a "good" approximation will be sought. One of 
the most commonly used criterion in the theory of function approximations is the integrated least square criterion given by

$$
v_{i}, i=1, \ldots 4 \int_{0}^{180}\left|G(x)-\sum_{k=1}^{4} v_{k} \cdot B_{k}(x)\right|^{2} d x
$$

Note that the function approximation problem is reduced to the problem of finding $v_{1}, \ldots, v_{4}$ that solve (b). We used the functions spap20 and fnval() from the spline toolbox in matlab to solve (b) for $v_{1}, \ldots, v_{4}$. The results are presented and discussed in section 5.2.3.

\subsubsection{Understanding Radial Basis Functions}

Understanding the life of certain engine components requires nonlinear mapping of points in a multi dimensional input space onto the real life (output space). RBFs are a set of functions that are often used to approximate the unknown nonlinear mapping function.

The major benefit of using RBFs is the considerable amount of flexibility in adopting shape and location parameters.

A multidimensional mapping $f(\mathbf{x})$ can be approximated using a vector based RBF as

$$
\tilde{f}(x)=W_{0}+\sum_{m=1}^{N_{C}} W_{m} \phi\left(\left\|x-C_{m}\right\|\right)
$$

where $\tilde{f}(x)$ is an approximation to $f(x)$, while $w_{0}, \ldots \ldots ., w_{N_{C}}$ are the coefficients of the approximation and $C_{m}, m=1, \ldots . ., N_{C}$ are location parameters.

In a network or a similar system, that is connected with RBFs the input is linked to the RBF via a center component $(c)$ while the RBF is linked to the output through a weight component $(w)$. Since the functions that need to be estimated are scalar, a 
relationship could be established between input $x^{(\mu)}$ and output $f^{(\mu)}$, using the previous equation

$$
f^{(\mu)}=w_{0}+\sum_{m=1}^{N_{C}} w_{m} \phi\left(\left\|x^{(\mu)}-c_{m}\right\|\right) .
$$

Expanding this when $\mu=1, \ldots \ldots, \mathrm{P}$

$$
\begin{gathered}
f^{(1)}=w_{0}+\sum_{m=1}^{N_{C}} w_{m} \phi\left(\left\|x^{(1)}-c_{m}\right\|\right) \\
\vdots \\
f^{(P)}=w_{0}+\sum_{m=1}^{N_{C}} w_{m} \phi\left(\left\|x^{(P)}-c_{m}\right\|\right)
\end{gathered}
$$

or using the matrix notation

$$
\underbrace{\left(\begin{array}{c}
f^{(1)} \\
f^{(2)} \\
\vdots \\
f^{(P)}
\end{array}\right)}_{f}=\underbrace{\left(\begin{array}{ccccc}
1 & \phi_{1}^{(1)} & \phi_{2}^{(1)} & \ldots & \phi_{N_{C}}^{(1)} \\
1 & \phi_{1}^{(2)} & \phi_{2}^{(2)} & \ldots & \phi_{N_{C}}^{(2)} \\
\vdots & \vdots & \vdots & \ddots & \vdots \\
1 & \phi_{1}^{(P)} & \phi_{2}^{(P)} & \cdots & \phi_{N_{C}}^{(P)}
\end{array}\right)}_{\Phi} \underbrace{\left(\begin{array}{c}
w_{0} \\
w_{1} \\
\vdots \\
w_{N_{C}}
\end{array}\right)}_{W},
$$

where $\phi_{j}^{(i)}=\phi\left(\left\|X^{(i)}-C_{j}\right\|\right)$. The above indicated relationship could be written as $f=\Phi W$, where $\Phi$ is known as the interpolation matrix, while $\mathrm{W}$ are the weights in the approximation $\tilde{f}$ to the unknown function $f$.

Solving for a good approximation $\tilde{f}(\mathbf{x})$ requires identifying the types of RBFs, the centers of RBFs, $\left(c_{m}\right)$, and the weights $\left(w_{m}\right)$.

Function selection is an important part in solving RBFs. During this study a Gaussian type of function was used. A Gaussian function has a local representation and is given by 


$$
\phi(\xi)=e^{\left(-\frac{\xi^{2}}{r^{2}}\right)}, \text { where }
$$

$r$ is the parameter that determines the effective domain of the RBFs. The Gaussian RBF positioned at the center $C_{m}$ is then

$$
\phi\left(\left\|x-c_{m}\right\|\right)=\exp \left(-\frac{\sum_{k=1}^{2}\left(x_{k}-c_{k}^{(m)}\right)^{2}}{r^{2}}\right) .
$$

A multidimensional Gaussian RBF has a nice property of being factored into a product of one dimensional Gaussian RBFs

$$
\phi\left(\left\|x-c_{m}\right\|\right)=\prod_{k=1}^{2} \exp \left(-\frac{\left(x_{k}-c_{k}^{(m)}\right)^{2}}{r^{2}}\right) .
$$

\subsubsection{Implementation of Radial Basis Function}

To find a "good" approximation to the unknown function $f(x)$ we induce the least square criterion:

$$
\mathfrak{I}=\|\tilde{f}-y\|^{2},
$$

where $\tilde{f}$ is the estimated life and $y$ is the actual life obtained from the manufacturer and solve the following minimization problem

$$
\min \left(\mathbf{w}_{1}, \mathbf{c}_{1}, \mathbf{c}_{2}, r\right)=\sum_{j=1}^{4}\left[y_{i}-f\left(\begin{array}{c}
x \\
-j
\end{array}\right)\right]^{2}
$$


Thus, the problem of function estimation $\tilde{f}(x)$ is reduced to estimation of a number of parameters including $w_{0}, w_{1}, w_{2}$ and $C_{1}, \mathrm{C}_{2}$, and $r$.

The global optimization in discrete space can be performed exhaustively in three steps as described below.

STEP 1 - Choosing $r$ parameterizing the Gaussian Radial Basis Function

$$
g(x)=\exp \left(-x^{2} / r^{2}\right) .
$$

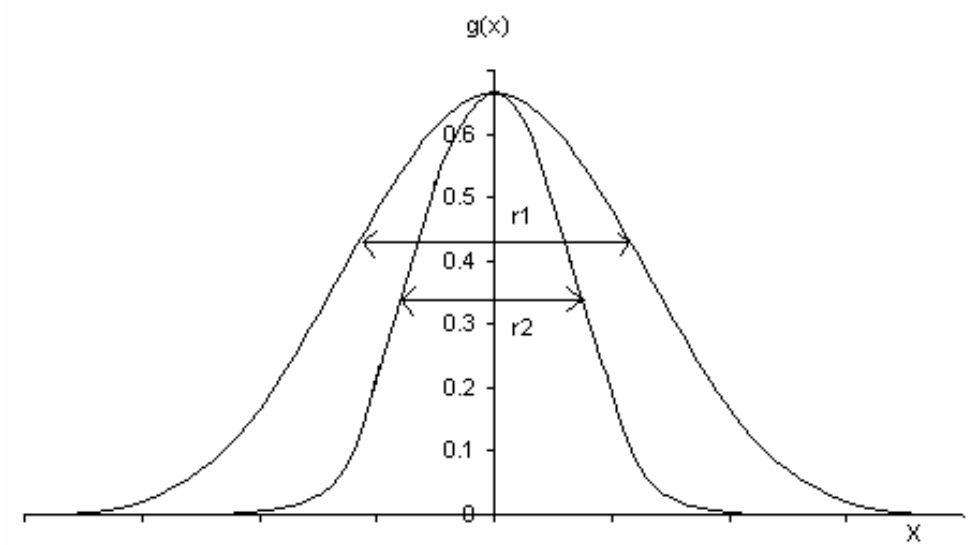

Figure 20: $r$ values were selected in relation to the coefficients of $B$-splines

The values of the r-parameters are selected by examining the coefficients of the B-splines approximating the pressure distributions. Figure 20 illustrates the influence of increasing the value of the parameter $r$ on the spread of the B-spline coefficients. The selection criteria are the spread of the coefficients and the minimum and the maximum values. After careful investigation, four values were selected for the $r$ vector. For every single $r$ value, calculations were performed to optimize the final result. The values of $r$ vector are as follows

$$
\mathbf{r} \in\{0.1,0.2,0.3,0.4\} .
$$


STEP 2 - The centers of the Gaussian RBFs are the other parameters to be determined. To find the optimal position of the RBFs we have to perform exhaustive search over a 3D continuous space. To reduce the computational complexity we assume a 3D lattice space (discretized space) and exhaustively search the optimal position of the RBFs on the lattice. Figure 21 illustrates a 1D lattice. Center components should be of the same dimension as the vector of B-spline coefficients. These center components were determined by the spread, minimum and maximum values of the each of the first, second, and third coefficients

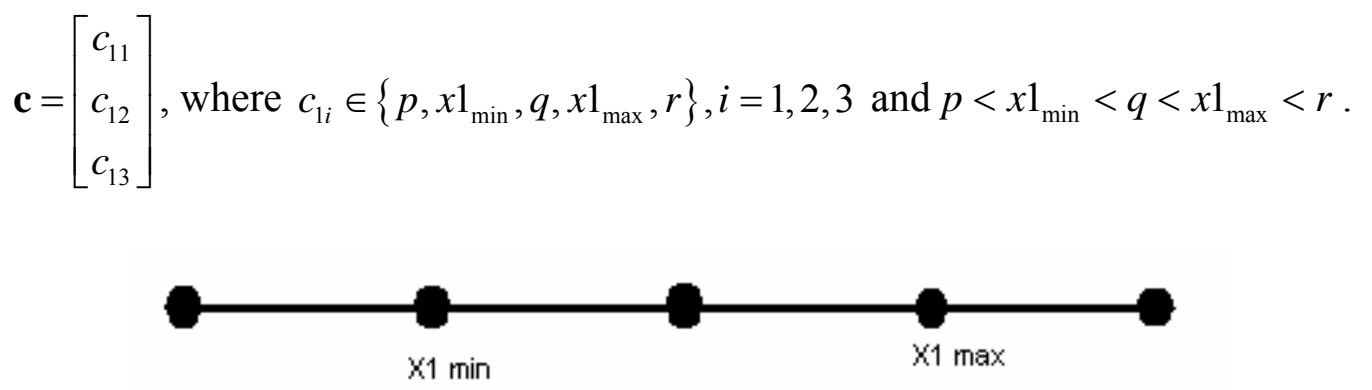

Figure 21: $C_{1 i}(i=1,2,3)$ combinations were acquired as shown

There are 625 combinations for each $C$ value, and since there are two $C$ values $\left(C_{1}\right.$ and $\left.C_{2}\right) 625 \times 625$ calculations need to be performed for each $\mathrm{r}$ value obtained in STEP 1.

STEP 3 - Finding coefficients of the RBFs, we seek the approximation to the function $f(\bullet)$ in the following form

$$
\tilde{f}=w_{0}+\sum_{m=1}^{2} w_{m} \phi\left(\left\|x-c_{m}\right\|\right) .
$$

Using the Gaussian form of the RBF,

$$
\phi(x)=\exp \left(-x^{2} / r^{2}\right) .
$$


Thus we have $\phi\left(\left\|x-c_{m}\right\|\right)=\exp \left(-\frac{\sum_{k=1}^{n}\left(x_{k}-c_{k}^{(m)}\right)^{2}}{r^{2}}\right)$.

Simplifying further with the multiplicative property of exponent,

$$
\phi\left(\left\|x-c_{m}\right\|\right)=\prod_{k=1}^{n} \exp \left(-\frac{\left(x_{k}-c_{k}^{(m)}\right)^{2}}{r^{2}}\right)
$$

and substituting (2) into (1),we obtain

$$
\tilde{f}=w_{0}+\sum_{m=1}^{2} w_{m}\left(\prod_{k=1}^{n} \exp \left(-\frac{\left(x_{k}-c_{k}^{(m)}\right)^{2}}{r^{2}}\right)\right) \text {. }
$$

Since there are four input-output pairs $\left(\mathbf{x}_{k}^{(\mu)}, y^{(\mu)}\right), \mu=1, \ldots, 4$ for the four different duty cycles, we compose four equations

$$
\tilde{f}^{(\mu)}=w_{0}+\sum_{m=1}^{2} w_{m}\left(\prod_{k=1}^{n} \exp \left(-\frac{\left(x_{k}^{(\mu)}-c_{k}^{(m)}\right)^{2}}{r^{2}}\right)\right), \mu=1, \ldots, 4 .
$$

Now, consider the objective function,

$$
J=\sum_{\mu=1}^{4}\left(y^{(\mu)}-\tilde{f}^{(\mu)}\right)^{2}
$$

that can be re-written in the vector form as follows

$$
J=(y-\tilde{f})^{T}(y-\tilde{f})
$$

Since we know $\tilde{f}=\Phi \cdot w$,

substituting $\tilde{f}$ in (4) $J=(y-\phi w)^{T}(y-\phi w)$. 
After expanding the above error function we have

$$
\begin{gathered}
J=y_{-}^{T} y-w^{T} \phi^{T} y-y_{-}^{T} \phi \underline{w}+w_{-}^{T} \phi^{T} \phi \underline{w} \\
\text { where, } y=\underbrace{\left(\begin{array}{c}
y^{(1)} \\
y^{(2)} \\
y^{(3)} \\
y^{(4)}
\end{array}\right)}_{(4 \times 1)}, \Phi=\underbrace{\left(\begin{array}{ccc}
1 & \phi_{1}^{(1)} & \phi_{2}^{(1)} \\
1 & \phi_{1}^{(2)} & \phi_{2}^{(2)} \\
1 & \phi_{1}^{(3)} & \phi_{2}^{(3)} \\
1 & \phi_{1}^{(4)} & \phi_{2}^{(4)}
\end{array}\right)}_{(4 \times 3)}, w=\underbrace{\left(\begin{array}{c}
w_{0} \\
w_{1} \\
w_{2}
\end{array}\right)}_{(3 \times 1)} .
\end{gathered}
$$

Our goal is to find a set of weights $w_{0}, w_{1}$, and $w_{2}$ that minimize the expression in (4).

After differentiating both sides of the equation (5) with respect to $w$ and setting the derivative to zero

$$
\nabla_{-} J=-(y-\phi \underset{-}{w})^{T} \phi=-y_{-}^{T} \phi+\underline{-}^{T} \phi^{T} \phi=0
$$

we obtain the following solution

$$
w^{T}=y^{T} \phi\left(\phi^{T} \phi\right)^{-1} .
$$

Thus the optimal set of weights resulting in the optimal approximation to function $f(\bullet)$ are given by

$$
\underline{w}^{*}=\left(\phi^{T} \phi\right)^{-1} \phi^{T} y
$$

Together with optimal weights $\mathbf{w}_{-}^{*}=\left[\begin{array}{c}w_{0} \\ w_{1} \\ w_{2}\end{array}\right]$ we can easily find the corresponding value of the least square function.

Now, given the estimated weights vector $w_{-}^{*}$, coefficient $r_{1}^{*}$, vectors $\mathbf{c}_{1}^{*}$ and $\mathbf{c}_{2}^{*}$ and cylinder pressure data describing a new application, the life of the new application can be estimated by taking the following steps: 
1. Find the distribution function of the cylinder pressure data, describing the new application.

2. Obtain the best approximation of the distribution function in-terms of Bsplines of the $2^{\text {nd }}$ order. Using $3^{\text {rd }}$ and $4^{\text {th }}$ order B-splines will give us a better representation on the distribution. Denote B-spline coefficients by Z

3. Map the weights of B-splines into the "life" space. To perform this step, use the estimated function $\tilde{f}$ with $w_{-}^{*}, r^{*}, \mathbf{c}_{1}^{*}$, and $\mathbf{c}_{2}^{*}$ substituted in place of initially unknown parameters, that is

$$
\tilde{f}^{*}(\mathbf{z})=w_{0}^{*}+\sum_{m=1}^{2} w_{i}^{*} \cdot e^{-\sum_{k=1}^{3}\left(\frac{\left(z_{k}-\left(c_{k}^{i}\right)^{*}\right)^{2}}{\left(r^{*}\right)^{2}}\right)}
$$

where $z$ are the coefficients of B-spline approximations obtained using data for the new application.

\subsubsection{Numerical Results}

For piston cylinders bench test data were modeled in terms of cylinder pressure and piston cylinder life. The distribution functions obtained from the pressure data describing cycle 1- cycle 4 are shown in Figure 22. Also, in the same graph the B-spline based approximations are graphed for the corresponding pressure distribution. The Bspline coefficients characterizing the distributions of cylinder pressure and the life data are summarized in Table 9. The lives for the pressure distributions were synthetically generated considering the roughness and the loads for the individual duty cycle. 
Accordingly, cycle 1 has the highest loads and speeds while cycle 4 has the least. This is imminent, since the piston in cycle 1 would have a life of 600,000 miles while the piston in cycle 4 would have an extended life of 800,000 miles.

Table 9: The life data and the B-spline Coefficients for the modeled cycles

\begin{tabular}{|c|c|c|c|c|}
\hline & Cycle 1 & Cycle 2 & Cycle 3 & Cycle 4 \\
\hline \multirow{4}{*}{ نُ } & 0.8942 & 0.9114 & 0.9039 & 0.9152 \\
\hline & 0.9595 & 0.9838 & 0.9773 & 0.9914 \\
\hline & 0.9726 & 0.9872 & 0.9874 & 0.9907 \\
\hline & 1.005 & 1.0024 & 1.0025 & 1.001 \\
\hline Life (miles) & 600,000 & 735,000 & 740,000 & 800,000 \\
\hline
\end{tabular}



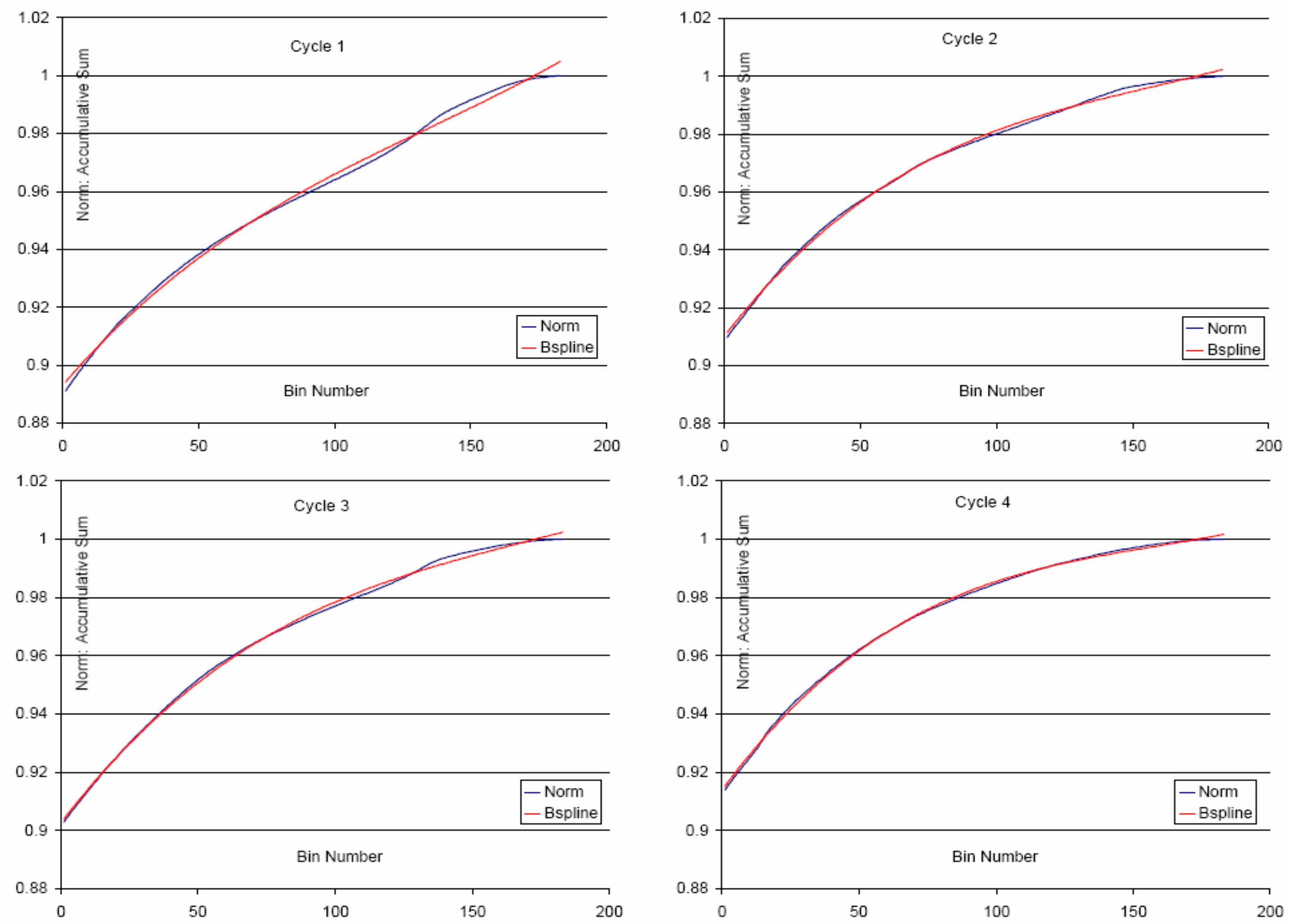

Figure 22: Shown are Cumulative Distribution Functions for Each Binned Pressure Distribution (Assumed Cycles) Graphed jointly with the Corresponding B-spline Approximations. 
As mentioned above in Step 1, four $r$ parameterizing values were selected for the RBFs that could be used in the calculations of the mapping function $f(\cdot)$

$$
\mathbf{r} \in\{0.1,0.2,0.3,0.4\}
$$

After solving (c) w.r. to $r$, we selected $r=0.4$. As described in Step 2, it was critical to find the optimal values for both $C 1$ and $C 2$. There are 625 combinations for each $C$ value, and since there are two $C$ values $\left(C_{1}\right.$ and $\left.C_{2}\right) 625 \times 625$ calculations need to be performed. Table 10 shows the 25 values that could be selected for both $C 1$ and $C 2$.

Table 10: The possibilities for $C 1$ and $C 2$

\begin{tabular}{|c|c|c|c|}
\hline CI & CII & CIII & CIV \\
\hline 0.9059 & 0.9803 & 0.9957 & 0.9867 \\
0.9159 & 0.9903 & 1.0057 & 0.9956 \\
0.9259 & 1.0003 & 1.0157 & 0.9768 \\
0.9359 & 1.0103 & 1.0257 & 1.02 \\
0.9459 & 1.0203 & 1.0357 & 1.0356 \\
\hline
\end{tabular}



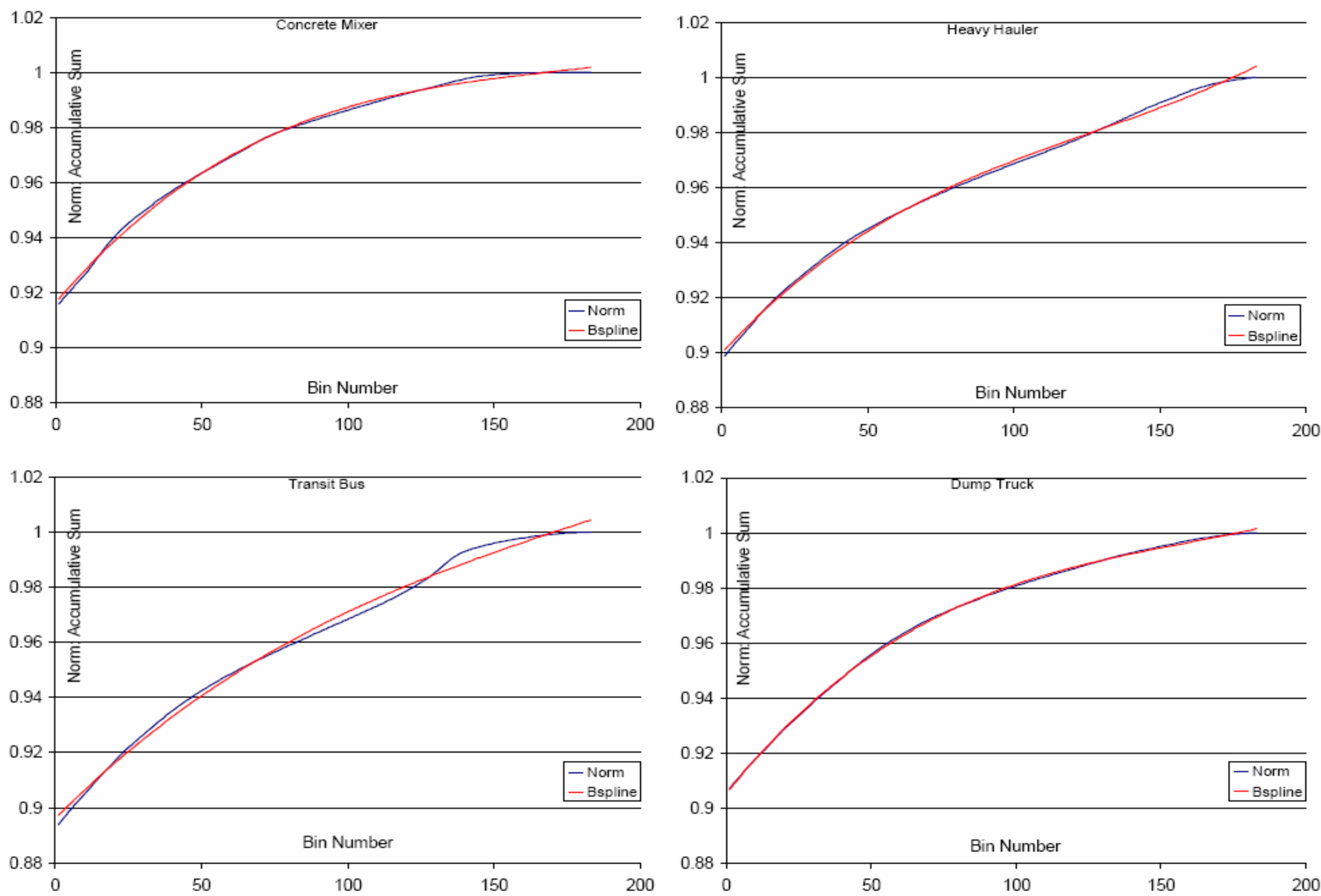

Figure 23: Shown are Cumulative Distribution Functions for Each Binned Pressure Distribution (Acquired Duty Cycles) Graphed jointly with the Corresponding B-spline Approximations. 
The input-output data in Table 9 were used to evaluate the non-linear multidimensional regression function mapping the input data into the output data. The application of the least square procedure for estimation of the weights, position vectors, and coefficient $r$ resulted in

$$
\begin{gathered}
w_{0}^{*}=-455140, w_{1}^{*}=569430, w_{0}^{*}=4924300, \\
\mathbf{c}_{1}^{*}=[0.9059,0.9803,0.9957,0.9768]^{T}, \mathbf{c}_{2}^{*}=[0.9459,1.0203,1.0357,1.0356]^{T}, \\
\text { and } r^{*}=0.4 .
\end{gathered}
$$

These estimates were then substituted into (7) to obtain the estimate of the mapping function $f^{*}(\bullet)$. To predict the component life for the individual duty cycles, we first determined B-spline coefficients providing the best approximations to the distribution functions shown in Figure 21. The coefficients of B-spline representations

\begin{tabular}{|c|c|c|c|c|}
\hline & $\begin{array}{c}\text { Concrete } \\
\text { Mixer }\end{array}$ & $\begin{array}{l}\text { Heavy } \\
\text { Hauler }\end{array}$ & $\begin{array}{l}\text { Dump } \\
\text { Truck } \\
\end{array}$ & $\begin{array}{c}\text { Transit } \\
\text { Bus }\end{array}$ \\
\hline \multirow{4}{*}{ نُ } & 0.9177 & 0.9011 & 0.9068 & 0.8972 \\
\hline & 0.9918 & 0.9702 & 0.9853 & 0.9612 \\
\hline & 0.9943 & 0.972 & 0.9876 & 0.9834 \\
\hline & 1.0018 & 1.0041 & 1.0015 & 1.0045 \\
\hline
\end{tabular}
are summarized in table 11.

Table 11: B-spline coefficients of the pressure distributions for the duty cycles (Testing data)

Using the RBF model developed above the component life for the power cylinders was estimated using equation (7). Table 12 presents the predicted life values for the four duty cycles. 
Table 12: Final Life Estimations for the Individual Duty Cycles

\begin{tabular}{|l|cccc|}
\hline & $\begin{array}{c}\text { Concrete } \\
\text { Mixer }\end{array}$ & $\begin{array}{c}\text { Heavy } \\
\text { Hauler }\end{array}$ & $\begin{array}{c}\text { Dump } \\
\text { Truck }\end{array}$ & $\begin{array}{c}\text { Transit } \\
\text { Bus }\end{array}$ \\
\hline Piston Cylinder Life (miles) & 803700 & 651490 & 751820 & 651750 \\
\hline
\end{tabular}

As indicated in Table 12, the concrete mixer has the maximum estimated life, while the transit bus and the heavy hauler have the minimum estimated lives. These data are in good correspondence with our expectations. Even though the tested transit bus had fewer loads than the heavy hauler and the concrete mixer, during its operation in the express way, the transit bus was utilizing its engine fully. Hence, due to the considerable loads, higher speeds and the continuous operation the transit bus has relatively lower piston cylinder life. Similarly, the heavy hauler with $80,000 \mathrm{lbs}$ of gross weight has a lower piston life of 651,490 miles. 


\section{CONCLUSIONS \& RECOMENDATIONS}

\subsection{Conclusions}

The performance testing and cycle development work performed for this study provides additional information needed for the development of testing protocols for diesel-powered on-highway equipment. The data produced through this research could be used to promulgate a better understanding of the various duty-cycles and help develop requirements for these heavy-duty vehicles.

This study also demonstrates that, even though all vehicles utilize the same engine with similar ratings, the cylinder loads depend largely on the application. From the applications discussed, the heavy hauler application has the most detrimental effect on piston life, while concrete mixer has the least. This is a result of the normal operating speed and load of the respective engines. The heavy hauler operates twice as fast as the concrete mixer. These added stresses along with the higher operating load cause the most rapid decline of piston life. The heavy hauler is rated for operation with a vehicle weight of $80,000 \mathrm{lb}$, where the concrete mixer was only rated for 45,000 lb. Though the engine speed plays a role on component wear, it is shown that in cylinder pressure has the primary role in determining the component life. It was shown that without affecting the other parameters, that the in cylinder pressure caused a dramatic reduction of material life.

The data shows a trend that can be used to predict the loads and subsequent requirements of engine performance for each respective duty cycle. This will greatly aid further design and reduce the over design of these engines and components. Production 
cost should be reduced as less material is required. Vehicle performance will likely be enhanced from a lighter more efficient engine.

It should be noted that this is an initial study and serves to better inform and direct the efforts of researchers and designers. Further efforts should include a wider range of duty cycles. It would be advantageous to have vehicles of the same work rating operate through a range of duty cycles to better identify the complete impact of each type of duty cycle. As the duty cycle has a critical role in the component and engine life, the combined effects of temperature with the duty cycle and in cylinder pressures is not yet known. This is of concern since these engines must perform in all environments. It is strongly recommended that an expanded study of temperature, in cylinder pressure, and more duty cycles be performed.

\subsection{Future Work}

The work on in-cylinder pressure for various duty cycles can be studied on offroad vehicles as well. This work also could be performed on other engine families to establish trends based on the performance of the respective family. From these trends the engine family will be optimized for performance. Ultimately this research and development will be expanded to encompass multiple parameters so that the design models will approach the actual engine. A database could be created with duty cycle information, in-cylinder pressure data, and component life data. This will allow the manufacturer to rapidly model or tailor an engine for various customer requirements. 


\section{REFERENCES}

1. "Life Data Analysis (Weibull Analysis)", Weibull.com, 02 Oct 2005, 15 Nov 2005, http://www.weibull.com/basics/lifedata.htm.

2. "Reciprocating Internal Combustion Engines - Exhaust Emissions Measurement", International Organization for Standardization, ISO/DIS 8178, Geneva, Switzerland, 1993.

3. "Slider Crank Model", Colorado State University Engineering College, 15 Nov 2005,25 Nov 2005, http://www.engr.colostate.edu/\%7Eallan/thermo/page2/page2.html

4. "Accelerated Life Testing Data Analysis ", Weibull.com, 04 Apr 2005, 15 Nov 2005, http://www.weibull.com/basics/accelerated.htm.

5. Aldridge, D. S., "An Introduction to Generating Vibration Durability Test Specifications for Automotive Engine Mounted Components", AC Rochester Division of GMC.

6. Aldridge, D. S., “A General Process for Defining Durability Requirements", Delphi-Energy And Chassis Division, 2004.

7. Aldridge, D. S., "Component and System Life Distribution Prediction Using Weibull and Monte Carlo Analysis with Reliability Demonstration Implications for an Electronic Diesel Fuel Injector", SAE Paper 2003-01-1363, Mar 2003.

8. Aldridge, D. S., "Prediction of Potential Warrenty Exposure and Life Distribution Based Upon Early Warranty Data”, Dephi corporation, 2005.

9. Ardanese, R., Mechanical and Aerospace Engineering, West Virginia University, Morgantown, Wv 26506. 2005

10. Assanis, D. N., Filipi, Z. S., Fiveland, S. B., and Syrimis, M. "A Methodology for Cycle-By-Cycle Transient Heat Release Analysis in a Turbocharged Direct Injection Diesel Engine", SAE Paper 2000-01-1185, 2000.

11. Brown, T. S. and Neil,1 W. S., "Determination of Engine Cylinder Pressure from Crankshaft Speed Fluctuations", SAE Paper 920463, Feb 1992.

12. Barnett, R.A., "Characterization of Infield Vehicle Activity Data and Exhaust Emissions from Diesel Powered Off-Road Vehicles," M.S. Thesis, Department of Mechanical and Aerospace Engineering, West Virginia University, Morgantown, WV, 2001. 
13. Brunt, M. F. J. and Platts, K. C. "Calculation of Heat Release in Direct Injection Diesel Engines”, SAE Paper 1999-01-0187, Mar 1999.

14. Carder, D. K., "Performance Evaluation of Exhaust Aftertreatment Devices Used for Emissions Control On Diesel Engines Employed in Underground Coal Mines," M.S. Thesis, Department of Mechanical and Aerospace Engineering, West Virginia University, Morgantown, WV, 1999.

15. Code of Federal Regulations, Title 40, Part 86 Subpart N, .Emission Regulations for New Otto-Cycle and Diesel Heavy-Duty Engines; Gaseous and Particulate Exhaust Test Procedures., Washington D.C, 1998.

16. Code of Federal Regulations, Title 40 Part 86, U.S. Government Printing Office, Washington DC, 2000.

17. Code of Federal Regulations, Title 40 Part 89, U.S. Government Printing office, Washington DC, 2000.

18. Cummins.com, 15 December 2005, http://www.everytime.cummins.com/every/applications/ism.jsp

19. Fleetguard.com, 15 December 2005, http://fleetguard.com/fleet/en/products/en_prod_fg_fuel.jsp?SMSESSION=NO

20. Gautam, M., Clark, N. N., Thompson, G. J., Carder, D. K., and Lyons, D. W. (2000), .Evaluation of Mobile Monitoring Technologies for Heavy-Duty DieselPowered Vehicle Emissions,. Phase I Report, Submitted to the Settling HeavyDuty Diesel Engine Manufacturers by West Virginia University, Morgantown, WV, March 2000.

21. Gautam, M., Clark, N. N., Thompson, G. J., Carder, D. K., and Lyons, D. W. (2000),.Development of In-Use Testing Procedures for Heavy-Duty DieselPowered Vehicle Emissions,. Phase II Report, Submitted to the Settling HeavyDuty Diesel Engine Manufacturers by West Virginia University, Morgantown, WV, March 2000.

22. Gautam, M., Clark, N. N., Thompson, G. J., and Lyons, D. W., "Assessment of Mobile Monitoring Technologies for Heavy-Duty Vehicle Emissions", Whitepaper Submitted to the Settling Heavy-Duty Diesel Engine Manufacturers, Department of Mechanical and Aerospace Engineering, West Virginia University, Morgantown, WV, 1999, Hwww.epa.gov/Compliance/civil/programs/caa/diesel/test.htmlH

23. Gautam, M., Clark, N. N., Thompson, G. J., Carder, D. K., and Lyons, D. W., "Evaluation of Mobile Monitoring Technologies for Heavy-Duty Diesel-Powered Vehicle Emissions", Phase I Final Report Submitted to the Settling Heavy-Duty 
Diesel Engine Manufacturers, Department of Mechanical and Aerospace Engineering, West Virginia University, Morgantown, WV, 2000,Hwww.epa.gov/Compliance/civil/programs/caa/diesel/test.htmlH

24. Gautam, M., Clark, N. N., Thompson, G. J., Carder, D. K., and Lyons, D. W., "Development of Inuse Testing Procedures for Heavy-Duty Diesel-Powered Vehicle Emissions", Phase II Final Report Submitted to the Settling Heavy-Duty Diesel Engine Manufacturers, Department of Mechanical and Aerospace Engineering, West Virginia University, Morgantown, WV, 2000, Hwww.epa.gov/Compliance/civil/programs/caa/diesel/test.htmlH

25. Gibble, J. C., .Comparison of Heavy-Duty Diesel Engine Emissions Between an On- Road Route and Engine Dynamometer Simulated On-Road Cycle., M.S Thesis, Department of Mechanical and Aerospace Engineering, West Virginia University, Morgantown, WV, 2003.

26. Holset.com, 15 December 2005, http://www.holset.co.uk/files/2_2applications.php

27. Kistler.com, 10 January 2006, http://www.kistler.com/mediaaccess/ml/000-020m09.95.pdf

28. Konstantas G. and Stamatelos A., "Quality Assurance of Exhaust Emissions Test Data”, Instn Mech. Engrs Vol. 218 Part D, 2004.

29. Krishnamurthi, M. and Gautam, M., "Development of a Heavy-Duty Engine Test Cycle Representative of On-Highway Not-to-Exceed Operation", West Virginia University. 2005

30. Leonhardt, S., Muller, N. and Isermann, R. "Methods for Engine Supervision and Control Based on Cylinder Pressure Information", IEEE/ASME Transactions on Mechatronics Vol. 4 No. 3, Sep 1999.

31. Mathworld.com, 23 October 2005, http://mathworld.wolfram.com/MonteCarloIntegration.html

32. NI.com, 12 August 2005, http://sine.ni.com/nips/cds/view/p/lang/en/nid/13677

33. Payri, F., Broatch, A., Tormos, B. and Marant, V., "New Methodology for InCylinder Pressure Analysis in Direct Injection Diesel Engines-Application to Combustion Noise", CMT-Motores Termicos, Jan 2005.

34. Rente T., Golovitchev V.I. and Denbratt, "Effect of Injection Parameters on Autoignition and Soot Formation in Diesel Sprays", SAE Paper 2001-01-3687, 2001. 
35. Riddle, W.C., .Design and Evaluation of the Emissions Measurement Components for a Heavy-Duty Diesel Powered Vehicle Mobile Emissions Measurement System (MEMS)., M.S Thesis, Department of Mechanical and Aerospace Engineering, West Virginia University, Morgantown, WV, 2001.

36. Rocco, V., "D.I. Diesel Engine In-Cylinder Pressure Data Analysis Under T.D.C. Setting Error", SAE Paper 930595, Mar 1993.

37. Rosemount Analytical Model 955 NO/NOx Analyzer Product Data Sheet, 1992, Rosemount Analytical Inc., La Habra, California.

38. Rosemount Analytical Model 402 Hydrocarbon Analyzer Product Data Sheet, 1992, Rosemount Analytical Inc., La Habra, California.

39. Rosemount Analytical Model 868/880 NDIR Analyzer Product Data Sheet, 1992, Rosemount Analytical Inc., La Habra, California.

40. Shareef, I. and Karmali, A. D., "Fatigue Life of Diesel Cams in Accelerated Test Environment", SAE Paper 2003-01-0052, Mar 2003.

41. Somat.com, 10 December 2005, http://www.ncode.com/page.asp?section=00010001000100010001

42. Ullman, T. L., Webb, C. C., Jackson, Cleophas C. Jr. and Doorlag, M. H., "Nonroad Engine Activity Analysis and Transient Cycle Generation", SAE Paper 1999-01-2800, 1999.

43. Williams, J. and Witter, M. C., "Individual Cylinder IMEP Estimation Using Crankshaft Angular Velocity Measurements", SAE Paper 2001-01-0990, Mar 2001.

44. Nagendran, Vinay, . Characterization of Exhaust Emissions from catalyzed TrapEquiped Non-Road Heavy-Duty Diesel Engines (MEMS)., M.S Thesis, Department of Mechanical and Aerospace Engineering, West Virginia University, Morgantown, WV, 2003. 


\section{APPENDIX A - Codes Used for Test cell Data Acquisitions and Calculations}

CODE 1- This code was used to transfer cylinder pressure data from binary format to csv format (Ardanese, 2005)

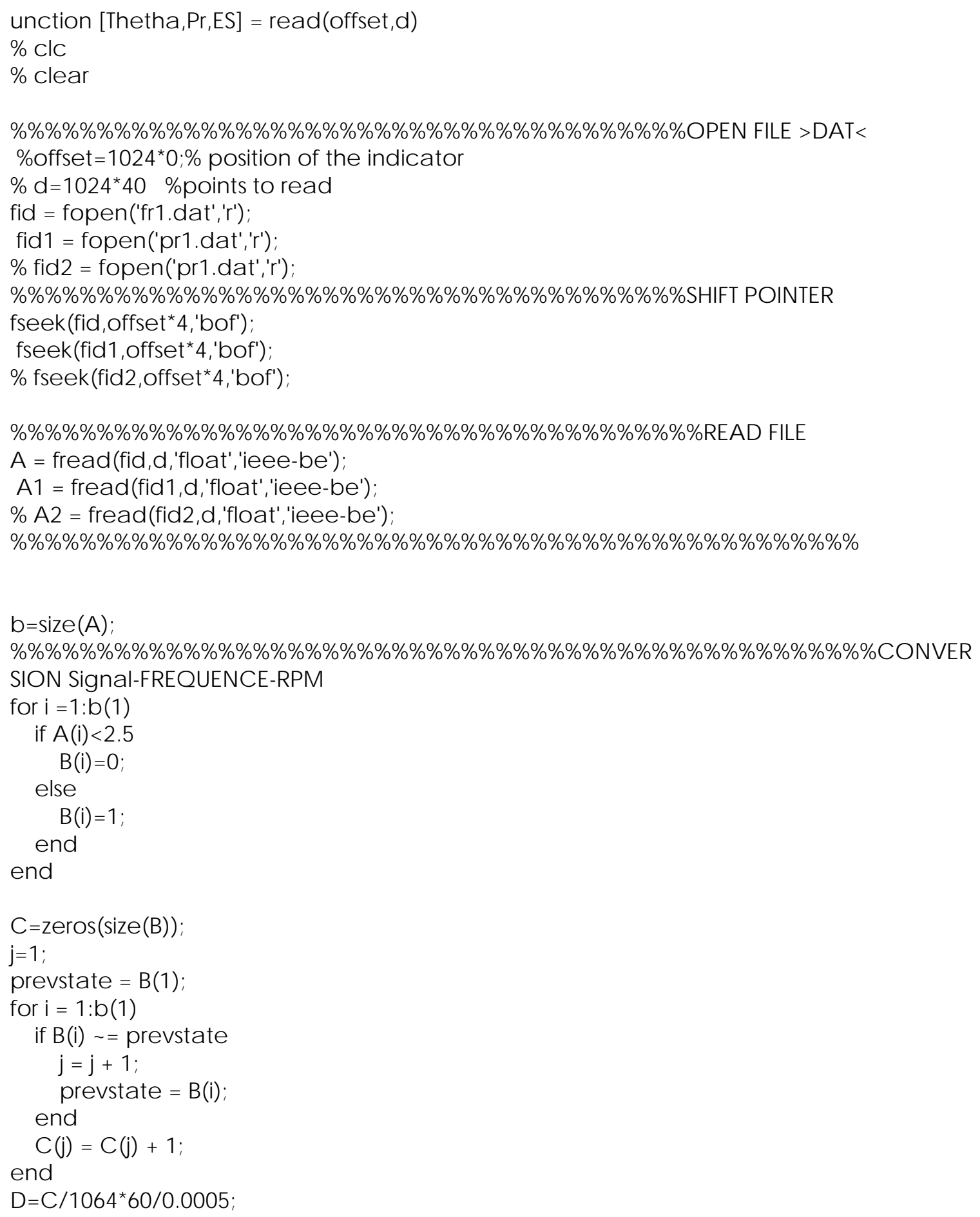




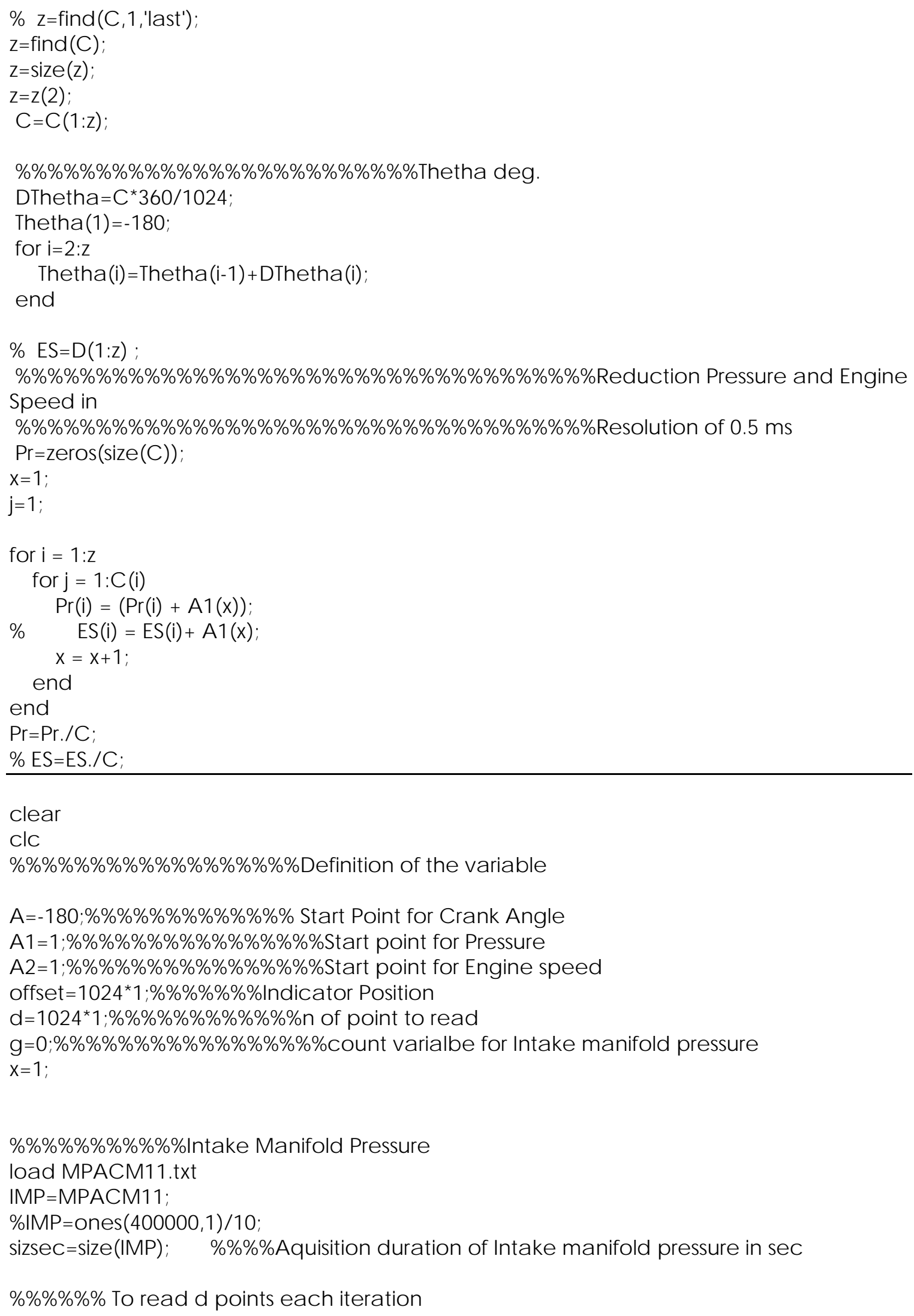




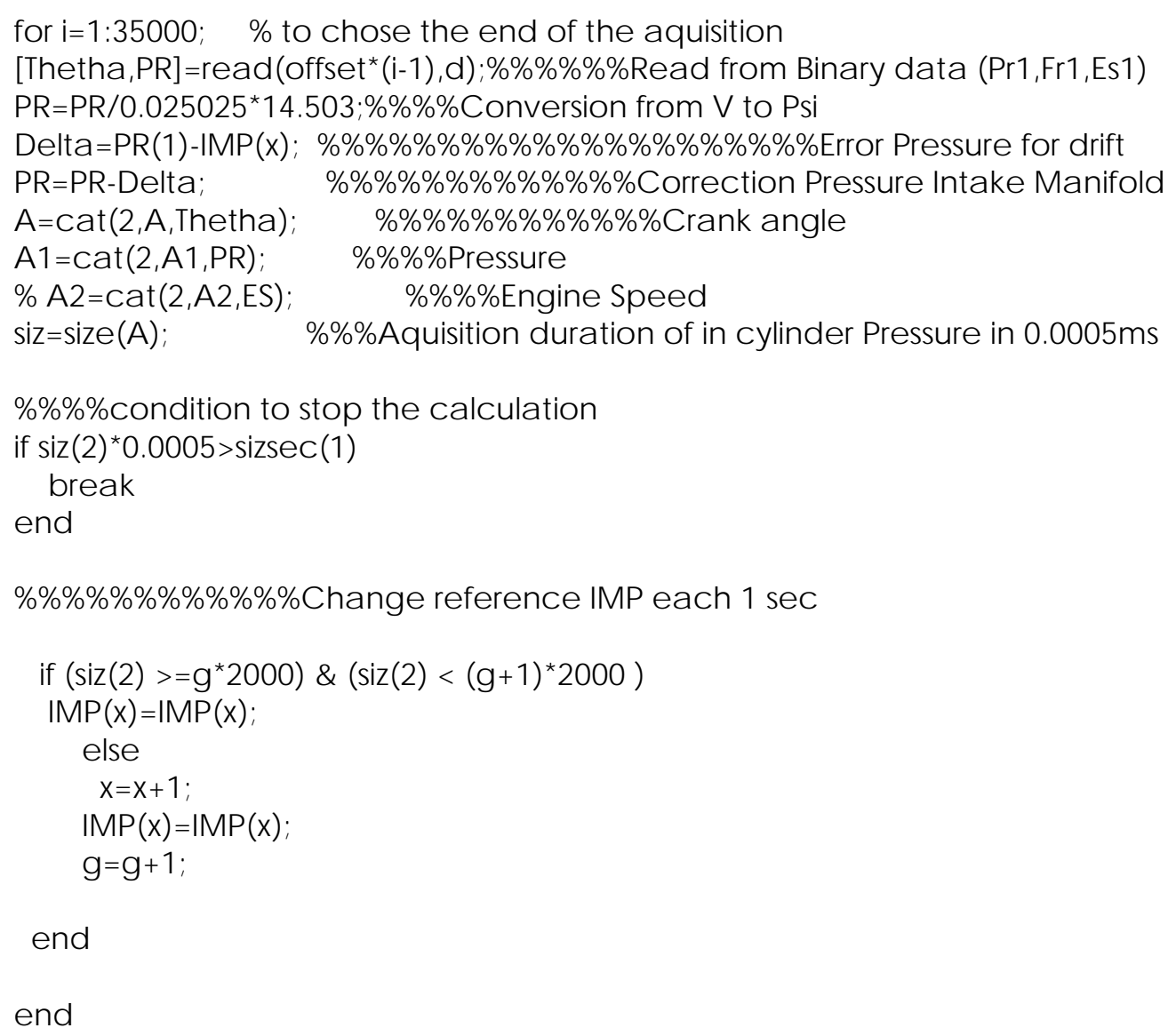


CODE 2- This was used to bin the in-cylinder pressure distribution

function a $x=a x i n t\left(x, X, A r e a \_X\right)$

if $x<X(1), x=X(1)$; end

if $x>X($ end $), X=X($ end $)$; end

ax=interp1 $(\mathrm{X}$, Area_X,X);

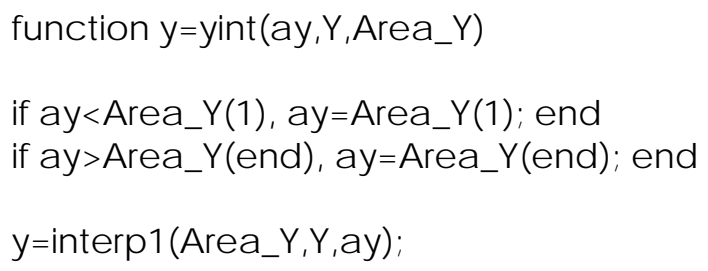


CODE 3- This code used in summing the area underneath the binned pressure distribution and creating accumulative sum.

clear;

\% Loading data to matlab via excel columns

[data ,txt] =xlsread('Pressure Bins.xls','Pressure Bins');

$\mathrm{X}=\mathrm{data}(:, 1) ; \% \mathrm{x}$ a xis of the $\mathrm{X}$ distribution

$y=$ data $(:, 1) ; \% x$ axis of the $Y$ distribution

a rea_X $=$ data $(:, 12) ; \%$ y axis of the $X$ distribution

a rea_y=data $(:, 17) ; \%$ y axis of the $Y$ distribution

figure(1)

plot $(x$, area_x $)$;

figure(2)

plot(y, area_y);

figure(3)

$\operatorname{plot}\left(x, y i n t\left(a x i n t\left(x, x, a\right.\right.\right.$ rea_$\left.\_\right), y, a$ rea_y $\left.)\right)$;

y_val=yint(axint( $x, x$, a rea_x),y,a rea_y);

a rray $=[x ;(y i n t(a x i n t(x, x, a$ rea_x $), y, a$ rea_y $))]$;

fido = fopen('cores.txt','a ');

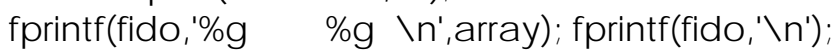

fclose(fido); 
CODE 4- This code was used to generate B-spline coefficients for the normalized accumulative summation graphs.

lear all, clc, close all;

dbstop error

$\%$ Read in the data

data $1=$ xlsread ('Pressure Bins.xls','lifedata ');

data $=$ data $1(:, 15)$

$\mathrm{x}=[1 \text { :length(data) }]^{\prime}$;

$\%$ Cubic Bspline

order $=4$;

$\%$ Generate knots of Bspline

knots = linspace (1,length(data),2);

knotsaug =augknt(knots, order);

$\%$ Generate Bspline form

$\mathrm{sp}=$ spap2(knotsaug,order,x,data);

$\%$ sp = spap2(3,order,x,data);

$\%$ Calculate the errors b/w the true data and the appoximated data

errors $=$ data-fnval(sp, $x)$;

$\%$ plot the true data and the appoximated data

bspline $=$ fnval $(s p, x)$;

fnplt(sp, '*');

figure(1)

hold on, plot(x,data,'ro'), hold off;

figure(2)

plot(errors);

\% bspline([ $\left.\left.\begin{array}{lllll}1 & 2 & 3 & 4 & 5\end{array}\right]\right)$

$\%$ splinetool(x,data)

$\%$ fnbrk(sp) 
CODE 5- This Code was used to generate the mapping function with the help of Radial basis Functions.

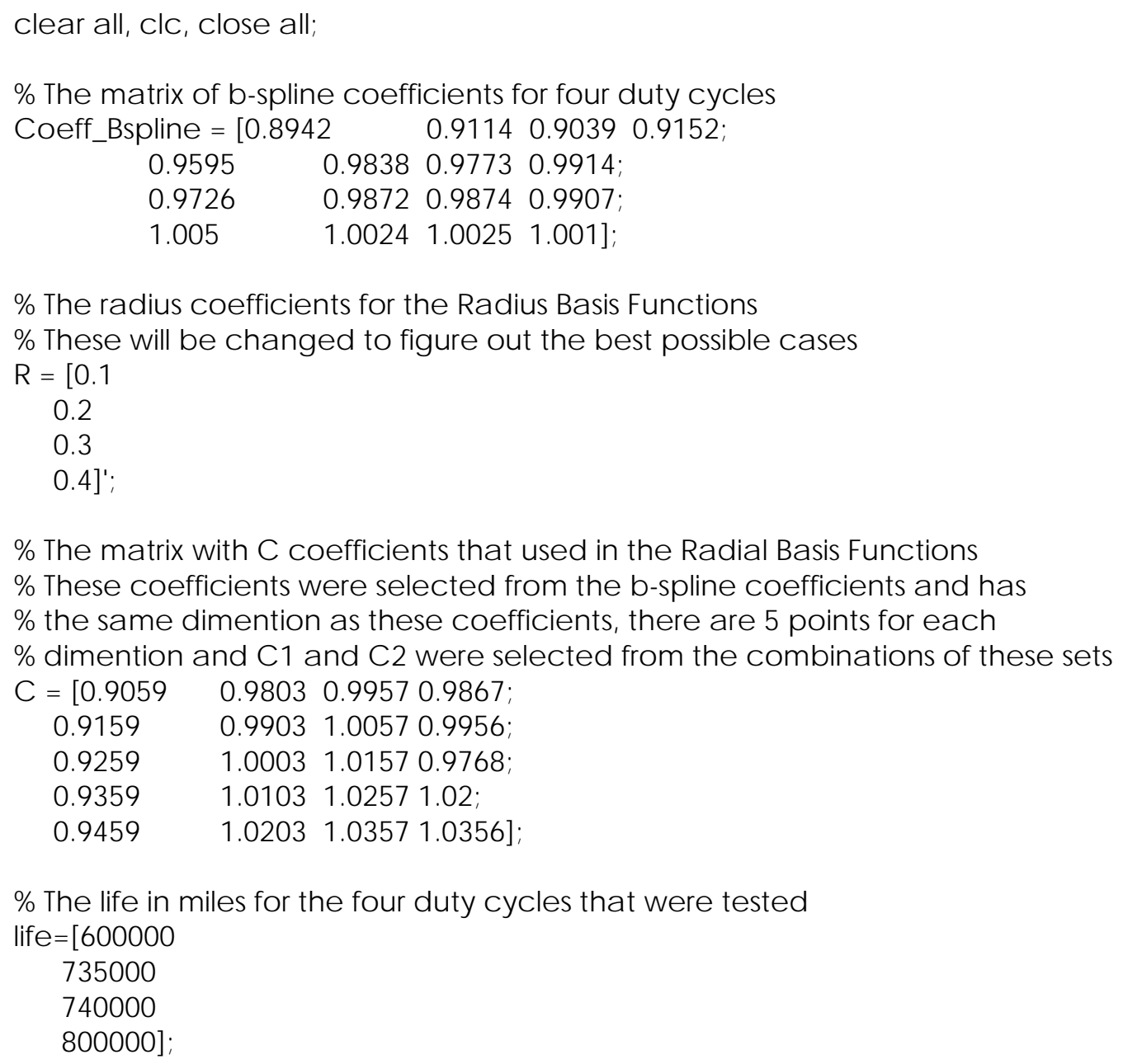

$\%$ The life in miles for the four duty cycles that were tested life $=[600000$

735000

740000

800000];

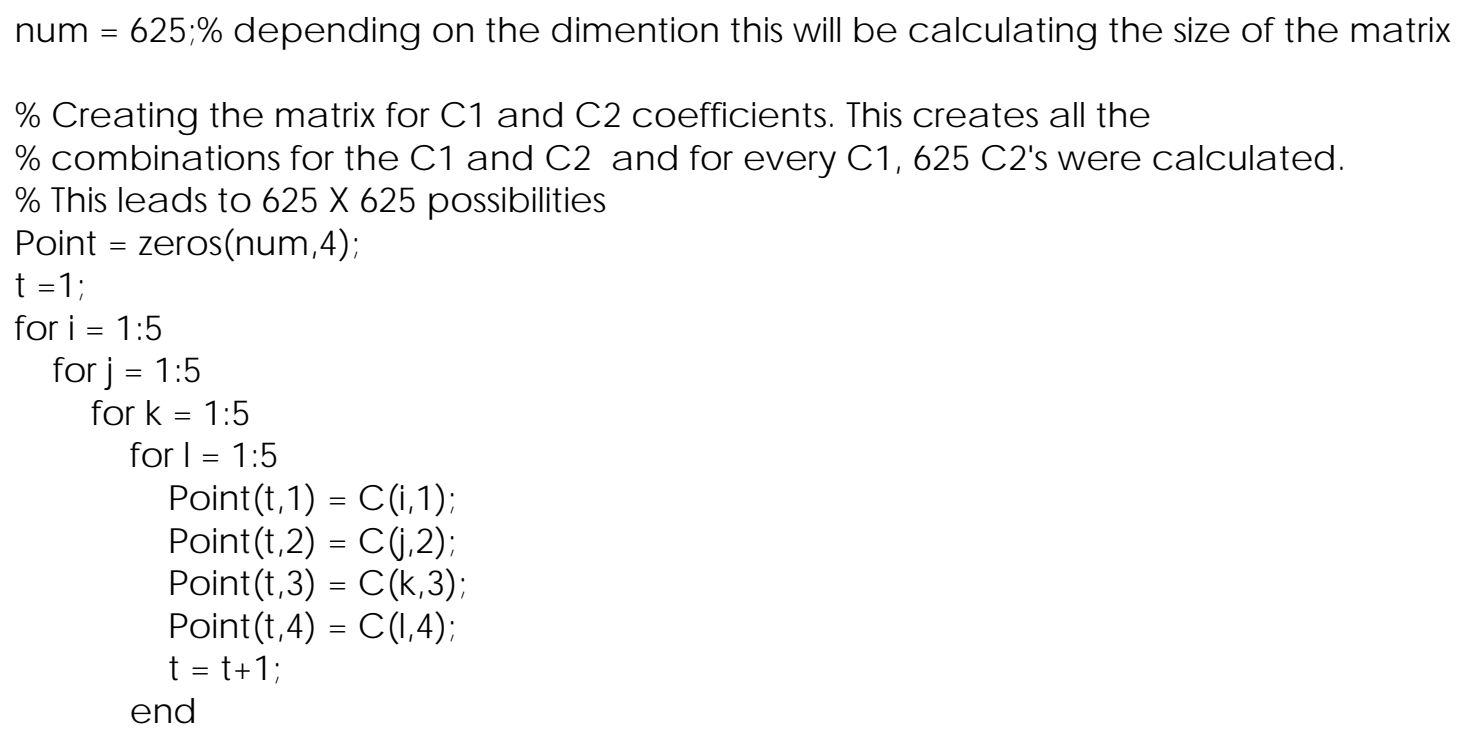




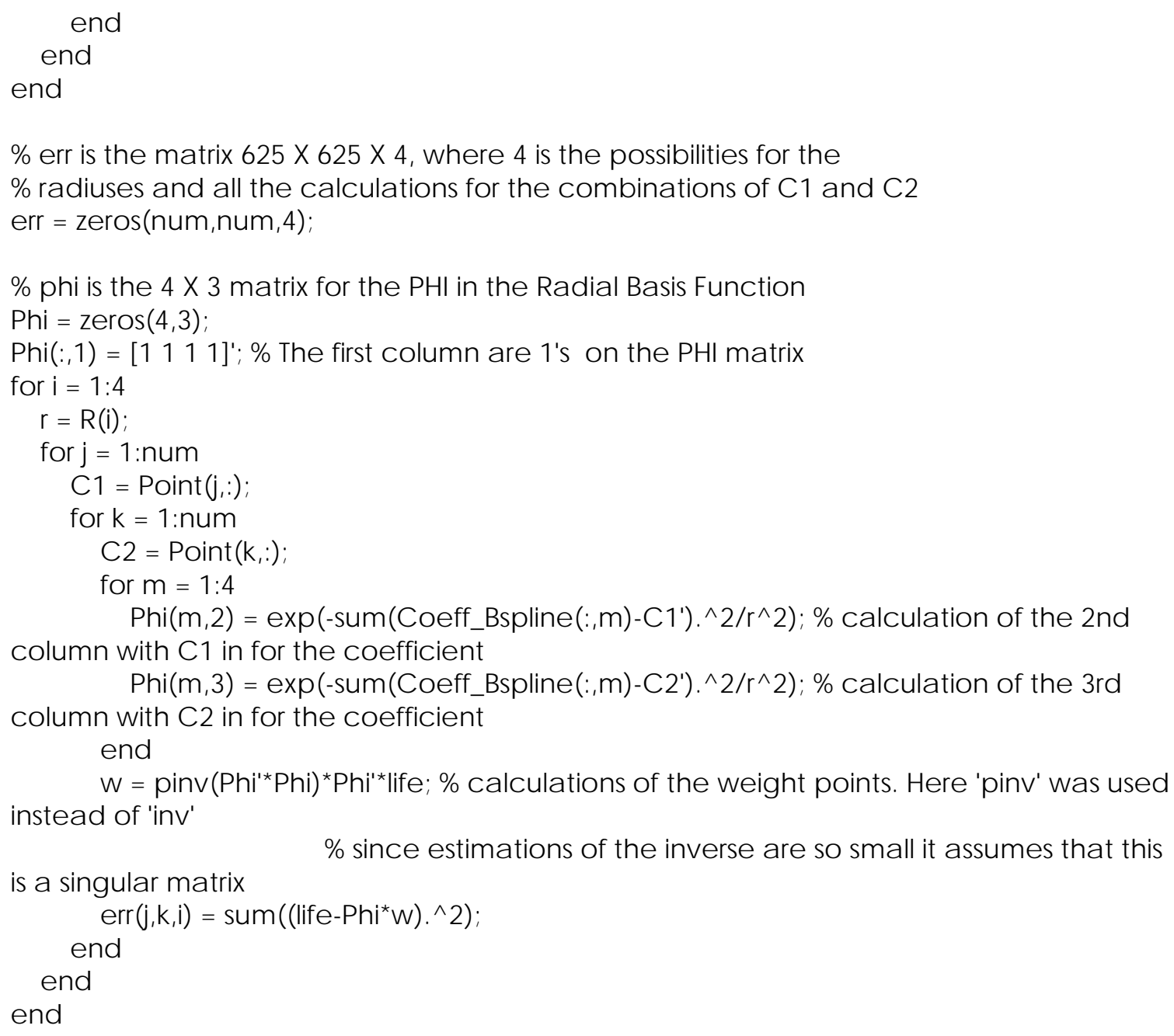

Estimated_life=Phi*w; \% this is the estimated life for the duty cycles.

miner $=\min (\min (e r r(:,:, 1)))$;

$[a, b]=\min (e r r(:,:, 1))$;

$[a$ 1,col_min] $=\min (a)$;

row $\min =b$ (col min);

id_min $=1$; \%Figuning out the $r$ that has the minimum error

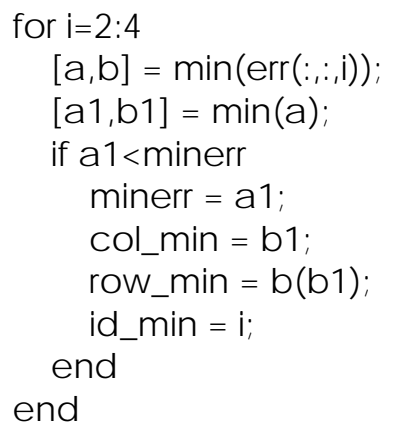


C1_min =Point(row_min,::);

C2_min =Point(col_min,:);

r_min=id_min;

save results 
CODE 6- This code was used to perform the final calculation to estimate component life with the help of RBF found in the previous code.

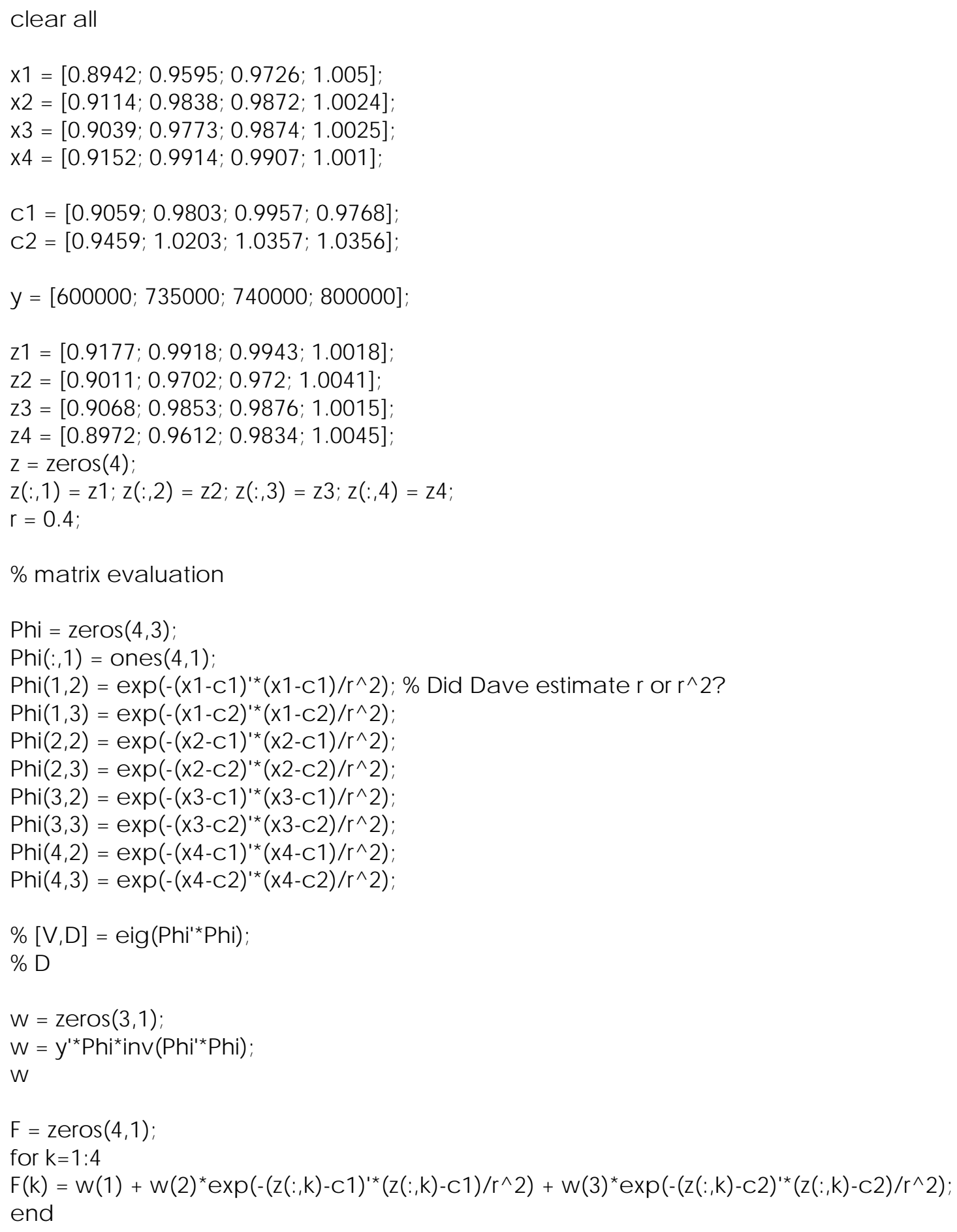


CODE 7- A variation of Code 6 , used to calculate the final life estimation.

\%These are the coeffic ients for the second set of duty cycles that were constructed.

load results

Coeff_Bspline $2=[0.9177 ; 0.9918 ; 0.9943 ; 1.0018]$;

Phi $=$ zeros $(4,3)$;

Phi(:,1) = $\left[\begin{array}{llll}1 & 1 & 1 & 1\end{array}\right]$; \% The first column are 1's on the PHI matrix

$\mathrm{Fr}=0.4$

$\mathrm{FC} 1=\mathrm{C} 1$ min;

$\mathrm{FC} 2=\mathrm{C} 2$ min;

Phi1 =exp(-sum(Coeff_Bspline2-FC 1').^2/(Fr^2)); \% calculation of the 2 nd column with C 1 in for the coefficient

Phi2 $=\exp \left(-\operatorname{sum}\left(\right.\right.$ Coeff_Bspline2-FC $\left.\left.2^{\prime}\right) .^{\wedge} 2 /\left(\mathrm{Fr}^{\wedge} 2\right)\right) ; \%$ calculation of the 3rd column with C2 in for the coefficient

$f=w(1)+w(2) *$ Phi1 +w(3)*Phi2; 